\title{
STUDIES IN PHILOSOPHY
}

\author{
Edited by \\ Robert Bernasconi \\ University of Memphis
}

A Routledge Series 


\section{STUdIES IN PHILOSOPHY}

\section{ROBERT BERNASCONI, General Editor}

\author{
THOUGHT EXPERIMENTS \\ On the Powers and Limits of Imaginary \\ Cases \\ Tamar Szabó Gendler \\ BETWEEN DEFLATIONISM AND \\ CORRESPONDENCE THEORY \\ Matthew McGrath
}

The Relevance of Phenomenology to THE Philosophy of Language and Mind Sean D. Kelly

Risk, AMBIGUITY, AND DeCISION Daniel Ellsberg

The Explanationist Defense of SCIENTIFIC REALISM

Dorit A. Ganson

New Thoughts About Old Things

Krista Lawlor

ESSAYS ON SYMMETRY

Jenann Ismael

Descartes' Metaphysical ReAsoning

Roger Florka

EsSAYS ON Linguistic CONTEXT

Sensitivity and its Philosophical

SigNificANCE

Steven Gross

Names and Nature in Plato's CRatylus Rachel Barney

REALITY AND IMPENETRABILITY IN KANT'S PHILOSOPHY OF NATURE

Daniel Warren
Frege AND THE LOGIC OF SENSE AND

REFERENCE

Kevin C. Klement

TOPICS IN THE PhILOSOPHy OF Possible WORLDS

Daniel Patrick Nolan

UNDERSTANDING THE MANY

Byeong-uk Yi

ANTRHROPIC BIAS

Observation Selection Effects

Nick Bostrom

The Beautiful Shape of THE Good

Platonic and Pythagorean Themes in Kant's Critique of the Power of Judgment Mihaela C. Fistioc

Mathematics in Kant's Critial PHILOSOPHY

Reflections on Mathematical Practice Lisa Shabel

REFERENTIAL OpaCity AND MODAL LOGIC Dagfinn Føllesdal

LEVINAS

Ethics, Justice, and the Human beyond Being

Elisabeth Thomas

The Constitution of Consciousness A Study in Analytic Phenomenology

Wolfgang Huemer 


\section{The Constitution of CONSCIOUSNESS}

A Study in Analytic Phenomenology

Wolfgang Huemer

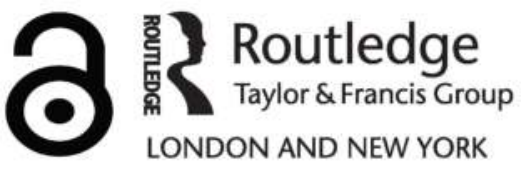


First published 2005 by Routledge

Published 2017 by Routledge

2 Park Square, Milton Park, Abingdon, Oxon OX14 4RN

711 Third Avenue, New York, NY 10017, USA

Routledge is an imprint of the Taylor \& Francis Group, an informa business

Copyright (C) 2005 Taylor \& Francis

The Open Access version of this book, available at www.tandfebooks.com, has been made available under a Creative Commons Attribution-Non Commercial-No Derivatives 4.0 license.

Library of Congress Cataloging-in-Publication Data

Huemer, Wolfgang, 1968-

The constitution of consciousness : a study in analytic phenomenology / Wolfgang Huemer. p. cm. - (Studies in philosophy)

Includes bibliographical references and index.

ISGN 0-415-97129-2 (alk. paper)

1. Husserl, Edmund, 1859-1938. 2. Constitution (Philosophy) 3. Philosophy of mind. 4.

Phenomenology. I. Title. II. Series: Studies in philosophy (New York, N.Y.)

B3279.H94H79

142'.7--dc22

2005020060

ISBN 9780415971294 (hbk) 


\section{Contents}

Acknowledgments vii

Introduction 1

Chapter One

Why do We Need a Theory of Constitution?

ChapterTwo

The History of the Notion of Constitution: Two Case Studies 17

Chapter Three

Towards a Theory of Constitution

Chapter Four

The Social Foundation of the Mind 69

Chapter Five

$\begin{array}{ll}\text { Constitution and Idealism } & 87\end{array}$

$\begin{array}{ll}\text { Conclusion } & 101\end{array}$

$\begin{array}{ll}\text { Bibliography } & 117\end{array}$

$\begin{array}{ll}\text { Index } & 125\end{array}$ 



\section{Acknowledgments}

The present text is a slightly revised version of my $\mathrm{PhD}$ thesis submitted at the Department of Philosophy, University of Toronto. I was exceptionally fortunate to work with outstanding philosophers throughout these years. I would first like to thank my supervisor Sonia Sedivy. Her open minded and modest approach to philosophy helped me to gain a clearer perspective and to better focus on the problems in question, her encouragement in difficult periods gave me the necessary motivation to continue with my project, and her suggestions and criticisms provided a stimulus without which I never could have written this text. I also want to thank my co-supervisor William Seager, for many and fruitful discussions and comments as well as interesting challenges, and James Morrison for his insightful comments on Husserl. It was a privilege to have Barry Smith as my external reader, his comments and encouragement were an essential help for bringing the manuscript to its present shape.

My interest in combining the results of Husserlian phenomenology and analytic philosophy of mind was first raised by my professors during my pre$\mathrm{PhD}$ studies, by Peter Simons and Johannes Brandl at the University of Salzburg, Eduard Marbach at the University of Berne, and Guido Küng at the University of Fribourg. This book shows how deeply their example has influenced my way of approaching philosophy, for which I sincerely thank them. A special thank goes to my colleagues in Erfurt, especially to Alex Burri and Christian Beyer, for their comments as well as the challenging and enlightening discussions.

In this text I try to show that consciousness depends on the social group in which one grows up and lives. I had the great fortune to grow up and live with a very special group of people, whom I owe more than can be expressed here. First, I want to thank my parents for their generous support, moral and otherwise, and my sister Angela, who always set an example. The intellectual exchange with my friend and colleague John Gibson was very helpful not only 
in the development and formulation of my own position, but also for situating my views in a larger philosophical landscape and gaining interest in new topics. I also want to thank my friends Luca Pocci, Marc-Oliver Schuster, Gardar Arnason, Bruno Cooren, Stefano Cracolici, and, most importantly, Karin Buttenhauser, for enriching my life before, during and after my years in Toronto.

I dedicate this book to Melania Parisi, for her love, patience, and affection. It is not an exaggeration to say that she added a new dimension to my life.

Parts of this work have been presented in publication before. Chapter 2 is a slightly revised version of an article that has appeared in Synthese 137 (2003), pp. 345-68, "Husserl and Haugeland on Constitution"; reprint with the kind permission of Kluwer Academic Publishers. Parts of chapter 5 have been presented at the International Wittgenstein Symposium 2001 and published under the title "The World as We See It: a Late-Wittgensteinian Argument for Direct Realism" in: Rudolf Haller and Klaus Puhl (eds), Wittgenstein and the Future of Philosophy: a Reassessment After 50 Years. Contributions of the Austrian Ludwig Wittgenstein Society IX (1), 2001, pp. 326-31. I want to thank the Austrian Ludwig Wittgenstein Society for their kind permission to reprint this article. 


\section{Introduction}

Philosophers tend to have the bad habit of detecting complex and mind-boggling problems in contexts that seem clear and obvious in everyday life. Take the example of our thinking about physical objects: at every moment of our conscious lives we perceive objects in our environment, sometimes we form beliefs about them or doubt their existence, sometimes we wish they were other than they are, some of them evoke an aesthetic judgment, and so on. When we characterize all these activities in terms of their being about or directed towards an object, it might look as if we were just stating a fact so obvious that it is hardly worth mentioning. As soon as we try to describe the details of this relation, however, things become increasingly complex and less obvious. Some of the objects towards which we are directed do not really exist, which might suggest that we are actually directed towards a mental object. This view, however, becomes problematic in the case of perception, where we are obviously directed towards physical rather than mental objects.

In this book I will use Husserl's notion of constitution to develop a position that can address these problems. I hope to achieve two major goals. First, I will sketch a picture of the relation between mind and world that acknowledges, but does not overemphasize, the differences between the realm of the mental and the realm of the physical. Second, by developing an account that combines Husserlian phenomenology with analytic philosophy, I will show that these two traditions are not two opposite and mutually repellent poles in the history of twentieth century philosophy; they should rather be seen as allies when it comes to systematically address problems in the philosophy of mind.

Descartes' distinction between res extensa and res cogitans as two different substances had a major influence on philosophy of mind of the twentieth century. Many philosophers rejected this ontological distinction as far too strong. Their reaction was to reduce the realm of the mental to the realm of the physical or to eliminate it altogether. One of the main factors that 
caused this reaction was the idea that all scientific disciplines can be reduced to more fundamental disciplines, which eventually would allow us to develop a unified theory of everything. This strategy, however, runs the risk of ignoring the fundamental differences between the realm of the mental and the realm of the physical.

The main goal of this book is to sketch a picture of the relation between mind and world that acknowledges these differences without asserting that there are two different kinds of substances. Mind and world are not seen as two opposite spheres, but rather as parts of a whole. The basic claim of this account is that we constitute the objects towards which we are directed in our mental episodes. This does not mean, however, that we create these objects, nor does it mean that we interpret something as something else. In perceptual experiences, I will argue, we are immediately directed towards objects in our environment that exist independently of these experiences. The theory of constitution describes how this relation can be established.

The basic notion of the account that I am going to develop stems from Husserl's phenomenology. By using some of Husserl's results in the context of contemporary analytic philosophy of mind I combine two major traditions of twentieth century philosophy. In the last three decades, various philosophers have pointed out that these two traditions have far more in common than is generally thought. It was argued, for example, that Husserl's philosophy, especially his early writings, has many parallels with Frege's; ${ }^{1}$ it was also documented that there was serious interest in phenomenology among early analytic philosophers like Bertrand Russell, Gilbert Ryle, and even among some members of the Vienna Circle. ${ }^{2}$ These historical studies have provided a more accurate perspective on the history of twentieth century philosophy, bringing to an end the myth of the big and insuperable gap between analytic philosophy and the phenomenological movement.

In this book I will take a different approach, though. Rather than pointing out the historical parallels, I will try to do analytic phenomenology by using some of Husserl's results in the framework of analytic philosophy. I will set up this framework on the basis of the Sellarsian/McDowellian distinction between the logical space of reasons and the logical space of nature. Once we accept this framework we face the difficulty to explain how these two logical spaces can be related. I will propose that Husserl's insights can be very fruitful for addressing this question. Even though I will systematically address a problem central to the philosophy of mind, this approach, if successful, also allows me to pursue a historical goal, namely to demonstrate that these traditions are not incompatible. I will completely bracket the historical dimension of the relation between Sellars and Husserl-even though a quite interesting 
story could be told about this aspect. ${ }^{3}$ My strategy is rather to show how we can use Husserl's results to address problems of contemporary analytic philosophy of mind and, in this way, to make a strong case for the claim that Husserl's phenomenology is not merely a chapter in the history of philosophy, but that it is highly relevant in the context of contemporary philosophy of mind. ${ }^{4}$

My interpretation of Husserl is based mainly on his analyses of time consciousness and passive synthesis. I do not pretend that by emphasizing these aspects of Husserl's thought I can provide an exhaustive interpretation of his overall philosophical system. Moreover, I will use some of Husserl's results to sketch a theory that stands in tension to the standard interpretations of Husserl's work, especially by giving emphasis to the social foundation of consciousness. I should, therefore, stress that my goal is not primarily to contribute to Husserl exegesis, but rather to use some of his results in a context where the work of this philosopher still does not get the attention it deserves. In pursuing this strategy, I run the risk of being criticized for drawing on minor aspects of Husserl's phenomenology or even distorting his views. I believe, however, that the overall goal justifies this strategy.

In the first chapter of this book I will introduce the problems that will be addressed by the theory of constitution. I will sketch a rough picture of how Descartes' distinction between mind and matter-as it was interpreted in twentieth century philosophy-has created an unbridgeable gap between mind and world. I will show that some of the major tendencies in contemporary philosophy of mind, eliminativism and reductionism, are both based on this distinction, and simply react to it in different ways.

In the next chapter, I will discuss the history of the notion of constitution. After providing a short overview of the role this notion played in the history of philosophy I will outline Husserl's and Haugeland's accounts of constitution. Husserl's notion underwent some considerable changes over the years; I will show how this development was influenced by the changes in his overall philosophical position. Haugeland is an interesting example of a contemporary philosopher who uses the notion of constitution to explain the relation between mind and world. Finally, I will point out the parallels and differences in these two accounts. The contrast of the work of two philosophers of very different backgrounds will allow me to introduce some central features of a theory of constitution.

Then I will develop an account of constitution. I will define mental episodes as positions in the logical space of reasons that are directed towards objects, which are taken to be positions in the logical space of nature. In order to show how these two logical spaces are related, I will argue that we constitute the objects towards which we are directed in our mental episodes. 
I will show that the process of constitution requires a holistic background. Husserl's analyses of time consciousness can give us the key to describe the relation between this background and an occurrent mental episode. Then I will address the question of how we come to perform constitution in the first place. I will argue that we establish constitutive commitment by establishing a first, minimal background, which rests on various factors: our biological makeup and environment, the passive processes of association, and the social group in which we grow up. Finally, I will show that not only the objects towards which we are directed, but also mental episodes, in which we are directed towards them, are constituted.

In the remainder of the book I will discuss two of the most important consequences of my account of constiturion. In chapter four I will elaborate on the idea that mental episodes rest on a social foundation. I will argue that we learn to constitute mental episodes through social practices and that, as a consequence, we cannot have ineffable mental episodes. Then I will show that the thesis that mental episodes rest on a social foundation does not imply that we cannot study the mind through phenomenological analysis. In the last chapter I will discuss whether constitution implies a form of idealism. I will adopt an argument presented by Wittgenstein in his later writings, which shows that metaphysical realism and idealism are both nonsensical positions. The argument, as I present it, leaves room for the (non-Wittgensteinian) claim that constitution implies transcendental idealism. I will show that this claim rests on the assumption that we can meaningfully distinguish between the object as it is in itself and the constituted object. I will conclude the book by discussing an ontological position, natural realism, according to which this assumption leads to an unnecessary complication, in order to show that idealism is not a necessary consequence of my account of constitution; it can and should be avoided. 


\section{Chapter One}

\section{Why Do We Need a Theory of Constitution?}

In his Psychology from an Empirical Standpoint Brentano divides all existing phenomena into the psychological and the physical. In order to distinguish these two kinds of phenomenon, he offers six criteria for psychological phenomena. The most important is undoubtedly the notion of intentionality. "Every mental phenomenon," Brentano argues,

is characterized by what the Scholastics of the Middle Ages called the intentional (or mental) inexistence of an object, and what we might call, though not wholly unambiguously, reference to a content, direction toward an object (which is not to be understood here as meaning a thing), or immanent objectivity. (Brentano 1995, 88)

Brentano was soon criticized for characterizing the intentional object as a mental entity. While this characterization might help to explain cases like hallucinations, imaginations of fictional objects, or dreams, where the corresponding object typically does not exist in the physical world, at least not in the way represented, it runs into problems when we consider the most common cases of perception. When I see a table, for example, it is essential that the actual table, the physical object, is in front of me. In my perception I am directed towards this physical object, and not towards some mental entity. Brentano's account of intentionality, thus, leads to an unnecessary duplication of the object, as Husserl points out in his Ideas:

But if, in this way, we try to separate the actual Object (in the case of perception of something external, the perceived physical thing pertaining to Nature) and the intentional Object, including the latter as really inherently in the mental process as 'immanent' to the perception, we 
fall into the difficulty that now two realities ought to stand over against one another while only one reality is found to be present and possible. I perceive the physical thing, the Object belonging to Nature, the tree there in the garden; that and nothing else is the actual Object of the perceptual 'intention.' A second immanental tree, or even an 'internal image' of the actual tree standing out there before me, is in no way given, and to suppose that hypothetically leads to an absurdity. (Husserl 1982, 219 [Hua III/1, 207f $]^{2}$ )

Because of these problems Brentano eventually changed his account of intentionality. He never succeeded, however, in explaining the problems concerning the ontological status of the intentional object in a satisfactory way. ${ }^{3}$ Husserl, of course, also cannot provide an easy answer to the problems concerning the relation between the act of perception and the perceived object. With his phenomenological reduction he brackets the realm of physical objects and develops a position that he characterizes as transcendental idealism. I will discuss Husserl's position in more detail below.

The difficulties in explaining the relation between a perception and the perceived object are not exclusively Brentanian ones. Every philosophical theory of perception that starts out with a distinction between the perceptual experience, which belongs to the realm of the mental, on the one hand, and what is perceived, i.e., the realm of perceivable objects, on the other hand, has to give an account of how the former can be about or directed towards the latter. And very often it is in this part of the theory that problems arise. Yet this distinction seems to be a crucial and commonsensical one, the obvious starting point of any theory of perception.

In the remainder of this chapter I will show that a position that puts too much emphasis on this distinction is confronted with serious philosophical problems. Descartes' characterization of the realm of the mental and the realm of the physical as two different kinds of substance is a good example. By insisting on the ontological difference between res cogitans and res extensa, i.e., between the mental and the physical, he is creating a gap that is so big that it becomes very difficult to give a satisfactory account of how these two kinds of substance can interact. From all we can tell now, however, it seems that for Descartes this is not a particularly important problem. He insists that this interaction does take place ${ }^{4}$ and even locates it: mind and body interact, according to Descartes, in a special part of the brain, the pineal gland. Descartes' primary interest is to distinguish mind and body as two kinds of substance. He is therefore less interested in discussing the particulars of the interaction between the two because this "might have been harmful" (Descartes 1991, 218) for his main goal. 
Many interpreters criticize Descartes for his account of the interaction between mind and body. One of the most common arguments is that such an interaction cannot take place because it contradicts the laws of physics, most notably the principle of the conservation of energy. The idea that physical processes in the brain can act on the mind-and vice versa-is incompatible with the idea that the realm of the physical forms a closed system where the total amount of energy always stays the same.

A common strategy for dealing with the problem of interaction is to state that it simply does not take place. We find this strategy-as a direct response to Descartes-in occasionalism, where all causal interaction is explained away by the intervention of an almighty being. We find it also, and more importantly, in various idealistic and materialistic positions that feel no need to explain how the mental and the physical can interact because they concentrate exclusively on one side of the gap, describing the whole picture solely in terms of the mental or the physical, respectively. The main problem that these views have in common, I believe, is that they are a reaction to, or better: an overreaction to Descartes' distinction between mind and matter. In what follows I will argue that the main motivation for adopting a monistic position is the assumption that we have to choose between offering a unified account in terms of the mental or the physical, respectively, on the one hand, or fall back on Cartesian dualism, on the other; since in contemporary philosophy materialism is much more widespread than idealism, I will concentrate mainly on the former.

The very fact that Descartes' distinction was so successful shows that it bears some important insights, arguing, as it does, that there is a fundamental difference between the mental and the physical. The problems of Descartes' position have their root in the fact that he addresses the question from an ontological perspective. In Mind and World John McDowell gives a characterization of the difference between the mental and the physical that can do justice to Descartes' insights, but avoids the ontological difficulties connected with his distinction. McDowell addresses the problem in terms of Wilfrid Sellars' notion of the logical space of reasons and that of the logical space of nature, that McDowell coins by analogy with the former. ${ }^{5}$ The concept of knowledge, Sellars argues, belongs to the logical space of reasons. This "space" is different in kind from other logical spaces in that it is constituted by rational relations that are-other than causal relations-intrinsically normative. Any attempt to reduce the logical space of reasons to that of nature "is . . . a mistake of a piece with the so-called 'naturalistic fallacy' in ethics" (Sellars 1997, 19, \$5). McDowell characterizes this position in the following way: 
Sellars's thesis is that the conceptual apparatus we employ when we place things in the logical space of reasons is irreducible to any conceptual apparatus that does not serve to place things in the logical space of reasons.

(McDowell 1998a, 433)

In the logical space of reasons we place knowledge and other episodes or states that have propositional content; they stand in rational relations to other positions in the same logical space-and only those. In his attack on the Myth of the Given Sellars argues that these episodes or states, including those of empirical knowledge, cannot stand in rational relations with non-conceptual episodes like sensations, impressions, or sense data. Hence, perceptual judgments cannot be justified by non-conceptual entities. He criticizes various forms of empiricism for having presupposed such a relation. Sellars does not deny that we have such non-conceptual episodes, insisting, rather, that they do not stand in justificatory relations to empirical knowledge; they can only cause certain conceptual episodes. ${ }^{6}$

This short characterization shows that Descartes' insights can be accounted for without buying into his ontological distinction. ${ }^{7}$ In the first chapter of Mind and World McDowell points out that Sellars' characterization of the difference between the mental and the physical can lead to a different kind of problem. If one reduces the relation between non-conceptual sensations and conceptual episodes to causal ones-a position McDowell attributes also to Donald Davidson, who he makes the main target of his critique $^{8}$ —one can avoid the Myth of the Given, but runs the risk to lose contact to the world: Sellars and Davidson, McDowell argues, cannot explain one of the crucial points of the relation between the mental and the physical, namely that "experience is a rational constraint on thinking" (McDowell 1996a, 18). McDowell holds that theories of perception must satisfy a "rational constraint constraint," as Brandom dubs it. ${ }^{9} \mathrm{He}$ insists on the idea that empirical knowledge has to be justified by the objects we perceive through our senses. If we define the relation between non-conceptual sensory input and conceptual thought as a merely causal one, we pay a high price: we cannot explain how empirical knowledge is justified. In other words, if we buy into Davidson's idea that "nothing can count as a reason for holding a belief except another belief" (Davidson 1986, 310) we lose contact with the world. Davidson could reply to this critique that on the basis of his theory of interpretation we can conclude that most of our beliefs are veridical. Even if we were brains in a mad scientist's vat, Davidson argues, our beliefs would be correct, nonetheless. He states that if "anything is systematically causing certain experiences (or verbal responses), that is what the thoughts and utterances are about. This rules out systematic error" (Davidson 1991, 199). He adds that 
who accepts his position, perceptual externalism, "knows he cannot be systematically deceived about whether there are such things as cows, people, water, stars, and chewing gum" (Davidson 1991, 199).

This reply, McDowell argues, does not properly address the problem:

The response does not calm the fear that our picture leaves our thinking possibly out of touch with the world outside us. It just gives us a dizzying sense that our grip on what it is that we believe is not as firm as we thought. I think the right conclusion is this: whatever credence we give to Davidson's argument that a body of belief is sure to be mostly true, the argument starts too late to certify Davidson's position as a genuine escape from the oscillation. (McDowell 1996a, 17)

The problem with Davidson's reply is, according to $\mathrm{McD}$ Dowell, that he tries to show that one's beliefs are largely true. Doing so, however, he seems to be taking it for granted that mental episodes have content. But, McDowell argues, "if we do not let intuitions stand in rational relations to them, it is exactly their possession of content that is put in question" (McDowell 1996a, 68); hence, Davidson's argument starts too late.

McDowell concludes that we are left with an oscillation between two positions that are equally problematic: either we adopt a position that is prone to fall into the Myth of the Given, or we give an account that is based on a causal relation between non-conceptual sensations and conceptual thoughts. But in the latter case, he argues, we cannot explain why mental episodes have content. Thus, we are threatened with losing contact with the real world. According to McDowell, the putative gap between mind and world is a putative gap between conceptual thought (including empirical knowledge) on the one side and the non-conceptual world on the other. The challenge for a theory of perception is to explain at what stage in the process of perception concepts are drawn in and in what relation they stand to the non-conceptual without falling into the Myth of the Given or Davidson's coherentism.

In the remainder of his book McDowell tries to show how we can escape this oscillation between the realm of the conceptual and the realm of the non-conceptual. Using some Kantian shoptalk he states that "we need a conception of experiences as states or occurrences that are passive but reflect conceptual capacities, capacities that belong to spontaneity, in operation" (McDowell 1996a, 23). Rejecting the idea of an interface between the nonconceptual world and conceptual thought he adopts a conception of perceptual experiences that reflect conceptual capacities by extending the realm of the conceptual into nature. Since this move recalls Hegel's philosophy ${ }^{10}$, McDowell expends considerable effort defending his position against the 
charge of idealism. He tries to give his position a naturalistic spin by taking up Aristotle's notion of second nature. For my purposes it is not necessary to discuss whether he succeeds in his defense against the charge of idealism. The important aspect of Sellars' and McDowell's position is that it provides a characterization of the differences between the realm of the mental and that of the physical based on the normative aspect of the former, which allows them to recognize the value of Descartes' insights, but avoid the ontological implications of his distinction.

On the basis of the Sellarsian/McDowellian distinction between the logical space of reasons and that of nature we can characterize idealistic and materialistic positions in the following way: a position is materialistic if and only if it holds either that the logical space of reasons can be reduced to the logical space of nature or that it can be eliminated. It is idealistic if and only if it holds either that the logical space of nature can be reduced to the logical space of reasons or that it can be eliminated. A logical space can be reduced to another logical space if the laws, regularities, relations, or principles that constitute that logical space can be explained in terms of those that constitute the other logical space.

Let us take a closer look at the two strategies used to argue for a monist position. I will first discuss reductionism, and then turn to eliminativism. In order to argue for reductionism one has to account for all essential particularities of the respective other logical space in terms of the one that one favors. What are the particularities of the two logical spaces? According to McDowell, the logical space of nature is constituted by natural laws. These laws describe physical objects and the relations between them, i.e., causal relations. The logical space of reasons, on the other hand, is constituted by rational relations that hold between conceptual episodes. These rational relations are not based on natural laws, but on the laws of logic, which essentially contain a normative element. The question whether a conclusion actually follows from a certain set of premises is not a question that can be decided by observation or on the basis of laws that describe causal relations. It can be decided only relative to the axioms and derivation rules of a logical system by determining whether they have been applied correctly.

The reductionist strategy of advocating materialism is to show that we can reduce rational relations to the laws of nature, a strategy that Sellars, as we have seen above, equates with the naturalistic fallacy in ethics. One way to perform this reduction is to reduce the laws of logic to the laws of psychology. This position, which was discussed under the title 'psychologism,' was defeated successfully by Frege and Husserl a century ago. ${ }^{11}$ 
So far, a reduction of the regulations that govern the logical space of reasons to the laws of science has not yet been achieved. Reductionism, however, is based on optimism about the future development of science: if not today, it is argued, some day in the future we will be able to reduce the mental to the physical. This strategy makes it difficult, if not impossible, to show that reductionism is wrong: one would have to show that reducing the space of reasons to that of nature is impossible in principle, for all conceivable scientific theories that might be developed some time in the future.

It might be helpful, however, to consider where the strong urge to perform such a reduction comes from. In the last few centuries, especially in the twentieth century, science has made enormous progress. In addition, special sciences like chemistry could be reduced to more fundamental disciplines like physics. These achievements have supported the idea that we can develop one general explanatory scheme that can account for everything that can be described as physical. The hope is that eventually we will be able to deduce all scientific laws from a handful of very general formulas and maybe some additional premises. This idea of a unified theory of everything physical nourished the fear that if we acknowledge the need of a special science that is not reducible to physics we would be forced to accept that there is something that cannot be described as physical and that is therefore ontologically different. In other words, we are forced to subscribe to dualism. Thus, the main motivation for reduction of the mental to the physical is the contention that we can choose only between reductionism (or eliminativism) and Cartesian dualism.

This dichotomy, however, seems to be popular only in the context of reductionism of the mental to the physical, but loses much of its appeal if one considers the example of the laws of logic, evolutionary theory, or economics: even if one acknowledges that the laws, rules, or regularities of these disciplines cannot be reduced to the laws of microphysics-as most scientists do, if not explicitly, so at least in their everyday scientific practice-one does not need to conclude that admitting the relative autonomy of these disciplines from microphysics entails ontological dualism or even pluralism.

A reductionist position does not need to be materialistic; we could also imagine a reduction from the physical to the mental. The advocates of such a position would have to show how we can reduce the laws of physics to the rational relations that constitute the logical space of reasons. In a century like ours that is shaped by a strong belief in the natural sciences, such a position seems quite exotic: it betrays the very idea of science, namely that there is a world independent of us, the regularities of which we try to describe with natural laws. The main difficulty faced by this position is to explain the necessity of causal regularities in the physical world in terms of 
rational relations. In our mental life we can choose to infer a certain belief from a set of other beliefs; we are free to make the move from one position in the space of reasons to another one. In nature, on the other hand, the same events in the same circumstances always have to cause the same effects, and necessarily so. Consequently, the idealistic reductionism would run into the same kind of problems as its materialistic version; it would be difficult to show that the rules that constitute the logical space of reasons can account for all particularities of the logical space of nature.

The other possible strategy used to argue for monism is to eliminate the logical space of reasons or of nature, respectively. Materialistic eliminativists, in general, share the fear of reductionists that any theory that cannot be reduced to physics requires us to adopt some form of dualism. They acknowledge, however, the difficulties of reducing the mental to the physical and prefer to eliminate talk about the mental altogether. However, if we take the doctrine that there is an essential difference between the two logical spaces seriously, it is difficult to see how one of them can be eliminated in an account that strives to be comprehensive. The eliminativist would have to show why one way of explaining certain phenomena is preferable to any other way. If we grant that the descriptions of the rational relations that hold between various mental episodes are not simply shortcuts for more complex scientific descriptions, but describe genuine phenomena, we have to acknowledge that the eliminativist cannot account for them. Eliminativism, thus, provides a onesided view that deliberately avoids seeing the whole picture, a strategy that is not only unsatisfying, but also unscientific.

These considerations show that there are good reasons to believe that both idealistic and materialistic positions are insufficient to give a comprehensive account of both the realm of the mental and that of the physical. The urge to develop a monistic position, is nourished by the assumption that if we cannot advance a unified account for mind and body we are forced back to the dark old days of dualism; it is, thus, a reaction to Descartes' characterization of the ontological differences between mind and body.

This does not mean that we should downplay the importance of Descartes' insight. In addition to the points raised above, there is another motivation to take an ontologically innocent version of the distinction between the mental and the physical seriously. This motivation is rooted in a feature of perception that Husserl talks about at the beginning of his course on passive synthesis:

External perception is a constant pretension to accomplish something that, by its own nature, it is not in a position to accomplish. Thus, it harbors an essential contraction, as it were. (Husserl 2001, 39 [Hua XI, 3]) 
The essential contradiction that Husserl is talking about arises from the following paradox: whenever we perceive an object, we perceive it under a certain perspective. When I see a table, for example, I have only a part of the table, some part of the surface, in my visual field. Nevertheless, I see the table, the object as a whole, and not just its surface. Thus, the contradiction of perception is that it pretends to present objects as they are, but in the process of perception we seem to have to add something to the sensory input in order to perceive objects rather than parts of objects. This line of thought has led some philosophers, among them Husserl, to conclude that we are directed towards the intentional object under a certain mode of presentation. From here it is only a short step to distinguishing the object of experience, i.e., the object as it is given to us, from the actual object, the object as it really is.

The problem with this view is that it makes things even more complicated. Instead of a twofold relation between perception and the object perceived we are now confronted with a threefold one: the object as it appears, the object as it really is, and the act of perception. The main difficulties of a position that holds this view are the ontological status of the object as it appears and its relations to the actual object. Are we directed towards the object as it appears or the object itself? To argue that we are directed towards the actual object in virtue of the object as it appears does not provide a remedy for our worries so long as we do not have a clear account of the relation between them.

What would such an account look like? The object as it appears cannot be a mental entity-that would have no explanatory value; we still would have to explain the relation between the mental and the physical object. It also cannot be identical with the physical object: our relation towards the object as it appears would be a relation towards the physical object. Accordingly, we would be directed towards the physical object in virtue of our being directed towards another physical object, which is an unnecessary complication without any explanatory value.

If not mental or physical, the mediating object could still be an abstract entity, philosophers with Platonistic inclinations would argue, a representation of the actual object with respect to the properties that we are directed at in our perception, and only those. Since we can perceive physical objects under an infinite number of aspects, one would have to postulate that each perceivable object has an infinite number of corresponding abstract objects, each of which represents one or a small number of aspects of the object. Many philosophers do not have problems of accepting a theory along these lines-after all, abstract objects do not cost anything, so even postulating an infinite number of them seems to be affordable. The main difficulties arise when one aims to explain how the relation of reference between the abstract and the physical object can 
be established, and how we can grasp abstract objects in the first place. Faced with these difficulties, the temptation to apply an old, but still most useful tool of philosophy, Ockham's razor, becomes irresistible.

Furthermore, positions that argue that we are directed towards the actual object in virtue of a mediator (like, in our case, the object as it appears) give rise to sceptical doubts. Since we can know objects only as they appear and not as they really are, it can be argued, we might be wrong or even systematically misled in our beliefs about the world. This leads us to another problem that can stem from a too strong distinction between object of perception and perceptual experience. We know from particular cases of misperception that our knowledge of external objects does not rest on a secure and infallible base. On the other hand it is often argued that the knowledge about our own mental life is infallible and cannot possibly be wrong because in this case both the act and the object of perception are on the same side of the gap, namely the realm of the mental. Descartes can conclude on this basis that the cogito ergo sum is the only secure and indubitable knowledge he has, the foundation for all other knowledge.

Once this priority of the mental is established, we are confronted with an asymmetry between knowledge of one's own mental life and that of other individuals. Descartes talks only about his own mental life when he says that he cannot be wrong concerning the fact that he is thinking. We can generalize this thought by saying that every thinking person is infallible about his or her own thinking. This stands in a sharp contrast to knowledge about the mental lives of other individuals which are not directly accessible to us. It also stands in contrast to knowledge about physical objects which are equally accessible to all of us, given that we are in sufficiently similar observational circumstances.

It is easy to see how this line of reasoning brings about the problems of intersubjectivity and of "other minds." Given that I can have secure and infallible knowledge only about my own thoughts, what justification do I have to assume that the people around me have a mental life, too? I can perceive only certain movements of their bodies. Their mental lives might be completely different from mine or they might not even have mental lives, moving around like zombies or sophisticated robots.

This line of reasoning leads eventually to a kind of mental atomism, where one takes the world to be inhabited by a number of ego-monads who exist independently from each other. In its most radical form it can lead to the solipsistic view that only my mind exists. Once a non-solipsistic version of this mental atomism is established one can go on to explain how these egos form social groups and cultures. The crucial assumption of this view is that the formation of a social group and, in consequence, a culture, depends on a 
number of egos, the existence of which is independent of the existence of the group. In other words, individuals could exist even if there were no social group, while the existence of the latter presupposes the existence of the former. This individualistic view is widespread not only among philosophers, it is also deeply ingrained in our society's understanding of itself. I do think, however, that this position is problematic.

In order to see the difficulties of this view, let us consider the relation between our mental life and language. Various philosophers have argued that language is a necessary condition for having mental episodes. Even though this position is not generally accepted, I think it is safe to say that at least a good part of our mental episodes depends on language; various of the most common kinds of mental episode have propositional structure, like beliefs, knowledge, etc. Moreover, the formation of a complex social structure or culture is unthinkable without the development of a language of some sort. ${ }^{12}$ Language, however, is not a faculty that can be achieved by an individual alone, it is essentially a social phenomenon. To learn a language means to grow up into a social group or-to put it in Wittgensteinian terms-into a form of life. Thus, the acquisition of language depends on one's being part of a social group. Since at least a good part of our mental life depends on the acquisition of language, the individualistic assumption that society depends on a number of ego-monads becomes questionable. It seems rather that the mental life of an individual depends on her being part of a social structure or culture, and not vice versa. While more needs to be said on the relation between consciousness and our being organized in social groups (I will come back to that topic in chapter 4), these difficulties show that an exaggerated individualism can be a consequence from the Cartesian distinction between the mental and the physical in conjunction with the idea of the priority of the mental.

This short discussion shows that many philosophical worries arise from Descartes' strong distinction between the mental and the physical. Although it was motivated by important insights, his insistence in the ontological difference between mind and world created an unbridgeable gap between the two realms. Many philosophers accepted Descartes' distinction, but even many of those who did not were influenced by it: their denial of the idea that there is a difference between the realm of the mental and the realm of the physical can be understood as a reaction to Descartes' distinction. 

Chapter Two

\section{The History of the Notion of Constitution: Two Case Studies}

I will now turn to address the problems raised in the preceding chapter by developing an account of constitution that allows us to acknowledge the essential differences between the mental and the physical without creating an unbridgeable gap between the two. In this chapter I will explain why I adopt the notion of constitution and where its philosophical roots are. Then I will outline and contrast the accounts of constitution proposed by Husserl and Haugeland.

\section{WHY CONSTITUTION? WHY HUSSERL? WHY HAUGELAND?}

The words 'constitution' and 'constitutive' have a variety of meanings as they are used in contexts as different as law, medicine, or philosophy. In philosophy they were first used by Seneca in the context of the mind-body problem. ${ }^{1}$ The terms become part of the philosophical terminology with Boethius' Latin translation of Porphyry's commentary on Aristotle. Hogrebe points out that in ancient and medieval philosophy the word 'constitution' is used in both logical and ontological contexts. ${ }^{2}$ In logical contexts, constitutive differences ${ }^{3}$ are used to characterize definitions of different kinds in the Porphyrian tree. In ontological contexts this expression is used to explain how objects are made out of or constituted from their constituents, namely form and matter. In medieval philosophy the ontological usage of 'constitution' becomes more general, as not only form and matter but all kinds of part are called 'constituents.' The difference between the logical and the ontological usage of the word can be found also in the subsequent centuries up to the twentieth century.

The notion of constitution plays a special role in the philosophy of Kant, the first philosopher to bring up the so-called 'problem of constitution,' i.e., the problem whether we can state a number of rules that set out the 
frame in which cognitive experiences are empirically possible. Kant calls these rules 'constitutive principles.' He argues that they are synthetic a priori. They involve the use of the categories and are, thus, the conditions of the possibility of experience.

Hogrebe points out that the big breakthrough of the notion of constitution in philosophy comes with Husserl's phenomenology. ${ }^{4}$ Husserl develops this notion quite independently from his philosophical predecessors. ${ }^{5}$ Ingarden states that 'constitution' is

a specifically Husserlian concept which Husserl, in the way he uses it, does not owe to the philosophical tradition. (Ingarden 1998b, 236 $[$ my translation $])^{6}$

One of the major goals of Husserl's phenomenology is to give an account of the essential structures of our conscious activities. Husserl thinks that intentionality is one of the main characteristics of our mental acts, and he develops his account of constitution to explain this main feature of our mental life.

Husserl, of course, was not the last philosopher to work with the notion of constitution. Carnap uses it in his book The Logical Structure of the World. He adopts the word 'constitution' in its logical meaning. According to Carnap, constituting an object or a concept means reducing it to some other, more basic objects or concepts. This reduction is performed by constitutional definitions. Carnap assumes that there are some basic objects or concepts that cannot be further reduced and, thus, are not constituted. ${ }^{7} \mathrm{He}$ outlines his program at the beginning of his book:

By constitutional system we mean a step-by-step ordering of objects in such a way that the objects of each level are constituted from those of the lower levels. Because of the transitivity of reducibility, all objects of the constitutional system are thus indirectly constituted from objects of the first level. These basic objects form the basis of the system. (Carnap 1967, $6[$ italics in the original $])^{8}$

In the philosophy of the second half of this century the notion of constitution is also used. It was taken up, among others, by Searle, Chomsky, and Habermas, who use it in the context of philosophy of language. In addition, it has become a technical term in mereology. ${ }^{9}$

Very recently, John Haugeland has developed an account of constitution that puts forth a new understanding of the relation between mind and world. Haugeland's theory, strongly influenced by Kant's, is interesting for two reasons. First, he tries to give an account of how we can be directed to- 
wards objects in our mental episodes; in other words, like Husserl he uses the notion of constitution to explain intentionality. Second, he applies his account to problems that are raised in contemporary philosophy of mind.

In what follows I will outline and compare Husserl's and Haugeland's notions of constitution. I will first outline the development of Husserl's account in the context of the development of his overall philosophical position. Then I will discuss Haugeland's use of the notion of constitution. Finally I will point out that there are notable parallels—as well as disagreements-in the work of two philosophers who come from very different backgrounds which will show, as I hope, that the notion of constitution can be applied successfully to address some of the most central problems of contemporary philosophy of mind.

\section{HUSSERL'S NOTION OF CONSTITUTION: A SHORT OUTLINE OF ITS DEVELOPMENT}

Since the notion of constitution played a central role in Husserl's philosophical writings throughout his life, it changes with all the major changes in his overall philosophical system. Husserl never introduced the notion of constitution in a systematic way; Fink correctly points out that it plays the role of an 'operative concept,' i.e., a basic, undefined concept that serves to formulate the definitions of other concepts of the theory. ${ }^{10}$ For this reason I will outline Husserl's notion of constitution in a historical way. ${ }^{11}$

There is a debate among Husserl interpreters whether the notion of constitution is already operative in Husserl's first major publication, the Philosophy of Arithmetic. In this book, Husserl explains the origin of basic arithmetical notions like 'number,' 'collection,' and 'set' by going back to the psychological activities of collecting and counting. One masters arithmetical notions by presenting a number of randomly chosen objects in fantasy. Then one concentrates, in a higher-order act, on the relation that holds among these objects. Since the objects are randomly chosen, these relations are psychological rather than physical: the only thing they essentially have in common is that they are objects of the same presentation. Abstracting more and more from the actual objects, one finally arrives at the concept of 'number.' In Formal and Transcendental Logic, some 30 years later, Husserl says in retrospect about this strategy that it was already what he later called a phenomenological-constitutive investigation. ${ }^{12} \mathrm{De}$ Boer, however, points out that there is a very important difference between the constitution of numbers in higher-order acts, as Husserl describes it in Philosophy of Arithmetic, and the notion of constitution he develops later: 
It is true that collective relations are produced by an act (i.e. an act of higher order). But this implies for Husserl in PA [i.e., in Philosophy of Arithmetic] that these relations do not exist on the side of the object. . . . the act of higher order has no correlate of its own; there is no object of higher order. (de Boer 1978, 119)

The basic difference between Husserl's account of higher-order acts in Philosophy of Arithmetic and the notion of constitution as developed later is that in the former there is no object correlating to the act; there are no objects like numbers that are perceived in higher-order acts. Rather, they are created in these acts as subjective entities. Constitution, as Husserl uses the notion later, on the other hand, "implies that the act has a correlate which it constitutes" (de Boer 1978, 119). According to de Boer this marks an essential difference between these two positions. He concludes that the notion of constitution is not yet operative in Philosophy of Arithmetic.

Bernet, Kern, and Marbach arrive at a slightly different conclusion. They argue that we are faced with an "initial, still deficient execution of a phenomenological constitutive analysis" (Bernet e.al. 1993, 17). ${ }^{13}$ For my purposes it is not important to settle this question here. It is of interest, however, that Husserl holds in his early book that higher-order acts in which we are directed towards mathematical entities do not have corresponding objects in the world. They rather create an immanent, mental object. In his later account of constitution, on the other hand, he rejects the idea that constituting an object means creating it.

Philosophy of Arithmetic was criticized harshly by Frege for confounding logic and psychology. "In reading this work" he writes in his review "I was able to gauge the devastation caused by the influx of psychology into logic" (Frege 1972 , 337). Husserl took this critique very seriously. Not only does he turn away from a psychologically based understanding of logic, he also formulates a profound and detailed critique of psychologism in the first part of his next book, the Logical Investigations. ${ }^{14}$ While it is debatable whether the notion of constitution is already operative in Philosophy of Arithmetic, there can be no doubt that it is operative in the Logical Investigations. It is developed in three contexts, the constitution of meaning, the constitution of perception, and the categorical constitution.

Sokolowski stresses that Husserl's account of constitution in the Logical Investigations is influenced strongly by his distinction between intentional form and sensory matter or, as he calls it, the 'matter-form schema. ${ }^{15}$ In this period Husserl distinguishes between intentional and non-intentional moments of the mental acts. The latter are like unstructured, raw sense data, which by themselves could not be directed towards an object. Intentionality 
comes into play only when these moments are apprehended by the intentional moments of the act. Husserl does not hold, however, that we do have raw sensations as independent acts on which the full-fledged acts of perception are based. Sensory matter and intentional form are moments of one and the same act: they could not exist independently from each other.

Husserl introduced the notion of constitution in the context of meaning. When one reads or hears a word, one is primarily directed towards the physical appearance of this word (the ink on the paper or the sound waves, for example). One is also directed, however, towards the meaning of the word and, in consequence, towards the object to which it refers. By treating the marks of ink on the paper as symbols or representations that stand for something else, we are directed, so to speak, through these symbols towards other objects. In these acts the meaning of the word is constituted.

Husserl then extended this analysis to perception, where we are faced with a similar situation. When we look at an object, we see only one side of it under a certain perspective, or, to put it in Husserlian terms, we have only an aspect [Abschattung] of the object. However, we do see the whole object and not only a part of it. The part of the object that we can see stands for the whole object in a similar sense as the material form of the word stands for its meaning. We perceive, so to speak, the full object through the aspect. The object is constituted in a series of perceptions, each of which gives us only one of its aspects.

The main application of the notion of constitution is in the context of the perception of what Husserl calls 'categorical objects.' Apart from simple objects like this table or this book that we perceive in simple perception, we can also perceive relations between objects like the fact that the book lies on the table, for example. Husserl calls these objects to which we predicate form 'categorical objects' or 'states of affairs.' We are directed towards these objects in acts of categorical perception. Their ontological status is different from that of simple objects, for they are based on simple objects, but they come into existence only when they are constituted, i.e., when the mind uses its predicative power of giving form to the state of affairs. "Thus, this categorical formation or creation of the form of the state of affairs means that the state of affairs has its form ... not independently of the predicative act. It is rather constructed or constituted by it" (Süßbauer 1995, 263 [my translation] ${ }^{16}$ ). Once they are constituted, however, they can be identified and recognized. Hence, they are created in the process of constitution.

In the light of his later account and compared to the other contexts where Husserl used the notion of constitution in Logical Investigations, the constitution in categorical perception is very untypical, for it is the only context where the object is created in the process of constitution. With this 
single exception we can state that it is a cornerstone of Husserl's theory that constitution requires an actual object corresponding to the act, the existence of which is independent of its being constituted.

In the following years Husserl extends his notion of constitution to a broader realm of objects. Husserl, who did not publish again for a full decade, presented this new development in his courses, mainly in the ones on Time Consciousness in $1905^{17}$ and on Thing and Space in 1907. ${ }^{18} \mathrm{He}$ discussed not only the constitution of the objects of outer perception, but also the constitution that takes place in acts of inner perception, i.e., in acts that are directed towards other mental acts, as it is the case when I remember the very act of seeing the tree before my window (as opposed to remembering the tree). This is the first time that Husserl talked not only about the constitution of the objects of our conscious experiences, but also about the constitution of these experiences themselves.

One of the basic assumptions of Husserl's phenomenology of time consciousness is that our mental acts are temporally extended. They consist of partial intentions of which Husserl distinguished three kinds: retentions, primal impressions, and protentions. Retentions are the parts of the act that are directed towards the object as it appeared just a moment ago; primal impressions are directed towards the object in its present state; and protentions form expectations about the object's future states. When we perceive temporal objects like melodies, we can perceive only one of their temporal parts at a moment. Husserl explained the fact that we can perceive temporal objects-and not only temporal parts of them-by showing how they are constituted in the act of perception.

Based on this analysis, Husserl could explain various layers of constitution; he showed not only how temporal objects are constituted in our mental acts, but also how these mental acts themselves are constituted. In addition, if we shift our attention from the object of the partial intentions to these intentions themselves we realize that they are all part of one and the same consciousness; in other words, they form one stream of consciousness. Thus, the stream of consciousness, Husserl argued, is constituted by the totality of these partial intentions; and through this structure the stream of consciousness can also be said to constitute immanent time, for it is due to this structure that we can experience time. ${ }^{19}$ Consequently, we can find various levels of constitution in Husserl's account of time consciousness: the object of the episode, partial intentions, and the time-constituting stream of consciousness.

(1) The things of experience in objective time ... (2) the constituting appearance manifolds of various levels, the immanent unities in pre-empirical 
time; (3) the absolute, time-constituting stream of consciousness. (Husserl 1991, 77 [Hua X, 73])

In the context of his phenomenology of inner time consciousness Husserl brings up a topic that will become crucial for his later account of constitution, namely his critique of the matter-form schema. I will discuss this topic below.

This period is marked by some major developments of Husserl's philosophical position. In $1905^{20}$ he starts to elaborate the phenomenological reduction. In our everyday mental life we adopt what Husserl calls the natural attitude: we pay full attention to the objects towards which we are directed in our mental acts. In this unreflective attitude we (generally) do not question their existence, we just take them for granted. By performing the phenomenological reduction one changes from the natural to the phenomenological attitude. The key idea of the phenomenological reduction is to bracket all these unreflecting beliefs in the external world. At the same time one has to shift one's attention from the objects of one's experiences to the experiences themselves. Let us take the example of some mental act like seeing a tree. In the natural attitude our conscious experiences focus on the tree: we might form the wish to have a picnic under it, imagine it being struck by a flash and burn down, or give a scientific description of it, etc. In the phenomenological reduction the tree itself loses importance; the attention shifts to the mental acts in which the tree is given. The task of the phenomenologist is to describe these acts, and by doing so to explain how external objects like this tree can become the object of our consciousness. The sceptical question of whether the tree really exists or not, which might pose a problem for the natural attitude, is no longer relevant. This does not mean, however, that the phenomenologist denies the existence of the world nor that the world does not play a role in phenomenological analysis. On the contrary, it plays an important role, but only insofar as it becomes object of our conscious experiences. ${ }^{21}$ The development of the phenomenological reduction, often described as Husserl's 'transcendental turn,' the outset of his 'transcendental phenomenology,' marks, according to Ströker, "a borderline between two different, although closely related, meanings of the Husserlian concept of constitution" (Ströker 1993, 105).

It was not until 1913, with the publication of Ideas I, that Husserl presented his phenomenological reduction in writing. With this book he aimed to introduce phenomenology to a broader audience. Since Husserl is introducing a very original and complex line of thought, he decided not to discuss some of the topics that became relevant for his account of constitution and that he had developed earlier. He did not consider his critique of the 
matter-form schema that he began to develop in 1907 and does not talk about time consciousness, "so as to maintain free of confusion what first becomes transparent from the phenomenological standpoint alone" (Husserl 1931, 236 [Hua III/1, 182]).22

After the publication of Ideas I, the notion of constitution is given an even more central position in Husserl's thought. This can be seen from the subtitle of the second, posthumously published volume of Ideas. Studies in the Phenomenology of Constitution. One of the crucial steps in this development is the distinction between static and genetic phenomenology that Husserl developed from $1917 \mathrm{on}$. Static phenomenology describes the kind of phenomenology that Husserl had previously developed. It takes for granted that we are dealing with certain realms of objects, like physical or mathematical objects, and certain kinds of mental act, like perceptions or memories, in which these objects are given. The task of static phenomenology is to describe the regularities and structures of the experiences in which we are directed towards these kinds of object.

In genetic phenomenology, on the other hand, one asks how it comes about that we are dealing with these kinds of object. Rather than assuming that there are certain realms of objects, genetic phenomenology explains how we constitute them. The question is no longer how we can perceive physical objects. It is instead: how does it come about that we constitute the realm of physical (or mathematical or etc.) objects? "The object is no longer the guidepost as it is in static phenomenology. It is rather something that has come to be" (Bernet e.al. 1993, 201).

The aim of genetic phenomenology was to give an account of how we constitute the objects towards which we are directed by analyzing the components out of which our experiences are built. Husserl did that by going back to his analyses of the temporal structure of consciousness, arguing that both the mental act and its object are constituted from the partial intentions that belong to one's stream of consciousness: retention, protention and primal impressions. Each of these partial intentions is directed toward some object, like a tone of a melody. The object itself, the melody, is constituted by the series of partial intentions that are directed towards a series of tones. The act of hearing the melody, on the other hand, is also constituted by these partial intentions. It consists of all those partial intentions that are directed towards the same object, namely the melody.

In order to explain why these constitutional processes take place the way they do we also have to take the history of the subject into account. Husserl argues that whenever someone constitutes an object, this constitution leaves a kind of trace. If one constitutes a certain object very often, one forms a habit that shapes future constitutions: 
That a nature, a cultural world, a world of men with their social forms, and so forth, exist for me signifies that possibilities of corresponding experiences exist for me, as experiences that I can at any time bring into play and continue in a certain synthetic style, whether or not I am at present actually experiencing objects belonging to the realm in question. ... This involves a firmly developed habituality, acquired by a certain genesis in conformity with eidetic laws. (Husserl 1960, 76 [ Hua I, 109f])

Our past mental episodes form a retentional background which in turn accounts for the possibility of having any mental episodes at all. ${ }^{23}$

Husserl's late account of constitution is shaped by his critique of the matter-form schema that he held in his early writings. We have seen above that in his course on time consciousness in 1905 he argued that partial intentions are composed of raw data that are apprehended by intentional forms. He held that the same matter that is at one moment apprehended in a primal impression as present will be apprehended at the next moment in a retention as past.

Between 1907 and 1909 he started to criticize this schema. His main argument against the schema was that it presupposes that there is a constant sensory content that is apprehended by different forms. He pointed out that an impression of sound, for example, can only be apprehended as present. In the next moment there is no longer the impression of the sound that is just apprehended in a different way, but a consciousness of having had an impression. "In short, there is a radical alteration, an alteration that can never be described in the way in which we describe the changes in sensations that lead again to sensations. ... One must not materialize the contents of consciousness" (Husserl 1991, 336 [Hua X, 324]).

In later writings, Husserl generalized this point in his critique of sensedatum theories. He never explicitly rejected the assumption that there are raw sense data that play a central role in the constitution of objects. He did claim, however, that all parts of consciousness are constituted. Husserl stated that " $[c]$ onsciousness consists in nothing but consciousness, and even sensation and phantasma is consciousness" (Hua XXIII, 265 [my translation] ${ }^{24}$ ), which means that there cannot be any raw data directly given to consciousness. In his study on the phenomenology of association, Holenstein shows that even though Husserl never explicitly drew that conclusion, there are clear passages that show that he overcame the matter-form schema also in the context of the constitution of objects. ${ }^{25}$

In the context of genetic phenomenology Husserl also developed his transcendental idealism. Since Husserl tried to explain the various realms of objects by constitutional processes that are performed by the subject, it seems that he implied that the existence of these objects presupposes the existence of 
a subject that constitutes them. The question of whether Husserl was an idealist or a realist is the subject of extensive debate which cannot be settled here. In more general terms I will discuss in chapter 5 whether constitution entails a form of idealism.

In his later phenomenology Husserl holds that there are several levels of constitution. Barry Smith characterizes these levels in the following way:

1.) normal intuitive spatio-temporal nature, the earth and natural things and stuff, both organic and inorganic, having real qualities and states and giving rise to sensations and also to practical motivations of various sorts;

2.) people and animals, moving and behaving in determinate ways, at rest, thinking, working, speaking, writing;

3.) artifacts, goods, implements, cultural objects, which presuppose deliberate, intelligent activity on the part of man;

4.) values and goals affecting our behaviour and at the same time giving sense and structure to our activities over time;

5.) morals and customs, languages, various social units and socially constituted entities with their particular norms and conventions. (Smith 1995, 415)

Each of these levels is based on the lower ones in the sense that we could not constitute the higher levels if we had not constituted the lower ones. This does not mean that there is a causal connection between these levels, in which the lower levels bring about the higher ones, as Holenstein points out. ${ }^{26}$ For my purposes, the basic processes of constitution are of central importance.

Husserl developed the distinction between active and passive genesis in the context of genetic phenomenology by arguing that in the former the ego is involved while in the latter it is not. ${ }^{27}$ The first level of constitution is, according to Husserl, passive. We constiture the spatio-temporal world with its basic elements (physical objects, etc.) only due to the temporal structure of consciousness and laws of association. These features do not involve the ego. The constitution of cultural objects, abstract entities, etc., on the other hand, cannot be reduced to these basic processes. It does involve an ego that actively constitutes it. Both active and passive constitution can create a habit and shape future constitution. "Not only passive formations of unity but also actively produced configurations of sense become habitual acquisitions of the subject" (Bernet e.al. 1993, 202).

In Husserl's last texts, kinesthetic experiences play a more and more central role in passive constitution. Together with the temporal structure of consciousness and association they are seen as one of the three levels of passivity. 
In conclusion we can state that according to Husserl's theory of constitution, we constitute the objects towards which we are directed in our mental acts. This does not mean, however, that we are creating the object when we constitute it. Husserl rather argues that the constituted object exists independently of the act in which it is constituted-with the exception of objects towards which we are directed in categorical perception. Through his analysis of the temporal structure of our mental acts Husserl realizes that not only the objects, but also the mental acts in which we are directed towards them are constituted. In addition, he argues that every process of constitution leaves a trace as every mental episode becomes part of a retentional background without which we could not have mental episodes in the first place.

The historical discussion of the development of Husserl's theory shows how closely his notion of constitution is intertwined with his overall phenomenological position. In order to better see how this notion can be used to address questions relevant to contemporary philosophy of mind, I will now turn to analyze how the idea of constitution was developed by a contemporary philosopher, namely by John Haugeland.

\section{HAUGELAND'S 'CONSTITUTIVE STANDARDS’}

Haugeland introduces his notion of constitution with an argument against causal theories of perception that was first developed by Dretske. According to these theories we perceive objects as objects because our perception is caused by them. I see a bicycle, for example, because there is an actual bicycle in front of me that causes my visual experience. Dretske criticizes this argument. ${ }^{28} \mathrm{He}$ notes that the object cannot cause the experience directly, but only over several steps of a causal chain. When I see a bicycle, the light that comes from the sun is reflected by the bicycle and has to travel through the air until it hits my eyes, where it causes certain neurophysiological processes that finally cause the visual experience of the bicycle. The object itself is only one of many causal antecedents of the perception. Now Dretske raises the question: what allows us to single out this specific part of the causal chain as the object of the experience? Causal theories cannot explain why one of the causal antecedents should play a more special role than the other ones.

Dretske's contention is that in order to single out the object of the experience we have to put our emphasis not only on the causal chain that brings about the experience but also on the informational relationships between the experience and its object. The basic idea is that a state of affairs can carry information about its causal antecedents. However, informational relationships differ in two important respects from the causal ones. 
First, a state of affairs can carry information about one of its distant causal antecedents without carrying information about proximal ones. This is the case when a state of affairs can cause another one in various different ways. Let us consider the example of a friend who sends me an email message every week. He writes them on a program that runs on his server and, when he is done, clicks the send-button; the message is sent to my server. It is not sent directly, though, it has to pass through several other computers and possibly a satellite before it arrives at its destination. There is a wide variety of paths from my friend's server to mine, and two messages do not have to take the same path to travel from one server another. In fact, they typically take different paths. In other words, receiving a message from my friend can be caused by different kinds of causal chain (some of them involving a satellite, some not). The fact that there is an email from friend in my mailbox does therefore carry information about a distal cause (his composing the massage on his server) without carrying information about a more proximal one (the particular path the massage takes from his server to mine).

Second, if a state of affairs carries information about one of its causal antecedents, it can at the same time carry information about the causal antecedents of this latter state of affairs. When I hear that the doorbell is ringing, for example, my sensory experience does not only carry the information that the doorbell is ringing, but also that somebody pressed the doorbutton. The experience, thus, carries information not only about its object, but also about causal antecedents of its object. The information that the doorbell is ringing, however, has a special status because we get the information that somebody pressed the doorbutton via this information and not vice versa. Thus, the experience gives a primary representation of the ringing of the bell, but not of the pressing of the doorbutton.

With these two characteristics of informational relationships we can, according to Dretske, explain why the object of experience plays a special role in the causal chain. He states that

the object of the experience in question (what it is we see, hear, smell and taste) is that object (or set of objects) whose properties the experience represents in a primary way. (Dretske 1981,162 )

This means that the object of the experience is the most proximal of the causal antecedents about which the experience carries information. When I see a red table, for example, the experience cannot carry information about any of the causal antecedents that are more proximal than the red table. Otherwise, the more proximal cause, e.g., some neurological process, would 
be the object of the experience. In order to show why physical objects and not some neurophysiological processes are the objects of our experiences, Dretske has to show that one and the same physical object can cause one and the same experience in different ways. He argues this point by noting that I can see the same red table at one point in bright daylight and later in dim candlelight. In both cases I have the same experience, I see a red table, but the neurological stimulation differs dramatically. Similarly, when I walk around the table I see it from different perspectives. The image projected on the retina changes continuously, but I always perceive the table as rectangular. In these cases, the same kind of object causes the same kind of experience via different kinds of stimulation of the nervous system.

In his article "Objective Perception" Haugeland discusses Dretske's argument. He shares the concern about causal theories of perception, but criticizes Dretske's solution of the problem. We have seen that Dretske has to show that an experience cannot carry information about any of its causal antecedents that are more proximal than its object. To support this claim, Haugeland argues, it is not enough to show that the experience can be caused by different kinds of stimulus, for the question arises of how we determine whether two stimuli are of different kind; "and whether two instances differ in kind depends on which kinds are being considered" (Haugeland 1998a, 245). Haugeland points out that Dretske's argument depends on the negative claim that there is no single kind of stimulus that mediated all and only the constant perceivings, otherwise that kind of stimulus would be the object of our perceptual experiences. In other words, Dretske does not only have to show that "there are respects in which the stimuli differ, ... he must argue that there is no respect in which these stimuli (and only these) are all alike" (Haugeland 1998a, 254). And, Haugeland continues, it seems to be impossible to formulate such an argument, because "it seems that there must be such kinds, if sensory perception is possible at all" (Haugeland 1998a, 246). If it is possible that we perceive the table from various perspectives, in different light conditions, etc., all these perceptions must have something in common that allows us to recognize them as perceptions of the same object, which means that there must be a projectible classification and thus a kind that all and only those causes would instantiate it. ${ }^{29}$ In consequence, according to Dretske's account the kind of stimulus, and not the red table, would be the object of our experiences. This shows that we cannot single out the object of experience in the causal chain on the basis of informational relations as defined by Dretske.

Haugeland proposes an interesting idea to solve Dretske's problem. In order to perceive objects as objects, he argues, one has to be committed to constitutive standards. The object of one's experience, then, is determined not 
only by the causal antecedents of the experience, but also by the constitutive standards to which one is committed. He illustrates this point with his favorite example, the perception of chess pieces and moves. The material appearance of chess pieces can vary immensely. One can play chess with wooden figures on a board or-like Dr.B. in Stefan Zweig's novel The Royal Gamewith little pieces of bread, some of them colored with dust, on a chequered bed cover. Chess pieces can even take the form of patterns on a computer screen. Whether we perceive something as a chess piece or not does not depend on its physical form, nor on its material properties, but on the function that is assigned to it according to the rules of chess. Similarly, a move of these pieces qualifies as a chess move if it accords with the rules of the game, or at least (in the case of a mistake) if the player who makes the move generally conforms to these rules and is ready to correct an error when one is pointed out. Chess rules, then, are constitutive standards for the perception of chess pieces. In other words, if one does not know the basic rules of chess, one cannot perceive chess pieces, one cannot see a rook, for example.

Chess perception is a convincing example because it shows nicely how commitment to constitutive standards, namely the rules of chess, enables us to perceive a certain sort of objects and events, i.e., chess pieces and moves. The problem with this example is, however, that it suggests that this holds only in cases where one perceives something, a piece of wood, a bread crumb, etc., as something else, namely as a chess piece. Haugeland stresses, however, that every experience that is about an object presupposes constitutive standards. When we look at the same object and you see a rook while I see a nicely shaped piece of wood, for example, the difference is not that you have constitutive standards while I do not. In order to see an object, we both have to be committed to constitutive standards. The difference between your and my visual experience is that your constitutive standards include the rules of chess, while mine do not. "What the perception is of is that which the constitutive standards govern" (Haugeland 1998a, 253).

The example of chess perception is special also in the sense that its constitutive standards, the rules of chess, can be fully spelled out. This is not true, however, for all of our constitutive standards, nor is it a necessary condition for having them. Haugeland states that even in the case of chess perception it is sufficient to have "some grasp or understanding of the game of chess" (Haugeland 1998a, 248). For understanding the game of chess one does not have to be able to fully spell out the rules of the game. In fact, many people who play chess are probably not able to do so. Nor is reading a rulebook sufficient for understanding the game. In many cases we have experiences of objects relative to constitutive standards which cannot be 
spelled out as easily as chess rules (if they can be spelled out at all), for example when we see rocks, sticks, or clouds. Consequently, being committed to certain constitutive standards cannot be equated with holding a certain set of beliefs. ${ }^{30}$

On the basis of his account of constitutive standards Haugeland can solve Dretske's problem. When I perceive a chess piece, it is essential that my perception is actually caused by this chess piece. But how can I single out the chess piece in the chain of causal antecedents of my chess perception? We do that, according to Haugeland, on the basis of the constitutive standards that we are committed to. In case I have a doubt whether I have actually seen a rook or rather a bishop that I have misperceived as a rook, Haugeland argues, the constitutive standards determine where I have to double-check. Let us, for example, assume that due to a strange perspective and lighting, the retinal patterns that are caused by the rook resemble those that are typically caused by a bishop under normal perceptual circumstances (good light, optimal perspective, etc.). Should we say in this case that I correctly perceive the retinal patterns of a bishop or rather that I misperceive the rook? Haugeland answers that clearly the latter is the case because according to our constitutive standards of chess it is not the retinal pattern but the object on the board that matters. In other words, constitutive standards of chess are about chess pieces rather than retinal patterns.

Haugeland's response to Dretske's problem shows clearly where the normative element of the mental comes in. Haugeland states that

the norms governing the perceptions as such, and in virtue of which they can be objective, are inseparable from the standards governing, and indeed, constituting, the chess phenomena as such. (Haugeland 1998a, 254)

In a later article "Truth and Rule Following" Haugeland addresses the question of what it means to be committed to constitutive standards, giving a more detailed account of constitution that he develops in close analogy to the notion of rule following. He distinguishes four aspects of constitution: constitutive regulations, constitutive standards, constitutive skills, and existential or constitutive commitment. These are mere aspects of the process of constitution. Unlike Husserl's layers of constitution they do not allow for distinctions in the realm of constituted objects. Let me elaborate each in turn.

Constitutive regulations are pretty much like the rules of a game, regulations that set out what the agents or players may or may not, must or must not do. If we take chess as an example, the constitutive regulations settle what moves are legal and when the players are entitled to make them, etc. 
Constitutive standards, on the other hand, govern not only the actions of the players, but all phenomena that occur within a game. They not only determine what moves are legal, but also how the game has to be set up. These standards specify what can and what cannot happen in the game and so determine the various positions and figures of that game. In the case of chess the constitutive standards define what a rook is or what castling is, and so on.

The third aspect of constitution, constitutive skills, are "resilient abilit[ies] to tell whether the phenomena governed by some constitutive standards are, in fact, in accord with the constitutive standards" (Haugeland $1998 \mathrm{~b}, 323$ ). While, as I have noted above, chess players need not be able to spell out the constitutive standards of a game in order to play it, they have to be in possession of the constitutive skills that are required by the game. A player has to be able to recognize illegal moves, correct them, and insist on their illegality if performed by the other player. Apart from constitutive skills we also have, according to Haugeland, mundane skills that are different from the former, though interdependent with them. Mundane skills "are the resilient abilities to recognize, manipulate, and otherwise cope within the game, including other players, as required and permitted by the rules-in effect, the ability to engage in the play" (Haugeland 1998b, 323).

Finally, the most basic of the four aspects of constitution is constitutive commitment which Haugeland describes as "a dedicated or even devoted way of living: a determination to carry on" (Haugeland 1998b, 341). It is a commitment to hold constitutive standards, apply constitutive skills and behave according to constitutive regulations. Haugeland argues that constitutive commitment is a governing rule the authority of which "comes from nowhere other than itself, and it is brought to bear in no way other than by its own exercise" (Haugeland 1998b, 341). Constitutive commitment, thus, is an attitude to apply rules, a basic rule that cannot be further reduced to other rules.

On the basis of the distinction between these aspects Haugeland sets out his account of constitution. How can he explain that we are directed towards objects? The most basic element of constitution is constitutive commitment, i.e., the commitment to perform constitution in the first place. The objects of perception are constituted according to the constitutive standards that we hold. Chess objects, for example, are constituted because the rules of chess are part of the constitutive standards held by the person who perceives them. Consequently, if the rules of chess had never been invented, chess objects would not exist. Constitutive standards can be applied only on the basis of constitutive skills. In other words, chess players have to be able to see whether a certain move is a legal chess move or not. Finally, the constitutive regulations determine what options a player has, what moves she can make and so on. 
Haugeland argues, as we have seen above, that the objects of perception are constituted according to constitutive standards. What does that entail about the ontological status of these objects? Haugeland answers this question in a deliberately provocative way. "To constitute is to bring into being" (Haugeland 1998b, 325). He argues, however, that this does not mean that 'constituting an object' means 'creating it,' nor does it mean 'interpreting something as an object.' Constitution, Haugeland states, rather means 'letting be.' He clarifies this slogan by defining objects as loci of potential incompatibilities in a constituted domain. ${ }^{31}$ But what exactly are loci of potential incompatibilities? When we look at the chess game, for example, our mundane skills allow us to perceive chess pieces and moves. We can perceive castles and diagonal moves on the chessboard. The constitutive standards of chess, however, do not allow us to move castles diagonally. They can only be moved along the vertical and horizontal lines of the board. Consequently, moving the castle diagonally, though conceivable, is incompatible with the constitutive standards of the game. It is, as Haugeland puts it, in the excluded zone. ${ }^{32}$ Castles and diagonal moves, thus, are loci where the incompatibilities with the constitutive standards can arise. In consequence, they are objective phenomena of the chess game.

Another example of an incompatibility in a constituted domain is a physical object that does not behave as predicted by the laws of physics. In that case, the behavior of the physical object that is perceived on the basis of our mundane skills is incompatible with the constitutive standards that govern the perception of physical objects. This incompatibility might lead to a change in the constitutive standards, i.e., the laws of physics. The physical object is constituted as an object because this incompatibility can arise.

Constitutive standards and the zone they exclude give sense to a distinctive sort of potential incompatibility among particular mundane exercises. Constituted objective phenomena are the loci of these potential incompatibilities. Such loci are what constitution lets phenomena benamely, as we shall see, empirical objects. (Haugeland 1998b, 337)

We can discover these incompatibilities only due to our constitutive skills which are co-constituted with the object. Once an incompatibility has been detected, there are several ways to react. If the phenomenon we perceive on the basis of our constitutive standards is an illegal chess move, for example, we have to correct the phenomenon by insisting on the constitutive standards. If, on the other hand, we perceive a physical phenomenon that is incompatible with the constitutive standards, we have two options: (i) we can either have a better look or adjust our instruments of measurement, i.e., 
we can improve our constitutive skills; (ii) in some cases we will have to change or improve the constitutive standards, e.g., the laws of physics.

Haugeland's account of constitution provides interesting ideas; I think, however, that there is a problem with his characterization of constitutive commitment. As I have pointed out above, Haugeland's distinction between the four aspects of constitution is closely related to the notion of rule following. His preferred examples are games, mainly chess and baseball. But this strategy leads to the following problem. If Haugeland's characterization of constitutive commitment is right, constitution is something that we can, but do not have to perform. He states that it takes "self-discipline and resolute persistence" (Haugeland 1998b, 341) to perform constitution. Does that mean that I can decide whether I want to have constitutive commitment or not? Can I decide to give up constitutive commitment for a two week holiday after a stressful period and then take it up again, like a chess game? I think that Haugeland does not point out clearly enough that once we are trained to have a certain constitutive commitment, we can no longer step outside it. We might change our constitutive standards, improve our constitutive skills, or etc., but it is impossible to give up constitutive commitment, nor does it take any effort or selfdiscipline to perform it. I will come back to that problem below.

\section{SOME CENTRAL FEATURES OF CONSTITUTION: CONTRASTING HUSSERL AND HAUGELAND}

Having outlined Husserl's and Haugeland's account of constitution I will now address the question of what we can learn from them by contrasting their positions. The basic differences between Husserl's and Haugeland's notion of constitution stem from their overall philosophical position. Husserl's notion of constitution has to be understood within the context of phenomenology, a position that works with a strict method, the phenomenological reduction, and a clear goal, the description of the essential elements of conscious phenomena from a first person point of view. Husserl uses the notion of constitution as an operational concept, i.e., a basic concept that is not defined and that serves to define the other concepts of the theory. Haugeland, on the other hand, does not share this methodological framework. Even though his account is influenced by Heidegger, it is not phenomenological in a narrow sense. Haugeland does not apply the phenomenological reduction, nor does he describe the essential elements of mental acts from a first person point of view. His position reflects the discussion of contemporary philosophy of mind, which results in his adoption of holism and the analogy between constitution and rule following. 
Unlike Husserl, Haugeland attempts to give a clear characterization of the process of constitution by defining the four aspects of constitution.

The central part of both accounts is the constitution of the objects of our mental states and episodes. Both philosophers state clearly that 'constituting an object' does not mean 'creating it.' In other words, objects do not pop into existence in the process of constitution. ${ }^{34}$ It is important not to confuse constitution and creation because that would lead to a very crude form of idealism that neither philosopher would accept. Nonetheless, the charge of idealism has been or can be brought up with respect to Husserl's position. The fact that Husserl characterizes his own position as transcendental idealism seems to be a clear sign that it has idealistic tendencies. Yet, in a letter from 1934 he writes:

No ordinary 'realist' has ever been as realistic and as concrete as $I$, the phenomenological 'idealist' (a word which by the way I no longer use) (Husserl 1994, $16[$ my translation $])^{35}$

The question of whether Husserl really was a realist or an idealist is still the subject of extensive debate among Husserl exegetes. One can find advocates for every conceivable position: it is argued that Husserl is an idealist ${ }^{36}$, that he is a realist ${ }^{37}$, that he is neutral with respect to this question ${ }^{38}$, and even that this question cannot be asked meaningfully in the context of Husserlian phenomenology. ${ }^{39}$ I cannot settle this exegetical question here. It is interesting to see, however, that the charge of idealism has been discussed with respect to Husserl and Kant, two philosophers who make extensive use of the notion of constitution, which might suggest that there are some systematic relations between constitution and (transcendental) idealism. Haugeland's realist account of constitution, however, shows clearly that an account of constitution does not necessarily involve a form of idealism. I will come back to this question in chapter 5 .

Husserl and Haugeland also agree that constitution does not mean interpreting something as something else. Both Husserl and Haugeland would argue that there cannot be a realm of basic objects that are not constituted and which are interpreted as something else in the process of constitution. According to Haugeland, the thesis that constitution is interpretation of something that is not constituted as something else "is philosophically self-defeating" (Haugeland 1998b, 326). He explains:

If all constitution were mere counting-as, it would always presuppose, hence never contribute to, an account of objectivity - which would forfeit the point. (Haugeland 1998b, 327) 
In addition, one would have to explain how we can possibly perceive these basic objects-be it atoms, sticks, or etc.-that are then going to be interpreted as something else, e.g., as rooks or tables.

The two philosophers would also reject the thesis that constituting an object means reducing it to some other, more basic object. This project, proposed by Carnap in The Logical Structure of the World, assumes that all objects can be reduced by constitutional definition to some basic objects that cannot be further reduced. Neither Husserl nor Haugeland discuss Carnap's notion of constitution. The idea of reducing objects to other objects of a more basic level by constitutional definition is not compatible with either of their accounts for it presupposes that there are basic objects that form the basis of the system and, thus, are not constituted (in the sense that they cannot be reduced to other objects by constitutional definition). In addition, the idea of constitutional definition is foreign to both accounts.

We have seen that for both philosophers constitution is not creation, nor counting-as or reducing-to. So what is constitution for them and what are objects constituted from? As I have discussed, Haugeland answers this question with the slogan 'constitution is letting be.' He defines objective phenomena in a formal way, namely as 'loci of potential incompatibilities in a constituted domain.' Haugeland does not explain what objects are constituted from. According to his account, we can conceive objects only relative to constitutive standards. This account does not allow for explaining what a table is in terms of the parts that it is composed of, its atomic structure, for example. Seeing something as a table or as a bunch of atoms means only applying different constitutive standards. According to Haugeland we cannot conceive that there is some raw, unstructured matter, i.e., matter that is not constituted, that every object is composed of.

Husserl's account of constitution, as we have seen, explains how we can group a series of moments of the stream of consciousness together and thus have one act of perception of one and the same object. According to Husserl, there are various strata of constitution, some of which can be explained in terms of more basic ones, as we have seen in the example of his analyses of time consciousness and the constitution of temporal phenomena. Like Haugeland he argues, however, that one cannot arrive at the most basic stratum that is composed of phenomena that are not constituted. No matter how far down we can go in our analyses, we will always find phenomena that are themselves constituted. The question of how the constituted object is related to the 'real object' in the physical world is not relevant for Husserl; he works within the phenomenological reduction and thus brackets the realm of the outer world. 
According to Husserl's account, not only the objects that we are directed at in our mental acts, but also these mental acts themselves, are constituted. When I see a table, for example, not only the table, but also the mental act of seeing it is constituted. Conscious phenomena, as we have seen above, are constituted by their partial intentions (retentions, protentions, and primal impressions). This move is quite interesting undermining as it does the Cartesian idea that thoughts or mental activities are the basic elements of our mental life that cannot be further analyzed.

Haugeland does not talk about the constitution of mental phenomena, but his account can cover this aspect. All he needs to argue is that there are constitutive standards for the realm of the mental. These might be the rules of folk psychology like 'you can see an object only if this object is actually in front of you' or 'if you believe that Paris is the capital of France you cannot at the same time believe that Vienna is the capital of France.' According to these rules, there are potential incompatibilities like 'I see a table' and 'There is no table in front of me'; or 'I believe that Paris is the capital of France' and 'I believe that Vienna is the capital of France,' uttered by the same person, one sentence right after the other. The loci of these potential incompatibilities are the mental phenomena 'seeing some object' or 'believing that something is the case.' Thus, they are objective phenomena with respect to the constitutive standards of mental phenomena. In consequence, every change in the constitutive standards that govern the realm of the mental brings about a change in our mental lives.

Another element that we find only in Husserl's account is that every constitution that is performed leaves traces. If we constitute a certain object or kind of object very often, we form a disposition to perform this constitution in the future. With this idea Husserl can account for what we might call the conservative character of constitution, i.e., for the fact that we tend to go on constituting the same (kinds of) objects unless there are strong reasons for a change. The more common a certain way of seeing things is, the stronger the reasons for a change have to be. It is, thus, much more unlikely that one would give up the constitution of everyday objects like chairs than that of objects posited by scientific theories like neutrinos.

Haugeland shows no interest in questions of the nature of these habits or 'traces.' Since his position is based primarily on skillful behavior, and not, like Husserl's, on conscious acts, he could easily account for this conservative aspect of constitution. In addition, Haugeland states the conditions for when and how we have to make changes in our constitutive standards or in the constitutive domain. These changes involve considerable reasoning and probably higher-order constitutive standards; Haugeland's theory in this point seems to 
be more oriented towards our scientific understanding of the world than our everyday experiences. Changes in constitutive standards can also take place in mental lives that are not complex enough to reason scientifically at a high level of abstraction and in very simple and basic mental phenomena. ${ }^{40}$ In these cases we do not need to reason to effect changes; they do not require any intellectual activity. Haugeland's approach, thus, seems to require a strategy that is far too complex.

In conclusion, we can state that both philosophers talk about the constitution of the objects of our mental states. Husserl brings in an additional element by arguing that our mental states are also constituted. Haugeland does not talk about the constitution of mental phenomena, but with his theory he can account for that aspect of constitution. I have pointed out that the charge of idealism has been brought up with respect to Husserl's position (as well as Kant's), which shows that there might be an affinity between the two notions; but Haugeland's realist account of constitution shows clearly that constitution does not amount to an endorsement of a form of idealism. Finally, Husserl argues that every constitution that is performed leaves a trace which explains the conservative character of constitution.

The contrast of the accounts of Husserl and Haugeland shows, I believe, how an account of constitution can address problems that are at the center of contemporary discussions in philosophy of mind. It can explain how our perceptual experiences can have empirical content that is determined not only by their causal relation to the environment but also by the holistic background of the person who has these experiences. With this second aspect it can also shed some light on the thesis of the social aspect of consciousness: the constitutive standards necessary for our perception of objects are intersubjective standards in the sense that they can be communicated through language and are based on our social practices. In addition, if we take Husserl's idea of the constitution of our own mental episodes seriously, we see that even the very fact that we have mental episodes such as perceptual experiences depends on our interactions with our social and physical environment. In the remaining chapters of this book I will outline an account of constitution along these lines. 
Chapter Three

\section{Towards a Theory of Constitution}

In the preceding chapters I have argued that the distinction between the mental and the physical, if it is given too much weight, can lead to serious philosophical problems. I have claimed that a theory of constitution can give us an alternative view of the relation between mind and world that avoids these difficulties.

I will now turn to sketch an account of constitution that can provide an understanding of the relation between mind and world that acknowledges, but does not overemphasize, the differences between these two realms. I will argue that in the case of perception mental episodes stand not only in a causal, but also in a direct, intentional relation to the perceived object. The notion of intentionality is taken to be a basic notion that cannot be further analyzed. In consequence, the account of constitution that I will develop does not explain why we are directed towards objects, but, if successful, will describe how this relation is established. It will do so by taking into account Husserl's point that not only the objects of our mental episodes are constituted, but so are these mental episodes themselves. On this basis I will argue-and here I am not following Husserl any longer-that one could nor have mental episodes if one were not part of a social group of thinking beings. In short, my strategy is to adopt the notion of constitution in order to advance a perspective on the relation between mind and world that follows Putnam's slogan

... let the metaphor be this: the mind and the world jointly make up the mind and the world. (Putnam 1981, xi)

\section{THE FUNDAMENTAL DIFFERENCE BETWEEN THE REALM OF THE MENTAL AND THE REALM OF THE PHYSICAL}

The need for an account of the relation between mind and world comes from an understanding that these two realms are fundamentally different. Sellars acknowledges this difference when he argues: 
Now the idea that epistemic facts can be analyzed without remainder even 'in principle' - into non-epistemic facts, whether phenomenal or behavioral, public or private, with no matter how lavish a sprinkling of subjunctives and hypotheticals is, I believe, a radical mistake - a mistake of a piece with the 'naturalistic fallacy' in ethics. (Sellars 1997, 19, \$5)

The naturalistic fallacy in ethics is the attempt to derive normative conclusions from purely descriptive premises. By mentioning that fallacy, Sellars implies that sentences that express epistemic facts cannot be derived from descriptions of physical facts. Epistemic facts and the logical space of reasons, thus, involve some basic property that cannot be reduced to any physical property. What is this property that makes the logical space of reasons unique?

One could argue with Brentano that mental phenomena are special because they, and only they, are intentionally directed towards other phenomena. The notion of intentionality, like the notion of good in ethics, one could say, cannot be reduced to any notion of the realm of the physical. The problem with this line of reasoning is, however, that we can find intentionality not only in the realm of the mental. Linguistic entities, written sentences that consist of ink traces on paper, for example, can represent objects or states of affairs as well; in other words, they are intentional, too. Thus, the Brentanist has to show that only mental phenomena have original intentionality from which all other forms of intentionality are derived. Though this strategy is a live option, it needs to be supported by a strong argument, especially since it has been attacked by a number of philosophers-among them Wilfrid Sellars. ${ }^{1}$

As I outlined in chapter one, Sellars argues rather that the logical space of reasons is based on rational relations between conceptual contents. Thus, there are two respects in which it is different from the logical space of nature. First, the logical space of reasons is the realm of the conceptual and second, the various positions in that space are justified by or justify other positions within that space. Neither of these points holds for the realm of the physical. The positions in the logical space of nature are neither conceptual nor do they stand in rational relations to one another. Rather, they stand exclusively in relations of cause and effect that can be described by strict scientific laws, i.e., by laws that hold necessarily.

This does not hold for the logical space of reasons. As we have seen in chapter one, the relations between various positions in that space are not physically necessary, but rather normative ones. Making an inference from one position in the space of reasons to another one depends on a correct application of the rules of logic. In other words, it can be questioned whether 
we are actually entitled to perform such an inference or not. In the realm of the physical, on the other hand, the question of whether there is a causal connection between two physical events does not depend on the correct application of the laws of physics. These laws rather describe the relations that hold in the realm of the physical.

In addition, many of the positions in the logical space of reasons are about the world. When we believe that something is the case, for example, the belief can be true or false, depending on how the world actually is. And, again, while it makes sense to ask whether a belief is correct or not, it does not make sense to ask whether a physical phenomenon is correct.

Thus, the Sellarsian statement that reductionism commits a fallacy that is of a piece with the naturalistic fallacy in ethics can be explained in the following way: the logical space of reasons, in contrast to the logical space of nature, is governed by normative rules. One cannot develop an account of the logical space of reasons in terms of the laws of physics without losing one of its essential aspects, the normative element. Therefore, Sellars is justified in insisting that there is a fundamental difference between the realm of the mental and the realm of the physical.

Sellars' anti-reductionist argument has influenced many philosopherseven though Sellars' influence was hardly acknowledged ${ }^{2}$; it has, however, also been criticized by various philosophers. It has been argued that even though there is a difference between the two logical spaces, a reduction might be possible. One day, when neuroscience will have made major developments, it is argued, it will be able to account for that normative element in purely scientific terms. Once this is achieved, we will have a better understanding of the normative aspect of the realm of the mental. Paul Churchland, for example, writes:

Eliminative materialism thus does not imply the end of our normative concerns. It implies only that they will have to be reconstituted at a more revealing level of understanding, the level that a matured neuroscience will provide. (Churchland 1981, 84)

The problem with this line of reasoning is that it is based on faith in the future development of science. Since Churchland cannot tell us what this future neuroscience will look like nor how it can reconstitute normativity at a more revealing level, it is difficult to show that he is wrong (as well as it is difficult for him to convince us that he is right). It is quite interesting, however, that in the three arguments for this optimistic scenario that he develops in his article "Eliminative Materialism and the Propositional Attitudes," he does not seem to take the problem very seriously. His first argument is that 
the fact that the regularities ascribed by the intentional core of FP [Folk Psychology] are predicated on certain logical relations among propositions is not by itself grounds for claiming anything essentially normative about FP. To draw a relevant parallel, the fact that the regularities ascribed by the classical gas law are predicated on arithmetical relations between numbers does not imply anything essentially normative about the classical gas laws. (Churchland 1981, 82)

This argument is based on a confusion of two different levels, namely that of the description of relations and that of the relations described. There is no doubt that there are rational relations between various descriptions of scientific facts. These relations can even be expressed in the language of mathematics or logic. The relations described in science, however, are causal, and not rational. The relations of the logical space of reasons, on the other hand, are rational. Sellars' argument is that the relations in the logical space of reasons are rational not because there are rational relations between the descriptions of the various positions in that logical space, but between the positions that are described. The normative element, thus, is intrinsic to the logical space of reasons; Churchland is wrong when he states that it enters "because we happen to value most of the patterns ascribed by FP" (Churchland 1981, 83).

Churchland's second argument is that "the laws of FP ascribe to us only a very minimal and truncated rationality, not an ideal rationality as some have suggested" (Churchland 1981, 83). Folk Psychology can never reach that ideal because we "have no clear and finished conception of ideal rationality" (Churchland 1981, 83). If we replace Folk Psychology with an exact science, we might be able to eliminate the explanatory failures of the former that stem from its inaccuracies. With this point, however, Churchland can show only that Folk Psychology - as we know it today-falls short of an ideal rationality. He does not show that Folk Psychology cannot be improved, nor does he explain why it should even strive for this ideal. After all, we might not be perfectly rational beings. In addition, even if Churchland could prove that Folk Psychology is an imperfect theory, it would not follow that eliminative materialism is correct; he would still have to show that rational relations can be reduced to relations posited by neuroscience. Churchland's second argument, thus, begs the question.

Finally, Churchland argues that

even if our current conception of rationality - and more generally, of cognitive virtue - is largely constituted within the sentential/propositional framework of FP, there is no guarantee that this framework is adequate to 
the deeper and more accurate account of cognitive virtue which is clearly needed. (Churchland 1981, 83)

Here, again, Churchland shows only that the resources of Folk Psychology might not be adequate to describe in a satisfactory way the rational relations that hold in the logical space of reasons. He does not show, however, that they can be reduced to causal relations that hold in the logical space of nature. Most importantly, he does not show that a matured neuroscience can do the job.

With this short discussion of Churchland's arguments I want to illustrate that reductive strategies are often based on blind faith in the future development of science. Reductionist philosophers admit that their strategy, as Fodor puts it,

is bald and insufficiently detailed: but ironing out its wrinkles is what perceptual psychologists are paid to do, and my impression is that they're getting along with the job pretty well. (Fodor 1995, 10)

Even though it is difficult, if not impossible, to show that this conviction is wrong, or, at least, too optimistic, I hope it has become clear that at least Churchland's arguments do not provide convincing reasons for accepting it. If we add that to the fact that Sellars has shown that there is a fundamental difference between the two logical spaces, I think we should remain suspicious of these strategies - at least until reductionists can provide a positive proof that we can actually reduce the rational relations that constitute the logical space of reasons to merely causal relations that hold in the logical space of nature; a task that is at least as hopeless as the negative proof that the reductionist strategy cannot be successfully carried out in principle.

Given this dialectical situation, I think that Sellars' arguments are strong enough to accept the fundamental difference between the realm of the mental and the realm of the physical. Accepting this difference does not imply the claim that there must be an ontological difference, or, to put it in McCulloch's terms, does not force us to embrace the Real Distinction between mind and body ${ }^{3}$, as a short consideration of Donald Davidson's position will show.

For Davidson, the world consists primarily of events, some of which we pick out describing them as mental events; others are described as physical ones. In his defense of anomalous monism ${ }^{4}$ Davidson has argued, however, that even though we can describe events in different ways, there is, ontologically speaking, only one kind of event; one and the same event can be described both as a mental and as a physical event ${ }^{5}$ : it is a physical event when we use the language of physics to talk about it, it is a mental event when we describe it with psychological vocabulary. Both physical and mental idioms 
make sense only within a larger theory, though. The meaning of these terms depends on the constitutive principles that hold in the respective scheme of description. Davidson accepts Sellars' point that the constitutive principles of physics are radically different from the ones that govern our talking about psychology, for the latter-and only those - are governed by the principles of rationality, they are, in other words, characterized by an intrinsic normative element. Due to this difference, we cannot identify types of physical events with types of mental events, for what counts as a type of event depends on the language we use when describing them. Nonetheless, Davidson insists that, ontologically speaking, there is only one kind of event. ${ }^{6}$ We can identify tokens of physical events with tokens of mental events, since one and the same event can be described in both ways; which shows that his position can be properly called monism.

Davidson's argument, however, does not necessarily entail monism. To derive this position from the distinction between the logical space of reasons and that of nature, one needs some additional premises that are not generally accepted, like the principle of the nomological character of causality, i.e., the idea that where there is causality, there must be a law. ${ }^{7}$ If one drops this principle and replaces it with some arguments for the ontological difference between the mental and the physical, one arrives at an equally tenable position of substance dualism (given, of course, that the arguments for substance dualism are convincing). This shows that the Sellarsian distinction between the space of reasons and that of nature is ontologically neutral; it commits us neither to dualism nor to monism and is thus able to account for the differences between the mental and the physical without embracing Descartes' ontological distinction.

\section{CAUSAL THEORIES AND HOLISTIC BACKGROUND}

So far I have emphasized the differences between the realms of the mental and that of the physical, now I want to draw my attention to the question of how the two can be related. If we accept with Brentano that mental phenomena can be intentionally directed towards physical phenomena, the question arises how this relation can bridge the gap between the space of reasons and that of nature. Before I develop a positive answer to this question by developing an account of constitution, I show that causal theories cannot give a satisfactory account of this relation.

Most contemporary theories of perception acknowledge rightly that there is a causal relation between a perceptual experience and the perceived object. There are, however, several arguments that show that causal accounts cannot fully explain the content of our perceptual experiences. In this section 
I will draw on arguments from Sellars and Husserl. We have seen above that Dretske argues that causal accounts cannot explain how we can single out the perceived object in the chain of causal antecedents of the experience. ${ }^{8}$

According to Sellars, the causal chain that brings about the experience is situated in the logical space of nature. The mental episode it causes, however, belongs to the logical space of reasons, standing in rational relations of justification to other mental episodes. The content and kind of the mental episode are, according to Sellars, determined not by the causal impact of the world, but rather by these rational relations to other mental episodes. Let me illustrate Sellars' point with two examples. One and the same causal impact on my sense organs might cause a mental episode that is about a house or about a facade, depending on my background knowledge; one and the same pattern of ink on paper might be perceived as a decorative pattern or as words, depending on whether the person who sees them knows to read them or not. In both examples I have exactly the same causal impact on my sense organs, but different mental episodes that are brought about. This shows that the content of the experience is not (fully) determined by the causal chain that brings up the experience.

The same conclusion follows from Husserl's point that in perceptual experiences we are directed towards objects like tables, chairs, etc. even though only some aspect of them, a certain part of their surface, is given in our visual field. Husserl, as I have pointed out above, states that there seems to be a contradiction in the nature of perception because it pretends "to accomplish something that, by its very nature, it is not in a position to accomplish" (Husserl 2001, 39 [Hua XI, 3]). In fact, merely causal accounts that regard the causal chain from the perceived object to the stimulation of the sense organ cannot explain why we perceive tables rather than parts of table-surfaces, given that the light waves that cause a visual experience of a table, for example, are reflected by a part of the surface only and not by the table as a whole.

These three arguments show that we need something in addition to a merely causal account that explains the structure and content of our experience by focusing exclusively on the causal chain that brings up the experience. The philosophers whose arguments I have outlined do not agree, however, on what it is that we need in addition to or-in Husserl's caseinstead of such an account. Dretske suggests that what is missing "is an appreciation of the way the informational relationships operate to determine what it is that we perceive" (Dretske 1981, 157). Sellars argues for a holistic understanding of the logical space of reasons in which each position is determined by its rational relations to other positions. Husserl, finally, develops a theory of constitution that explains how an object is constituted 
from the partial intentions of the perceptual experience which are themselves constituted. While Dretske argues that informational relations exist in the world, Sellars enriches and Husserl replaces the causal accounts with theories that are restricted to the realm of the mental.

Dretske's account, I think, has two problems. First, as Haugeland has pointed out, even with his account of informational relations Dretske cannot explain how we can single out the object of perception from the long chain of causal antecedents of the experience. ${ }^{10}$ Second, Dretske's contention that informational relations are part of the physical world is a strong ontological assumption. In terms of ontological simplicity, Sellars' and Husserl's positions are favorable since they do not force us to any ontological commitment, but simply try to explain how the mind works.

Sellars and Husserl address the question of how the content of mental episodes is determined in different ways. Nonetheless, their views have several aspects in common. For my purposes, however, historical considerations concerning the similarities and differences of these two approaches are of only peripheral interest; consequently I will not contrast their positions, but rather accept the conclusion of their arguments that causal accounts are not sufficient to explain perception of objects (let alone mental episodes of other kinds).

I will now turn to the question of what we need in addition to causal accounts to determine the content of mental episodes. Let me start with considering the example of two persons who stand before the same construction. One of them, who has never been there before, sees a whole house, while the other person, who has often seen the construction in the past and walked around it etc., sees a facade. The difference in the content of their experience cannot be explained by differences in the causal chain from the object to their sensory organs. Ideally this causal impact is exactly the same for both: they see the facade from the same position under the same circumstances. The difference is that the person who sees the facade has a much richer background of past experiences about the object perceived than the one who sees the whole house. This example shows nicely that the content of an experience does not depend only on the chain of causes that bring about the sensory stimulus, but also on a holistic background of other mental episodes.

In his texts on the background hypothesis ${ }^{11}$ Searle argues that the background not only enriches or alters the content of an experience, but that it is a necessary condition for its having content. In other words, not only the person who sees the facade rather than the whole house has a background. Both experiences require a background, which in our example, however, differ in relevant respects. Searle admits that he knows "of no demonstrative arguments that would prove the existence of the 
Background" (Searle 1983, 144), but he motivates the assumption that there is one with the examples of understanding the literal meaning of a word, understanding a metaphor, and physical skills like skiing, all of which, according to Searle, require a background. ${ }^{12}$

Sellars develops an argument for a similar thesis. He points out that perceptual experiences not only justify other positions in the logical space of reasons, but they are also justified by them; the rational relations go in both ways.

If I reject the framework of traditional empiricism, it is not because I want to say that empirical knowledge has no foundation. . . . There is clearly some point to the picture of human knowledge as resting on a level of propositions - observation reports - which do not rest on other propositions in the same way as other propositions rest on them. On the other hand, I do wish to insist that the metaphor of 'foundation' is misleading in that it keeps us from seeing that if there is a logical dimension in which other empirical propositions rest on observation reports, there is another logical dimension in which the latter rest on the former. (Sellars 1997, 78, \$38)

Sellars argues that the minimal requirement for experiencing that something is green is having the concept 'green' and knowing 'the appropriate fact of the form $X$ is a reliable symptom for $Y$, namely that (and again I oversimplify) utterances of 'This is green' are reliable indicators of the presence of green objects in standard conditions of perception" (Sellars 1997, 76f, \$37). According to Sellars, perceptual experiences contain propositional claims. ${ }^{13}$ Since these experiences stand in rational relations to other positions in the space of reasons, they must have conceptual structure. I will adopt Sellars' use of the notion of perceptual experience as a conceptual entity.

We have seen that both Sellars and Searle argue that the content of an experience is determined by a holistic background. It remains to show how this background can perform its task, how it can actually shape the content of the perceptual experience. Searle does not discuss this problem; he seems to be satisfied with pointing out that we cannot explain the content of the experience without making use of the background hypothesis.

Sellars' formulation of there being a 'logical dimension' in which observation reports depend on other empirical descriptions suggests that there is a logical relationship, some kind of inference from the background to the current experience. These inferences do not always have to be actively drawn, as the case of perceptual experiences shows, where the content of the experience involuntarily impinges on us. In order to stress the fact that these relations do not have to be active, I will use the term 'rational relations' 
rather than 'inferences.' I will discuss the notion of rational relation in more detail in the next chapter.

With his notion of constitution, Husserl gives a very detailed account of the relation between mental episodes and their holistic background. In the next section I will show how Husserl addressed this problem in his phenomenological analyses and outline an account of constitution of objects along Husserlian lines. My interpretation is based mainly on his analyses of time consciousness and passive synthesis. Husserl's overall philosophical position developed over the years and underwent several changes. As I have indicated, the interpretation I am proposing is not a standard interpretation. It does not try to cover all aspects of Husserl's thought, but concentrates on what he wrote on a specific topic, time consciousness and passive synthesis, in a certain time period. ${ }^{14}$ In some aspects of the account of constitution that I am going to sketch I will clearly go beyond Husserl. My main purpose is not to give a comprehensive interpretation of Husserl's work, but to show how a specific aspect of his thought can give us an interesting perspective on the relation between the mental and the physical.

\section{CONSTITUTING OBJECTS}

The main thesis I want to develop is that the intentional relation between mental episodes and objects is based on the fact that we constitute the objects towards which we are directed. This does not mean that we create objects in the process of constitution. In the case of perceptual experiences, a theory of constitution complements causal accounts; perceptual experiences are caused by the objects that they constitute. Before I go on to show how constitution and a causal account complement each other I will discuss the question of whether constituting an object can be characterized as interpreting something as something else.

It might be tempting to think that constituting an object means interpreting raw sense data as objects. A causal account might explain how these raw data are delivered to the mind, and a theory of constitution could show how we apprehend these data and interpret them as objects. The example of seeing a house vs. seeing a facade, that I have used above, might even support this idea: in both cases, one might argue, we have the same raw material that is interpreted differently. This strategy recalls empiricism as well as Husserl's early distinction between sensory data and the intentional form of an act. This characterization of constitution, however, would presuppose that we can interpret raw data in a way that allows them to bring about (conceptually structured) contents of perceptual experiences; they would provide reasons that justify the experience. A position along these lines would, thus, fall into the Myth of the Given. 
Husserl rejects the thesis that constitution is interpretation of raw data in his later work. While he claimed in his early publications that perceptual experiences are composed of two components, non-intentional matter and intentional form, he states later: "when descriptive theory of consciousness begins radically, it has before it no such data and wholes, except perhaps as prejudices" (Husserl 1960, 38 [Hua I, 77]). I have discussed briefly Husserl's arguments against the matter-form schema above. ${ }^{15}$

The thesis that constitution is interpretation can also be understood in a different way. In the process of constitution, one might argue, we interpret some objects as something else. Haugeland has shown that this position

is philosophically self-defeating. ... The project is to understand the objecthood of objects-their standing as criteria for objective skills-in terms of their constitutedness. But counting-as presupposes the objecthood of the objects that are to be counted as something else, and merely adds onto those objects some new relative features (relative to whatever they are counted as). (Haugeland 1998b, 326)

Accounts that characterize constituting as interpreting some object as something else face the difficulty to explain how we can perceive the basic objects, figurines, atoms, rocks, or whatever they might be, as objects. Moreover, they aim to explain what objects are by relying on our being acquainted with some (basic) objects already.

So far I have claimed that constituting an object does not mean creating it, nor does it mean interpreting something as something else. In addition, I have shown that the constitution of objects requires a holistic background. The question, now, is how a holistic background can shape the content of the occurrent mental episode. This question seems particularly pressing in the case of perceptual experiences because they are essentially passive. We cannot actively determine their content; rather, it impinges on us.

The passivity of constitution can be understood in two ways. ${ }^{16}$ First, constitution is passive in that it depends on the environment of the perceiver. If the perceptual experience in question is caused by an elm tree, for example, the perceiver cannot decide to constitute a palm tree instead. In the case of perceptual experiences constitution is passive in that it is restricted by the objects that cause the perceptual experience. In this context, 'passive' is used in the sense of 'receptive.' Second, it is passive in the sense that we do not have to actively perform constitution. In other words, constitution does not require any effort. If one looks at an elm tree, for example, one does not have to decide to perform constitution in order to have a perceptual experience of that tree. In this context, the word 'passive' means 'inactive.' 
Constitution in perceptual experiences is passive in either sense, it is receptive and inactive, as the examples that I have used in the preceding paragraph show. This is not true for all mental episodes, however. If I wish to have a yellow bicycle, for example, the object of my episode is constituted passively in the sense of inactive; I do not have to make an effort to constitute a bicycle, I can draw on my previous experiences about bicycles. It is not passive in the sense of receptive, though. In order to wish to have a yellow bicycle I do not have to perceive one; the constitution of the object is not necessarily triggered by an object that is perceived at the same moment.

In some mental episodes, constitution is not passive in both senses. This is the case in episodes where one is directed towards a new kind of object, for example when a scientist postulates a new kind of particle or when a science fiction author invents a planet that is populated by a form of intelligent life. They do not have experiences of these kinds of entity to draw on in the process of constitution; in consequence, it is not passive in the sense of inactive. In addition, they do not perceive the objects they postulate or describe; constitution is therefore not passive in the sense of receptive.

Let us now turn back to the question of how a holistic background can shape the content of mental episodes, especially of those that are passive in both senses, receptive and inactive. The answer to this question, I think, lies in Husserl's analyses of time consciousness. Husserl's basic contention is that mental acts are temporally extended. ${ }^{17}$ This is most obvious in the case of the perception of temporal objects, like hearing a melody. At any moment we can hear only one temporal part of the melody, a tone, for example. Nonetheless, we hear a melody, i.e., we have a mental episode that is directed towards the melody as a whole rather than a succession of mental episodes that are directed towards single tones. This shows that like the perceived object, the act of perception also has to be temporally extended.

Husserl argues that the constitution of the object of the experience depends on the succession of partial intentions in which we are directed towards this object. According to Husserl, there are three kinds of partial intention, retentions, protentions, and primal impressions. Primal impressions are directed towards the present temporal phase of the object, the very tone of the melody that I am hearing in this moment, for example. Retentions are directed towards the tones towards which I was directed in a primal impression just a moment ago, and protentions are expectations directed towards the tones that I will be directed at in my primal impressions in the next moments. Retentions and protentions are very different in structure: while the former are directed towards what was actually experienced a moment ago, the content of the latter is not as clearly determined. The more one is familiar with a certain object, the more 
detailed are one's protentions. When I hear a melody that I have never heard before, I only expect to hear some other tone, while in the case of my favorite song I am expecting a very specific tone. In order to underline this aspect, Husserl also uses the term 'horizon' to characterize protentions.

Husserl carefully analyzes the structure of partial intentions and their modification, their "sinking into the past," as it were. ${ }^{18}$ For my purposes it is not crucial to review all these analyses in detail. It is important, however, to see that Husserl's phenomenological analyses of mental episodes show that they are not basic, atomic units of our mental life. They are rather composed of various parts which, in turn, could be further analyzed. According to Husserl there is no 'lowest level' that we could reach, there are only practical limitations: the analyses become more and more difficult with every level one goes down. In what follows, I will adopt Husserl's notion of retention to describe how the holistic background can shape the content of an actual mental episode.

When Husserl developed this notion in his early texts on time-consciousness he was clearly influenced by Brentano's notion of original association or proteraesthesis. ${ }^{19}$ Retentions are a form of memory that retains what one was aware of just a moment ago. The retention does not present the tone as a present tone, as primal impressions do, but - in a manner of speakingtransforms it into a "past tone." At every moment, a primal impression gets transformed into a retention and the other retentions get pushed back into the past, so to speak. With each of these transformations, a retention becomes less and less lively until it eventually "disappears into obscurity, into an empty retentional consciousness" (Husserl 1991, 27 [ Hua X, 26]). Husserl illustrates the retentional modification with the following diagrams: ${ }^{20}$

The horizontal lines represent the progress of time. A, P, and E are temporal phases of the mental episode, A probably stands for the beginning [Anfang], E for the end [Ende], and $\mathrm{P}$ for a temporal phase [Phase] of the mental episode. The diagonal lines represent retentions that "sink into the past." Fig. 1 shows the sinking of the retentions that are part of the occurrent mental episode. Fig. 2 shows that even after the episode is over, there is still a series of retentions that are directed towards this episode-and, similarly, that having a protention is different from expecting something. The retentional modification of the mental episodes is represented by the vertical lines.

Husserl, as well as Brentano, insists that having a retention is in a crucial way different from remembering something. Retentions are partial intentions; they are parts of mental acts, while remembering something is a mental act on its own that, like every other mental act, is partly composed of retentions. Moreover, retentions are directed towards the immediate past. One can remember events, on the other hand, that one has experienced a long time ago. 
The series of nows (ever new life)

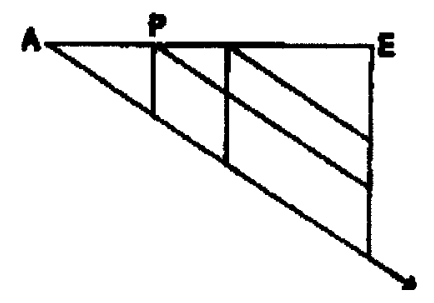

Sinking into the past (march of death)

Figure 1

The series of nows perhaps filled with other objects

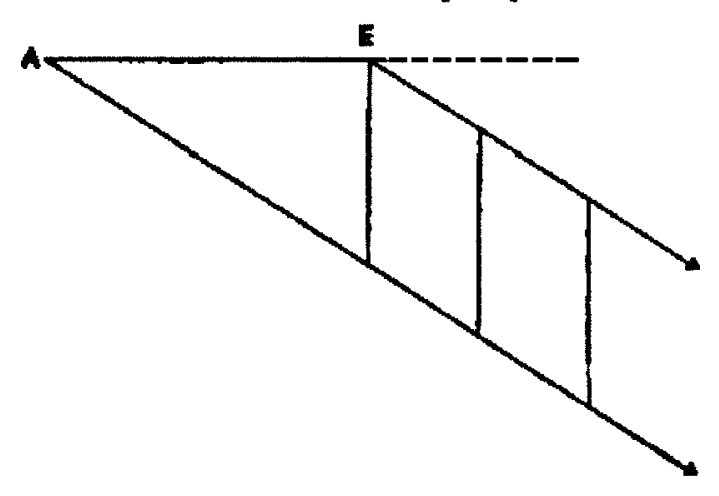

Figure 2

According to Husserl's theory of time consciousness, every mental episode undergoes retentional modification where it becomes less and less lively until it arrives at the zero-point of liveliness. In his early texts on time consciousness, Husserl argues that retentions eventually disappear from consciousness. ${ }^{21}$ In later texts, however, he holds that mental episodes that underwent retentional modification and have, thus, reached the zero-point of liveliness, do not completely disappear. They rather form a background for all future mental episodes; they are, thus, "not nothing," as Husserl puts it in course notes that he has written in the early 1920s:

Every concrete datum of the sphere of the living present sinks, as we know, into the phenomenal past, succumbs to retentional transformation and thereby necessary leads into the region of affective nullity into which it is incorporated and in which it is not nothing. (Husserl 2001, 216 [Hua XI, 167]) 22 
A few lines later Husserl points out that every mental episode requires a background that consists of past episodes that have sunk in their retentional modification to the zero point of liveliness:

according to what has been said, a background or subsoil of non-vivacity, of affective ineffectiveness (nil) belongs to every present [i.e., to every occurrent mental episode]. (Husserl 2001, 217 [Hua XI, 168])

Husserl concludes this section with a statement that this retentional background that is formed by all our past mental episodes is void of liveliness, structure and clarity. In other words, we are not continuously aware of this background as part of our experience, it needs some phenomenological analysis to show its existence.

One may well say that within the zero-stage, all special affections have passed over into a general stage, all special consciousness have passed over into a general undifferentiated affection; all special consciousness have passed over into the one, general, persistently available background-consciousness of our past, the consciousness of the completely unarticulated, completely indistinct horizon of the past, which brings to a close the living, moving retentional past. (Husserl 2001, 220 [Hua XI, 171])

In conclusion, Husserl argues that some moments of our mental episodes that he calls 'retentions' keep us aware of the immediate past. With every moment, each of them loses clarity and liveliness. In his early writings on time consciousness, Husserl holds that after a certain period, when retentions have become very unclear and nebulous due to their continuous modification, they disappear altogether. In later texts, however, he argues that they never actually disappear; they rather become part of a holistic background ${ }^{23}$ which is necessary for having mental episodes in the first place.

With this account of a retentional background Husserl provides a useful instrument for describing how a holistic background can determine the content of a mental episode. In order to do so, however, we have to take a look back at Husserl's analysis of the basic level of constitution. I have pointed out above that, according to Husserl, mental episodes consist of several moments or partial intentions, like retentions, protentions, and primal impressions. The flow of consciousness is understood as a series of primal impressions that are continuously transformed into retentions. This retentional modification is understood as a purely formal process, which abstracts from the content of the partial intentions. 
When Husserl claims that mental episodes are temporally extended he characterizes them as a series of partial intentions. Now the question arises how a series of partial intentions can form a mental episode. What determines whether a specific primal impression still belongs to the mental episode that I am just having or rather marks the beginning of a new one? The temporal modification does not suffice to group partial intentions together into a mental episode because it is purely formal and abstracts completely from the content: ${ }^{24}$ every primal impression undergoes retentional modification, no matter what it is about.

According to Husserl, these unities of partial intentions that form the mental episode are established by association. "The most primitive elements [Gegebenheiten] of consciousness constitute themselves as associative fusions which can affect the I due to their contrast to a different background" (Holenstein 1972, 112 [my translation] ${ }^{25}$ ). Consequently, these unities are a "function of the three laws of association: similarity, contrast, and contiguity" (Holenstein 1972, 49f [my translation] ${ }^{26}$ ). Accordingly, a series of primal impressions that form a temporal sequence and the content of which stays constant (or undergoes only gradual changes) are grouped together, while an abrupt change, a contrast, marks the beginning of a new unity. Let me illustrate this point with an example. When I look at a tree, I have a series of primal impressions that have the same (or very similar, I am of course simplifying here) content. After some time, I might turn my eyes and look at the roses that grow next to the tree. In this moment, there is a sudden change in the content of the primal impression that is followed by a new series of primal impressions that have roughly the same content. Accordingly, the primal impressions I had during my looking at the tree form a unity, and so do the ones I have now, looking at the roses. The sudden change between these two series marks the end of the first unity of primal impressions and the beginning of the next. The processes of establishing these unities are passive in the sense of inactive; they do not require any effort. Before I go on to show that these unities play a central role in the constitution of objects I will discuss their structure in more detail. In doing so I will address the question of whether Husserl is committed to the Myth of the Given.

Husserl characterizes these unities as sense data [Empfindungsdaten]. $\mathrm{He}$ also suggests that they evoke processes of association that are based on similarity, continuity, and contrast. To put it in Sellarsian terms, they stand in rational relations to other positions in the space of reasons. Hence, Husserl seems to argue that sense data stand in rational relations to positions in the logical space of reasons and, consequently, to fall into the Myth of the Given. Before accusing him of committing this fallacy, however, we 
have to take a closer look on his notion of sense data, and its development over the years.

Holenstein shows that Husserl uses the terms 'sense data,' 'hyletic data,' 'affection,' 'impression,' etc., in an ambiguous way ${ }^{27}$, he uses them for raw sense data that are part of the logical space of nature as well as for mental episodes that are positions in the logical space of reasons. In his early writings, Husserl claims that there are raw, unstructured, and non-intentional sense data that are part of the mental act. In this phase of his work he clearly appeals to the Myth of the Given. Between 1907 and 1909, however, he starts to criticize the matter-form schema in the context of his analyses of time consciousness. ${ }^{28}$ In his later philosophy, Husserl extends this point to a more general critique of sense datum theories, although he never arrives at the point of explicitly rejecting the notion of raw sense data in the context of the constitution of objects. ${ }^{29}$

In his study on Husserl's notion of association, Holenstein shows that Husserl actually develops an alternative to the notion of raw sense data in his discussion of the unities of partial intentions. ${ }^{30} \mathrm{He}$ states, however, that Husserl was not aware of this development. Hence, according to Holenstein, Husserl in fact rejects the notion of raw, unstructured, and non-intentional sense data, even though he never explicitly draws this conclusion. This change in Husserl's position finds its expression in the use of terminology. In his later works, Husserl increasingly uses the word 'affection' rather than 'sense datum.' In analogy to this terminology I will call the unities of partial intentions that are formed by association 'affective unities,' adopting an expression that Husserl uses at some places.

In his late philosophy, Husserl presents two main arguments that show that affective unities are different from raw sense data. ${ }^{31}$ First, they are constituted; they have temporal structure and, thus, consist of a series of partial intentions. In consequence, they are not ready-made objects that are given to consciousness. Second, sense data are supposed to be immediately given, affective unities are not; we can know about them only through reflective analysis. According to Holenstein, these two arguments show that Husserl actually gave up the notion of raw sense data.

The main difference between raw sense data and affective unities is that only the latter have intentional structure. This does not mean, however, that they are directed towards full-blown objects. They are intentional because they are unities of partial intentions that are grouped together according to the 'laws of association.' Holenstein argues that consequently affective unities have a certain 'gestalt-structure'. ${ }^{32}$ "Without making it explicit, Husserl replaces in his phenomenology of association the notion of sense data with 
gestalt-psychological notions" (Holenstein 1972, 114 [my translation ${ }^{33}$ ). The intentionality of affective unities is pre-objective, though. In a late, hitherto unpublished manuscript, Husserl distinguishes between "primal association [Urassoziation] of non-objects, of intentional unities (pre-objective) and later affections of apperceived unities and eventually of object-unities." ${ }^{34}$ The constitution of affective unities is a necessary prerequisite for the constitution of objects.

In conclusion, even though Husserl uses words like 'sense data' for affective unities in his later writings, he is not prone to fall into the Myth of the Given. If we have a closer look at the structure of affective unities and the role they play in Husserl's later philosophy, it becomes clear that they belong in the space of reasons. If this interpretation is correct, Husserl (in the reconstruction of Holenstein) clearly rejects the idea that there are raw, unstructured sense data that justify mental episodes, even though he never explicitly says so.

Let us now come back to the question of how affective unities figure in the constitution of objects. We have seen that these unities are intentional in a pre-objective sense. Husserl states that they are indispensable for the constitution of objects: "Affective unities must constitute themselves, so that in subjectivity a world of objects can be constituted" (Husserl 2001, 210 [Hua XI, 162]). ${ }^{35}$ In addition to affective unities, the constitution of objects also depends on the retentional background which functions as a "reservoir of objects." 36 In order to draw on the retentional background, affective unities have to establish a connection to past experiences in which we have constituted the same object. This can be achieved in virtue of association, which picks out past episodes that involved affective unities sufficiently similar to the occurrent ones. The problem, now, is that the notion of sufficient similarity is rather vague, since any two affective unities are similar in an indefinite number of respects. ${ }^{37}$ In consequence, this account does not explain why we constitute certain kinds of object rather than others; why, to use Quine's famous example, we constitute rabbits rather than undetached rabbit parts. The relevant respects in which two affective unities have to be similar are determined by association. It is impossible to explain why the similarity of certain respects of affective unities is relevant in the process of association while others are not. Thus, 'association' is a basic notion in the account of constitution that I am proposing that cannot be further analyzed or explained in other terms. Even though this strategy does not allow us to explain why a certain respect of similarity is relevant, it is sufficient to describe how we actually perform the constitution of objects.

A consequence of this aspect of the proposed account is that we cannot distinguish between relevant and irrelevant or, to put it more drastically, 
between correct and incorrect respects of similarity; we are rather constrained to describe which respects of similarity are considered relevant by the persons who perform constitution. This leaves us with the possibility that persons whose process of association involves respects of similarity that are very different from ours constitute different kinds of object. If we admit that constitution depends in part on the social group in which one lives, we could come to conclude that different cultures might constitute different kinds of object. Which kinds of respect of similarity are considered relevant is, however, also determined by our evolutionary history and by the fact that all human beings encounter the same kinds of object. Therefore we can expect that there are no radical differences in the kinds of object that are constituted by human beings of different cultures.

Once one has established the connection between the present affective unity and the retentional background, one constitutes not only the object, but also the mental episode in which we are directed towards this object. This requires that one has established what Haugeland calls 'constitutive commitment,' i.e., the habit of constituting objects under these circumstances. I will discuss this aspect of constitution in more detail in the next section; now I will turn to the question of how we can adopt Husserl's theory in order to give an account of the relation between mind and world. I should mention that with this move I am going beyond Husserlian phenomenology. Husserl's main methodological principle, the phenomenological reduction, requires one's bracketing of all beliefs in the physical world. The relation between mind and world, therefore, is out of reach for the phenomenologist.

My strategy is to place the Husserlian account of constitution into the Sellarsian/McDowellian framework that is based on the distinction between the logical space of reasons and the logical space of nature by arguing that there can be two kinds of relation between physical objects and mental episodes, namely causal ${ }^{38}$ and intentional ones. Husserl's account of constitution explains how we can be directed towards objects in our mental episodes. In perceptual experiences, one constitutes the objects that are perceived, i.e., physical objects in the environment of the perceiver. The account of constitution does not propose that mental images are created that represent physical objects in our environment. It rather establishes a direct connection to these objects, namely the intentional relation between a perceptual experience and the object perceived. We can say, with McDowell: "there are no images . . . in the phenomenology of vision: it is the relevant tract of the environment that is present to consciousness, not an image of it" (McDowell 1994, 191).

Like Husserl, I think that 'intentionality' is a basic notion that cannot be further reduced to any other notions. Most importantly, it cannot be reduced 
to merely causal processes on the neurophysiological level. The causal relation between object and mental experience can be described with the laws of science, it belongs to the logical space of nature and, thus, cannot account for the pre-objective intentionality of partial intentions, nor for the intentionality of mental episodes, both of which belong to the space of reasons. This does not mean that the causal relation is completely irrelevant for our having mental episodes. As I have pointed out above, we could not have perceptual experiences if they were not caused by the objects perceived. The causal relation, however, cannot explain the fact that mental episodes are directed towards objects. As McDowell puts it, merely causal accounts, as they are developed in cognitive science, offer "what may be an enabling explanation of consciousness, but not a constitutive one" (McDowell 1994, 203).

The claim that intentionality is a direct relation between perceptual experiences and the physical objects presupposes that all objects towards which we can be directed in perception, like tables, roses, clouds, etc. exist in the actual world. There are, thus, strong parallels between the account of constitution that I am proposing and the position that Putnam calls 'natural realism.' He describes this position in the following way:

A natural realist, in my sense, does hold that the objects of normal, 'veridical' perception are usually 'external' things. ... The natural realist ... holds that successful perception is just a seeing, or hearing, or feeling, etc., of things 'out there,' and not a mere affectation of a person's subjectivity by those things. (Putnam 1994, 454)

Putnam states that in perception we stand in direct, cognitive contact to the objects perceived. According to this view, we do not perceive raw, unstructured matter - that would be an appeal to the Myth of the Given - but objects like rocks, computers, and bicycles, etc., that are part of the physical world.

Putnam lists a series of philosophers who, according to him, have shared this position; he names James, Wittgenstein, Austin, and, interestingly enough, Husserl. I think, however, that the interpretation of Husserl as a natural realist is far-fetched. Due to the phenomenological reduction, Husserl cannot make any assumptions about the ontological status of the intentional object in the context of phenomenology. In addition, Putnam gives very little textual evidence, he quotes only one of Husserl's books, the Crisis of European Sciences. ${ }^{39} \mathrm{He}$ does not mention the fact that Husserl describes his own position as 'transcendental idealism,' does not discuss Husserl's phenomenological method, nor does he acknowledge that there is an extensive discussion concerning the question of whether Husserl was a realist or an idealist. 
Even though there are serious doubts about going so far as claiming that Husserl actually was a natural realist, I will adopt a realist position when further developing my account of constitution. After all, I have already made a step beyond Husserlian phenomenology by discussing this very problem.

We are now in a position to address Dretske's problem. ${ }^{40}$ Dretske criticizes causal theories by pointing out that they cannot single out the object of our experience from the long chain of causes that eventually brings up the experience. He argues that the object of experience is determined by informational relationships between the object and the experience. According to the account that I am proposing, on the other hand, we do not have to single out the object of experience from a long list of causal antecedents; rather our experiences are immediately directed towards their objects. In consequence, I can share Dretske's concern about causal theories without having to assume that there are informational relations in the world.

Furthermore, the account of constitution that I am proposing can do without the distinction between actual and intentional object. When we are directed towards an object, it is always given under a certain aspect which depends not only on perceptual conditions like perspective, lightning etc., but also on the retentional background of the perceiver. Let us consider an example of a perceptual experience. When I see my PowerBook, the constitution of the object towards which I am directed, the laptop I am currently using, involves computer-related experiences I had in the past. Imagine that we find a way to send this computer back in time, let's say to the 1950 s. If someone looks at the PowerBook, she cannot see a portable computer, because she has no computer-related experiences to draw on in the process of constitution. She rather sees a machine of a certain color and shape that has a keyboard and a screen. We can go even further back in time, let's say to the early $1800 \mathrm{~s}$. In that period people will not even see a machine that has a keyboard and a screen, neither having been invented then. Their experience will be about a grayish object of rectangular shape, etc.

In all these cases, the perceivers are directed towards the same object; the differences in their retentional backgrounds determine under which aspect the object is perceived. This example shows that there is not one single 'correct' way of constituting the object. There are many ways to get it wrong, though; one cannot constitute a book when one really looks at a computer, etc. In that case, one would merely have a misperception. In his Dewey Lectures, Putnam makes a similar point, describing an example that was presented by William James: ${ }^{41}$ 
[James] employs the example of someone choosing how to describe some beans that have been cast on a table. The beans could be described in an almost endless variety of ways, depending on the interests of the describer, and each of the right descriptions will fit the beans-minus-the-describer, and yet also reflect the interest of the describer. (Putnam 1994, 447)

If we replace the words 'describe' by 'constitute,' 'the interests of the describer' by 'the retentional background of the perceiver,' and 'describer' by 'the person who performs the constitution' in the second sentence of the quotation, we arrive at a description of the position that I am arguing for. The sentence, then, would read: "The beans could be constituted in an almost endless variety of ways, depending on the retentional background of the perceiver, and each of the right constitutions will fit the beans-minus-the-person who performs the constitution, and yet also reflect the retentional background of the perceiver." There are many ways to describe the beans, consequently there is not a single correct description. That does not mean, of course, that we can say about the beans whatever we want; some descriptions just get things wrong. And similarly in the constitution of objects: one and the same object can be constituted quite differently in two veridical perceptions, nonetheless we can distinguish between veridical perceptions and misperceptions due to the normative element of perception.

Due to the methodological principles of phenomenology, the relation between physical objects and mental episodes lies out of reach of the phenomenologist. With the discussion in the last few paragraphs I have clearly broken these principles and, as Husserl would put it, fallen back into the natural attitude. I hope the discussion has shown that it can be nonetheless very fruitful to adopt Husserl's account of constitution for describing the relation between physical objects and mental episodes. There are, I believe, two major points that make this strategy interesting. First, it provides an account that is not prone to fall into the Myth of the Given, nor does it run into the problems of coherentism that, as $\mathrm{McD}$ owell has argued, cannot account for the fact that our mental episodes have content. Second, it aims to describe how a holistic background can shape the content of an occurrent mental episode.

So far I have discussed mainly the constitution of objects of perceptual experiences. The account I have outlined, however, can easily be generalized to other mental episodes like remembering, imagining, wishing, dreaming, and so on. They all draw on the reservoir of objects that is provided by the retentional background. The constitution of objects in these experiences does not involve a causal relation between a physical object and the episode, but only rational relations to other positions in the logical space of reasons. 
Mental episodes that do not stand in a direct relation to a physical object, like my wish to own a yellow bicycle, are parasitic on perceptual experiences: I can constitute the object only because I had perceptual experiences of bicycles and of yellow things in the past. The discussion of the development of constitutive commitment and the constitution of mental episodes in the next two sections will give a better understanding of the priority of perceptual experiences.

\section{DEVELOPING CONSTITUTIVE COMMITMENT}

In the second chapter I showed that Haugeland distinguishes four aspects of constitution, the most basic of which is constitutive commitment. He does not explain, however, how we come to develop constitutive commitment; and Husserl also does not discuss how we come to perform constitution. In this section I will address this question.

The hypothesis that every mental experience requires a holistic retentional background might be challenged by an infinite regress argument. The background, I have argued, consists of mental episodes that underwent retentional modification. These mental episodes, however, required another background that consisted of other mental episodes that underwent retentional modification themselves, and so on ad infinitum.

This regress is not unavoidable, though. It can be argued that the creation of a first, minimal background does not require past experiences, but does "involve a long history of acquiring piecemeal habits of response to various objects at various circumstances" (Sellars 1997, 44f, \$19). ${ }^{42}$ Husserl argues that we cannot think of a 'first mental episode,' i.e., one that does not require any background but will provide a background for future mental episodes. He states "not only that every Now [i.e., every occurrent mental episode] leaves a trail of retentions; we cannot conceive of a Now that does not already have retentions" (Husserl 2001, 467 [Hua XI, 378]). The beginning of one's having mental episodes, he continues, is only thinkable as part of a process, but not as the beginning of a process. And, using strong metaphors, he says that before the beginning of our mental lives there has to be something, an emptiness, an undifferentiated, silent dozing. Husserl continues by stating that "transcendental life and transcendental ego cannot be born; only the human being in the world can be born" (Husserl 2001, 469 [Hua XI, 379]).

According to Husserl, thus, we cannot conceive of a first mental episode that does not yet have a background, since every mental episode requires a background that consists of past mental episodes that underwent retentional

modification. The beginning of our mental life is seen as a slow awakening 
from an undifferentiated, silent dozing rather than a sudden start that takes place in a specific moment, like birth. In another place, Husserl argues that children have to learn to have mental episodes. He states: "With good reason it is said that in infancy we had to learn to see physical things, and that such modes of consciousness of them had to precede all other genetically" (Husserl 1960, 79 [Hua I, 112]). Husserl does not discuss how we learn to have mental episodes, nor does he explain how we are to imagine this period of undifferentiated dozing and how the awakening comes about.

I believe that Husserl's expression of a dark, unstructured period of dozing, or better, the slow process of awakening from such a period of dozing, can be a useful metaphor. It can be understood as the period where one has to develop constitutive commitment. In order to do so, one has to establish a first minimal background that enables us to have our first mental episodes. With every additional episode, this background becomes richer until we can talk of a full-blown mental life. But how can a first minimal background evolve from an undifferentiated state of dozing?

In the period of awakening from the state of dozing one does not have mental episodes. One does have, however, the potentiality to establish constitutive commitment. We can explain this potentiality by claiming that one does already have primal impressions that are intentional (in a pre-objective sense) and undergo retentional modification. At this level, the passive processes of association are already operative and group together partial intentions to affective unities in the way described in the preceding section. However, since one does not have a retentional background yet, there is no constitution of objects or mental episodes. In other words, one does not experience objects at this stage of the development. We can respond to primal impressions and affective unities differentially, though, for they are intentional and, thus, have some form of content.

During the process of growing up we are trained by our social group to react to certain of these affective unities in systematic ways. The process of learning these patterns of behavior depends on various factors. For one, it depends on the physical environment and the biological makeup of our sense organs, the latter determining what aspects of the objects in the environment can cause primal impressions. It also depends on the laws of association that determine what affective unities can be formed. Finally, it depends on the social group in which we grow up, which enforces a certain kind of behavior in reaction to associative unities.

For the development of the mental life of human beings, the most important aspect of learning a pattern of behavior is the acquisition of language, the most subtle and most complex of our social practices. During the phase of 
developing constitutive commitment, all the moves one can make in the logical space of reasons are based on association. All moves, therefore, are passive; one does not yet actively perform them. In the process of growing up, we are trained to use words to react to affective unities. We learn that various affective unities can be named by the same word. Hence, the acquisition of language presupposes that we can detect that affective unities are similar in some relevant respects. Language, then, goes on to teach us what respects of similarity are relevant in our culture. In addition, the acquisition of language is important in another respect. The language we learn has a certain structure. By learning what grammatical role nouns, adjectives and verbs, play in our language, we learn, roughly speaking, to constitute objects, predicates and events. Thus, by acquiring a language we are trained to see the world in a certain way. The structure of language does not come from nowhere. It has evolved in a long history of human beings interacting with the world. This evolutionary history can indicate some constraints on what kinds of similarity can be relevant in the process of constitution; it cannot, however, explain why in our development we constitute the kinds of object we do and not other ones.

In sum, we are trained to develop a pattern of behavior in reacting to affective unities that allows us to understand what respects of similarity between affective unities are relevant in our culture. This pattern enables us to constitute objects. We could say, thus, that this pattern functions as a first, minimal background; and even though this background cannot account for the complexity of our mental lives, it does provide a background rich enough for some basic mental episodes which undergo retentional modification and eventually become part of the background. With every additional episode that undergoes retentional modification, the background becomes more and more fine-grained and thus gradually reaches the complexity and structure necessary for explaining the mental life of a full-grown human being. Since we establish this first background in interaction with our environment, perceptual experiences play a privileged role in the process of establishing constitutive commitment. As Husserl points out, perceptual experiences "precede all other [kinds of mental episode] genetically" (Husserl 1960, 79 [Hua I, 112]). In the next section I will show how we come to constitute other kinds of mental episode.

We have seen that the establishment of a first, minimal background can be explained without referring to mental episodes. The only kind of rational relation that is involved in this process is association, which is a purely passive process at this level. At this point we do have, one could say, a retentional background of pre-objective associative unities that underwent retentional modification. 
A similar line of reasoning (that, of course, does not involve the idea of a retentional background) can be found in Sellars who also argues that in order to set up a first, minimal background we do not have to have mental episodes yet:

Thus, while Jones' ability to give inductive reasons today is built on a long history of acquiring and manifesting verbal habits in perceptual situations, and, in particular, the occurrence of verbal episodes, e.g. 'This is green,' which is superficially like those which are later properly said to express observational knowledge, it does not require that any episode in this prior time be characterizeable as expressing knowledge. (Sellars 1997, 77, \$37)

Since one does not have a background that is necessary for having mental episodes in the period of setting up this first, minimal background, the state one is in can be no more than a slow awakening from a state of dozing in which we do not yet have mental episodes. This state, however, is a necessary prerequisite for our mental life, since it is in this state that a minimal background is set up.

This outline of the development of a first, minimal background or establishing constitutive commitment entails that one does not actively choose to develop this commitment, but that it is rather enforced on us by our biological makeup and the social group in which we grow up. We have seen in the second chapter that Haugeland characterizes constitutive commitment as "a dedicated or even devoted way of living: a determination to carry on" (Haugeland 1998b, 341). I think, as I have pointed out above, that this characterization does not express the fact that we do not have the choice of establishing this commitment, nor can we decide whether we want to go on with it or not. Once one has developed a certain retentional background, it might be changed or refined by future experiences, but one cannot give it up altogether, at least not by active choice; we are, in a manner of speaking, trapped and forced to carry on. ${ }^{43}$

I am aware that this sketch of establishing constitutive commitment is very crude and superficial. It is not my goal, however, to work out an account of developmental psychology. My goal was merely to show that the account of constitution presented above does not fall into an infinite regress.

\section{THE CONSTITUTION OF MENTAL EPISODES}

So far I have argued that we constitute the objects towards which we are directed in our mental episodes. Now I want to go on to show that not only the objects, but also the mental episodes themselves are constituted. This move is 
not new, nor original. As I have pointed out above, Husserl already claims that we constitute conscious phenomena.

I have described the constitution of objects in terms of associative processes that have affective unities as their subjects. According to this account affective unities are intentional (in a pre-objective sense). In virtue of association, they establish a connection to the retentional background, which is a central part of the process of constitution. Now I will go on to argue that in addition to their role in the constitution of objects, affective unities also constitute sensory fields.

The extension and merger to field-forms is analyzed [by Husserl] as a special kind of intentional constitution, as passive association. 'Sense data' extend and melt into unities because it obviously belongs to their nature as affection to refer intentionally beyond themselves. (Holenstein 1972, $103[\text { my translation }]^{44}$ )

Holenstein uses scare quotes for the expression 'sense data' to remind us that he is not talking about raw data but rather about intentional unities. ${ }^{45}$

I have argued above that when we establish constitutive commitment we learn to detect relevant similarities between affective unities. One of them is the similarity between affective unities that belong to the same sensory field. In consequence, when we develop constitutive commitment we not only start to constitute objects, we constitute them in different ways as seen objects, heard objects, felt objects, etc. These different ways of constituting objects account for the different kinds of perceptual experience like seeing, hearing, or touching something, and so on. Thus, we learn that there are various kinds of position in the logical space of reasons.

From here it is only a small step to understand that we can make moves from one position to another. At a certain moment one might realize, for example, that when one sees a green apple and then touches it, one will feel a smooth, solid surface. Thus, one learns that one can make a move from a certain kind of visual experience to a certain kind of tactile experience. This move is closely connected with bodily movements, suggesting that the body plays a central role in the development of constitutive commitment. In addition, the temporal modification accounts for the fact that we can move from being directed towards the present aspect of the object to being directed towards a past aspect of the object-we learn to remember past experiences.

In the process of learning to constitute various kinds of mental episode one also has to learn to constitute objects that do not stand in a direct causal relation to the episode, as it happens in episodes like wishing or imagining 
something. The process of learning to move to these positions requires enforcement from the social group in which one grows up, especially through the acquisition of language. We learn, for example to constitute empirical beliefs by being trained to react to certain kinds of affective unity with the utterance "There is an apple!", and similarly for other affective unities and other positions in the language-game. By the time one has grasped a fuller understanding of the language-game, one understands that this utterance is actually justified by a perceptual experience. In addition, one learns that it is an expression of an empirical belief which is a position in the logical space of reasons that is justified by perceptual experiences and that stands in other rational relations to other positions in that logical space-most importantly, it can be corrected if it is false. ${ }^{46}$ In this way one learns to move in the space of reasons, which shows that it is the acquisition of language that allows us to learn what counts as a reason.

Through this process one acquires a large repertoire of positions. Other than just seeing an apple and believing that it is there one can desire or remember it. While the constitution of the object of the empirical belief draws on a perceptual experience that takes place at the same time, the episodes of remembering or desiring draw on one or more past experiences. With time, and with further competence in language, one learns to vary the way in which one is directed towards the object; eventually one can move to even more complex positions like feeling sympathy, doing calculations, etc. These examples show that by developing constitutive commitment, one starts not only to constitute objects, but also the mental episodes in which we are directed towards these objects.

I do not want to suggest that one can literally acquire positions in the logical space of reasons one by one. In order to have mental episodes, one has to have a full battery of positions and know in which rational relation they stand to other positions in the logical space of reasons, i.e., which moves one can make. This does not mean that in order to have a mental episode, one has to have a full and stable knowledge about all positions and possible moves that, once it is established, will always remain the same. The retentional background is rather subject to continuous change. With growing experiences, our concepts become richer. This goes hand in hand with discovering that there are new moves that can be legitimately made and new positions that can be taken. When I learn that apples are edible, for example, I realize that I can make the move from believing that there is an apple to believing that there is an edible object.

Moreover, when the concepts become richer, there are changes in the retentional background which, in turn, bring up changes in the way we constitute certain objects in our perceptual experiences. When I see an apple now, after 
having learnt that apples are edible, I do not see any longer merely a green, solid object; I rather see an edible, green, solid object. As Sellars points out, perceptual experiences not only justify other positions in the logical space of reasons, there is also a logical dimension in which the former rest on the latter. ${ }^{47}$

This aspect can also explain how we can come to constitute new objects. After a period of training one might start to perceive objects that one could not see before. Let's take the example of a doctor and a patient who are analyzing the pictures of an ultrasound scan. On the screen, where the patient can see only different shades of gray without clear boundaries, the doctor actually sees a pictorial representation of the kidney, the liver, etc. Both look at the same screen, but only the doctor can see the organs. She does not see gray shades and then interpret them as pictures of kidneys, etc., but rather has a visual experience of a (pictorial representation of a) kidney. Similarly, a trained chess player can see at one glance whether white is in a good position or not, while it takes an average person a lot of time and hard thinking to find out. Also in this example, the difference between the chess expert and the laymen is that the former sees the actual position where the latter only sees a group of chess figurines. These examples show how changes in the retentional background can lead to changes in the way we constitute objects, which demonstrates the importance of education-understood in a broad sense as enrichment of one's culture that includes both an initiation to certain kinds of practice as well as a development of new practices: by making certain kinds of experience in a systematic manner, we enrich our retentional background with the effect that we learn to perceive objects we could not perceive before; and to arrive at kinds of position in the space of reasons that were out of reach before. 

Chapter Four

The Social Foundation of the Mind

The social aspect of constitution is an element that clearly does not play a central role in Husserl's account of constitution. What is more important, it seems to stand in opposition to Husserl's overall philosophical position, which is based on the first person authority over one's own mental episodes. There might, thus, be a tension between the Husserlian elements and the social aspect of constitution, which play a central role in the account sketched above, which is why I will discuss this dimension in more depth in this chapter.

\section{IN WHAT SENSE ARE MENTAL EPISODES SOCIAL?}

I have argued above that we learn to constitute different kinds of mental episode in a process of social formation. This claim presupposes, of course, that we can draw a distinction between the content and the kind of a mental episode, a distinction that is mirrored by the one between the illocutionary force and propositional content of a speech act. Accordingly, we can also distinguish between rational relations in the space of reasons that hold in virtue of the content and those that hold in virtue of the mental kind of the episode. An example of the former is the move from believing that there is an apple on my plate to believing that there is an edible object on my plate; an example of the latter is the move from seeing that there is an apple to believing that there is an apple.

Mental kinds are characterized by the rational relations of mental episodes to other positions in the logical space of reasons that do not hold in virtue of the content of that episode. In order to acquire new mental kinds one has to learn which moves one can make to and from these positions in virtue of their being of a certain mental kind. Apart from some basic mental episodes one learns about these possible moves through social practices, mainly by learning how the word that describes a specific mental kind is used in language. 
In order to constitute the episode of holding an empirical belief, for example, one has to understand that this is the kind of position that is justified by empirical experiences. Similarly, an act of remembering is, roughly speaking, a position that is justified by perceptual experiences one had in the past.

There might be a temptation to assume that one has had various kinds of mental episode already before one learns about their rational relations in the logical space of reasons. When someone learns that holding an empirical belief is a mental episode that is justified by a perceptual experience, she does not learn to constitute it, one might argue; she rather learns that the kind of mental episode that she already had before counts as "holding an empirical belief"; similarly it might be argued that one can see objects, i.e. one can have visual experiences before learning the rational relations that hold between visual experiences and other positions in the logical space of reasons. This line of reasoning is clearly based on the Cartesian assumption that one can have mental episodes and, in addition, can have full introspective knowledge concerning one's occurrent mental episodes, even if one does not know anything about their rational relations to other mental episodes, or, to bring it more to the point, even if one does not master rational relations at all. It might even be argued that there are some episodes about which one can have full introspective knowledge without being able to describe or communicate them at all, and that only artists, composers, or poets can come close to expressing the inexpressible.

This view stands in sharp contrast to the account of constitution that I am proposing, which has no place for mental episodes that cannot be expressed in language or manifested in other social practices. Since mental kinds are defined by their rational relations to other positions in the space of reasons, one can experience an episode of a certain kind only if one has at least a rough understanding of what moves one can make to and from this episode in virtue of its being an episode of this kind. Similarly for the content of the episode: in order to have an experience of a certain object, one has to have at least a rough understanding of which moves one is entitled to make in virtue of the content of experience. In order to acquire this knowledge, these rational relations have to be manifested in language or other social practices. Hence, it is possible in principle to describe the kind and the content of mental episodes by showing their rational relations to other positions in the logical space of reasons or by referring to the social practices through which we have mastered these relations.

The fact that our being able to constitute certain kinds of mental episode depends on social practices entails an interesting consequence: if our social practices were different, so would be our mental lives. Let us imagine 
an isolated community in a hidden and secluded valley deep in the Alps which has never been in contact with any person from outside the community. Let us assume further that the community's language and social practices are quite different from ours. If it is correct that the acquisition of mental kinds depends on social practices, these people must have experiences at least some of which are different in kind from the ones we have.

I think that this assumption is quite reasonable; I do want to emphasize, however, that the conceivable differences cannot be as radical as it might at first seem. Due to the similarities of our biological makeup-we are all equipped with the same sense organs-we should expect that also the members of our imaginary Alpine tribe distinguish between seeing, hearing, smelling, and feeling something. In addition, some mental kinds emerge from one of the basic aspects of language, namely describing the world. Exclamations like "There is an apple!" and their respective counterparts in other languages express mental episodes that are justified by perceptual experiences. If we admit that every language of a certain complexity must involve illocutionary acts that serve to describe the world, it is very likely that we will also find the notion of holding empirical beliefs in all language communities. The mental lives of all human beings will therefore include at least various kinds of perceptual experience and episodes like holding empirical beliefs.

It is, however, possible that language communities differ with respect to other, more complex mental kinds. There might be a community that does not know episodes like being jealous, performing mathematical calculations, or doubting something, for example. The point is not that there might be people who merely do not have a word for jealousy, calculations, or doubt in their vocabulary, but rather that they never actually experience these kinds of mental episode. This means, of course, that their social practices differ from ours in some relevant respects. I do not want to argue that they can have a conceptual scheme, a way to see the world so radically different from ours that we cannot translate it into our scheme. Given that people from this community come in touch with our culture and learn to speak our language, they will be able to understand "jealousy," "doubt," and "calculation" and might, eventually, even doubt, have the experience of being jealous, and perform calculations. ${ }^{1}$ As long as the members of this community do not get in touch with members of our community, however, their mental lives will not include these kinds of experience.

This argumentation heavily relies on the claim that all mental episodes can be expressed in language or at least be manifested in social practices. It is often argued, however, that we have experiences that cannot be described at 
all. When Dante comes to describe the highest spheres of paradise in the Divine Comedy, for example, he writes:

From that point on, what I could see was greater/than speech can show: at such a sight, it fails - /and memory fails when faced with such excess.

(Dante Alighieri 1982, 292, [Par. XXXIII, 55])

Dante reports that during his visit to paradise he had visual experiences that were so particular that the means of language do not suffice to describe them, nor can memory cope with them.

One way to resolve this tension is to distinguish between feelings or sensations on the one hand, and experiences on the other. ${ }^{2}$ Feelings and sensations are impacts on the nervous system that, ideally, can be fully explained and predicted by scientific laws and, therefore, are standings in the logical space of nature. Experiences, on the other hand, are constituted mental episodes that stand in rational relations to other mental episodes, which means that they must be conceptually structured. They are positions in the logical space of reasons and, thus, cannot be explained by the laws of science, but follow the rules of rationality. While experiences are directed towards something as an object, sensations are not intentional. In some cases mental episodes are caused by feelings, like perceptual experiences that are caused by sensory stimulation. This does not mean, however, that feelings become a part of the experiences, as McDowell points out:

The fundamental point is the distinction between foundations and (mere) causal antecedents: non-conceptual pain (in pre-linguistic infants) is a causal antecedent of the ability to have conceptual pain episodes, not a continuing ingredient in them which grounds the conceptual structures involved. (McDowell 1989, 288)

Thus, we can distinguish the feeling of pain from the experience of pain, for example. In order to experience pain, one has to know its rational relations to other positions in the logical space of reasons; in other words, one has to have constitutive commitment. One has to know that from experiencing pain one can move to believing that one is injured and wishing to see a doctor, for example. The experience of pain is caused by a feeling of pain. Once constitutive commitment is established, however, one cannot have a mere feeling of pain, but one automatically constitutes the pain-experience, for one cannot give up constitutive commitment, as I have argued above.

An organism that has not established constitutive commitment, on the other hand, can feel pain simply if it has a nervous system that is complex 
enough to process a certain kind of stimulus. This stimulus might even cause the reflex to move away from the source of the pain. This movement, however, is not an intentional action, but a mere stimulus-response pattern that can be fully described in terms of scientific laws. It is, thus, not a move in the logical space of reasons. While it might be difficult, if not impossible, to describe the feeling of pain, there must be some social practice on the basis of which we can express the experience of pain; otherwise we could not constitute it in the first place. If there is no word for a specific experience in our language, one could still describe it in virtue of its rational relations to other mental episodes, in this way also mystical experiences like the one Dante speaks about must be describable. Similarly, the goal of poetry cannot be to describe the indescribable, but rather that which is difficult to express with words.

Thus, when Dante writes "How incomplete is speech, how weak, when set/against my thought" (Dante Alighieri 1982, 196 [Par. XXXIII, 121f]) he merely points out that he had experiences that are difficult to describe, but describing them cannot be impossible in principle. In fact, after pointing out the difficulties of expressing what he has seen, Dante goes on to describe the ineffable, i.e., his experience of God, using a geometrical metaphor of three circles of different colors that are of the same dimension.

In sum, I am proposing that experiencing different kinds of mental episode depends on a process of acquiring various positions in the logical space of reasons which, in turn, depends on mastering the rational relations that hold between these positions. Since we learn about these relations by growing up in a social group and adopting social practices, having mental episodes essentially depends on growing up in a social group. If one were missing that social foundation, one could still have neurological reactions that some might be inclined to call feelings or sensations. In order to have experiences, however, one has to be able to perform moves in the logical space of reasons, which requires one's adaptation of social practices.

\section{WHAT KINDS OF RATIONAL RELATION ARE THERE?}

$I$ have argued that mental episodes are positions in the logical space of reasons that are defined by their rational relations to other positions. So far I have not discussed, however, what kinds of rational relation hold between mental episodes. Using the term 'rational relation,' I want to stress that these relations - unlike causal relations - cannot be described on the basis of scientific laws. Sellars, who originally developed the metaphor of the space of reasons, often talks about the relations between different positions in that space in terms of justification and inference. This might suggest that positions in the space of reasons are judgments that justify and are justified by other judgments, with the 
obvious exceptions of perception or language entry transitions, and action or language exit transitions, which play a special role in this logical space. ${ }^{3}$ Perceptual experiences are not inferred from other positions in the logical space of reasons; according to Sellars they are justified by reliability conditions. ${ }^{4}$ Perception is, thus, a transition from something that is not a position in the logical space of reasons to a position in that space. Intentional actions, on the other hand, are transitions from a position in the space of reasons to a bodily movement that is not a position in that space.

All other positions in the logical space of reasons justify and are justified by other positions. This does not mean, however, that we need to make a logically valid inference to move from one position in the space of reasons to another. Sellars has a very broad notion of inference, distinguishing between formal or logically valid inferences on the one hand, and material inferences on the other. The latter are direct inferences of statements like $\phi a$ to $\psi a$ that are valid due to the meaning of the terms involved. Accordingly, the propositions "The streets will be wet" directly follows from the proposition "It is raining"; Sellars contradicts the claim that this inference is an enthymeme, which could be turned into a valid inference only by adding the missing premise "If it is raining, the streets will be wet." 5

Sellars' move hints at the fact that a formal logical understanding of justification and inference cannot cope with the wide variety of rational relations that can hold in the logical space of reasons. One might even have to go one step beyond Sellars' notion of inference to describe all the moves that we are entitled to make. It might be too restrictive, for example, to equate possible moves in the space of reasons with valid inferences from true propositions to other true propositions, ${ }^{6}$ for that might exclude phenomena like creativity or fantasy from the range of possible moves.

Let me illustrate this point with two examples. First, one can move to the mental episode of $(i)$ imagining a pink elephant from the positions of $(i i)$ seeing (or remembering) an elephant and (iii) seeing (or remembering) something that is pink. The move from these two positions to the first requires us to apply the predicate of (iii) to the subject of (ii). In addition, positions of imagining are not true or false; we are thus required to transform the two judgments into a kind of position that does not have a truth-value. To put it less formally, we have to modify the mental kind and merge the contents of the two positions to move to the third. Now, we could say that the episode of imagining a pink elephant is justified by the other two episodes. I think, however, that this characterization does not well describe our actual move. The point is not that $(i)$ is justified (in the strict, logical sense), but that we could not move to this position had we not had an experience that was about an elephant and one about 
something that was pink. Imagining a pink elephant, thus, does not require us to make a valid inference-not even a material inference, for we do not move from true propositions to another true proposition-but rather to make a move that is better described in terms of fantasy or creative thinking.

Second, in the preceding section I have pointed out that episodes of remembering something are justified (in the strict sense) by past perceptual experiences. If we only think in terms of logical justification, this should be sufficient to characterize this mental kind. It is, however, not enough to show how we actually move to positions of this kind. We move to episodes of remembering something from other experiences which strictly speaking do not justify them. Listening to a song, for example, might remind me of the day when I first met my partner. In what follows, I might remember the dress she was wearing, the first words she said to me, etc. The episode of remembering is justified (in the strict sense) by the fact that I had certain experiences in the past. The actual move I perform to the episode of remembering that moment, on the other hand, is made from the mental episodes of hearing the melody.

These examples show that the relations that hold in the logical space of reasons go far beyond valid inferences; they also include moves that are best described as association, creative thinking, or fantasy, etc. Nonetheless, all the positions in the space of reasons are part of a rationalizing account that shows why it is reasonable to make the actual moves we do. Moving from hearing a melody to remembering the first time I met my partner, for example, can be accounted for by the fact that I heard that very melody when I first saw my partner.

I cannot give a full list of all the kinds of move one can make in the space of reasons. There are, however, some characteristics that can help to distinguish various groups of moves. The above examples have shown that there are moves that change the 'direction of fit, ${ }^{, 7}$ like the move we make from perceptual experiences to episodes of imagining or wishing something. The former have, to use Searle's terminology, a world to mind direction of fit, i.e., they can be true or false; the episode of imagining something has the null direction of fit, it does not have a truth value, nor can it be fulfilled by the world. Wishing something, finally, has the mind to world direction of fit; if my wish does not accord with how things are in the world, I have to change the world, and not my wish.

In addition, we can distinguish between moves that require a certain effort, like making logical inferences or imagining something, and moves that do not, like an association that brings about an episode of remembering something. The latter kind of move includes passive processes that Husserl calls 'passive synthesis' and 'association' and that, according to him, establish the first level of constitution. These passive processes of association also take a 
central place in the account of constitution that I have outlined in the third chapter; they bring about affective unities and establish the associative connections between these unities and the retentional background.

The fact that we do not have to make an effort to establish these passive relations does not imply that they are causal relations. It is in our power to change these passive processes; we can constitute different objects even though the causal chain that leads to the experience stays the same. Due to what above I have called the conservative character of constitution it is not easy to bring about these changes, and in general one needs a good reason to do so; our habits that guide the process of constitution are very strong. There are some examples, however, where we can make these changes quite easily. When one comes to a city for the first time, for example, one tends to see houses. If one is told that this is not an actual city, but only a group of facades built for the sole purpose of shooting movies here, one switches to constituting facades rather than houses, even though the visual experiences are caused by the same objects. There are even some cases where we can switch back and forth between constituting two different objects. This can be the case when we look at a picture puzzle like the duck-rabbit (fig. 3$):{ }^{8}$ once one has discovered the ambiguity of the picture, one can switch back and forth from constituting a visual experience of a picture of a duck to constituting a visual experience of a picture of a rabbit.

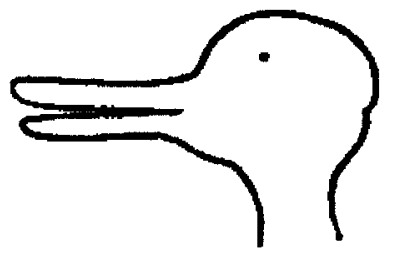

Figure 3

\section{PERCEPTUAL EXPERIENCE VS. THE SOCIAL DIMENSION OF THE LOGICAL SPACE OF REASONS: THE BRANDOM- MCDOWELL DEBATE}

In recent years Robert Brandom and John McDowell have engaged in a debate concerning the social dimension of the logical space of reasons. ${ }^{9}$ One of the central topics of this exchange was Brandom's critique that McDowell's notion of prejudgmental perceptual experience reflects a residual individualism in his position. Since the notion of perceptual experience as prejudgmental episodes also takes a central place in the account of constitution that I am 
proposing, I will now go on to discuss whether there is a tension between this notion and the social aspect of the space of reasons. I will first outline the debate between the two philosophers and then apply it to the notion of perceptual experience that I am working with. This discussion will show that my account of constitution does not imply individualism.

The debate begins with an argument by McDowell against a deformation of the Sellarsian picture of standings in the logical space of reasons which consists in an "interiorization of the space of reasons, a withdrawal of it from the external world. This happens when we suppose that we ought to be able to achieve flawless standings in the space of reasons by our own unaided resources, without needing the world doing us any favors" (McDowell 1995, 877). McDowell argues against positions like Davidson's coherentism, according to which there is only a causal, but not a rational relation between mental and physical events. He criticizes these positions by pointing out that the only way in which we can make sense of positions in the space of reasons is by acknowledging that some of them are justified by facts. He holds that there is a "direct figuring of manifest fact in the space of reasons" (McDowell 1995,890 , fn. 24). Consequently, the world is part of the logical space of reasons, which is, as McDowell notes, identical with "the space of concepts" (McDowell 1995, 888).

In his reply to McDowell, Brandom states that he is in general agreement with McDowell's argument but thinks that it should be supplemented with a stronger emphasis on "a crucial dimension of the space of reasons that McDowell never mentions: its essentially social articulation" (Brandom 1995, 895). He argues that McDowell is individualizing the space of reasons, a deformation as bad as its interiorization. According to Brandom, there is a residual individualism in McDowell's position that has its roots in his notion of perceptual experience that he defines as a "conscious experience that is prejudgmental, but nonetheless through and through conceptually contentful" (Brandom 1998, 369). Brandom holds that there is a gap between McDowell's diagnosis and the therapy he recommends which becomes visible in his "move from the need for rational constraint by the world . . to rational constraint by experience" (Brandom 1996, 255). McDowell's individualism consists in his view that one's perceptual judgments are justified by one's own perceptual experiences. Insisting on that notion of perceptual experience, McDowell is "overlooking other alternatives" (Brandom 1998, 374) that could solve the problems that concern him.

One of the alternatives that Brandom has in mind is his own account that defines standings in the space of reasons in terms of commitments and entitlements to these commitments. Occupying a position in the space of 
reasons, Brandom suggests, is "staking a claim, that is, undertaking a commitment of the sort that might be expressed by making a claim or assertion" (Brandom 1995, 898). One has to be entitled to undertake such a commitment. In addition, a commitment can inherit or derive its entitlement from another one. "Together this means that commitments can both serve as a stand in need of reasons" (Brandom 1995, 898).

According to Brandom, knowledge "incorporates and depends on the social difference of perspective between attributing a commitment (to another) and undertaking a commitment (oneself)" (Brandom 1996, 904). In the case of non-inferential knowledge, the knower might be unable to give justification for committing to a judgment. The justification for my position can come from another person who attributes the commitment to me. According to Brandom, there "is an inferential connection between a suitably noninferentially acquired commitment attributed to you and a corresponding commitment that I undertake. It is treating your commitment as a (defeasible) reason for my own" (Brandom 1995, 906). Non-inferential knowledge, thus, is justified by the fact that reliability conditions are met, a fact that is attributed to the knower by the interpreter. While McDowell holds that every knower can arrive on her own at perceptual knowledge, Brandom argues that in order to know one depends on an interpreter who justifies one's knowledge.

The externalist epistemologist who takes reliability to warrant the attribution of knowledge in the absence of justification relies precisely on this essentially interpersonal pattern of inference. . . . although it is enough that the subject of knowledge be reliable to be entitled to a belief (without having to be able to cite that reliability as a reason for it), the attributor of knowledge has to be able to cite that reliability as such a reason. (Brandom 1995, 906)

According to Brandom, positions in the space of reasons are judgments that stand in justificatory relations to other judgments or facts. Some of these relations, however, are interpersonal. I might hold a position that I cannot justify myself, but that could be justified by someone else. The fact that I am reliable with respect to observational judgments in specified circumstances, which is attributed to me by an interpreter, makes them likely to be true in those circumstances. Brandom concludes that this position meets the rational constraint constraint: "That reliability (in specified circumstances) as a reporter is likelihood of truth (in those circumstances) of reports ensures that the connection envisaged by reliabilists between reported facts and reports of them is not merely causal, but also rational" (Brandom 1996, 251f). With this strong emphasis on the social aspect of the logical space of reasons Brandom claims that 
he can do without the notion of prejudgmental perceptual experiences that justify perceptual judgments and still hold the principle that there must be a rational relation between mind and world. With this theory of a perspectival interplay, Brandom states, he avoids McDowell's residual individualism.

McDowell criticizes Brandom's conception of the social space of reasons; he doubts that Brandom actually succeeds in demonstrating that there is a rational relation between facts and observational reports. "From the point of view of the responder, the response Brandom wants to be entitled to see as an observational report degenerates, just because of the picture's externalism, into a blind reaction to she knows not what" (McDowell 1996b, 294). That is, the observation report is not justified by the facts, but is only a blind reaction. Moreover, the observer does not even know what she is reacting to. Brandom's position "eliminates the perceivable facts from what was supposed to be the perspective of the perceiver" (McDowell 1997, 161) and consequently fails to show that there is a rational relation between facts and observation reports.

Brandom replies to this critique by pointing out that the rational connection is established by the interpreter who can provide the justification for the observer's statement. McDowell counters that this does not suffice to establish a rational relation between facts and observation reports because, according to Brandom's theory, neither the observer nor the interpreter can stand in direct rational relations to facts. He states "that the supposed interpreter's observational hold on reality is in turn made unintelligible by the picture's externalism" (McDowell 1996b, 295). He argues that at least some observers have to stand in direct rational relations to facts, which can be achieved only through perceptual experiences. Thus, one cannot replace the notion of perceptual experience with the social dimension of the space of reasons to establish that rational relation. In other words, Brandom cannot meet the rational constraint constraint which, however, is part of conceptualism, the view that the space of reasons extends into the actual world, which, according to Brandom, is "a defining point for Pittsburgh neo-Hegelians" (Brandom 1996, 259) ${ }^{10}$.

In his reply, Brandom rejects the conclusion of McDowell's argument. According to his account, the interpreter does not have to stand in direct, rational contact to the world in order to attribute the meeting of the reliability conditions to the perceiver. "Those who keep deontic score take interlocutors to be entitled only to those noninferential reports that arise by exercise of (what they take to be) reliable reporting capacities" (Brandom 1997, 191). It is sufficient for the interpreter to know that I am trained in making a kind of non-inferential report, in order to attribute commitment to the perceiver. Brandom goes on: 
From the point of view of such a scorekeeper, I may be entitled to my claim that the potsherd in front of me is Toltec rather than Mayan if I in fact have become reliable in distinguishing them - even if I am still so uncertain of my newly learned skill in this regard that I am not disposed to claim such reliability as a justification of my noninferentially acquired beliefs. (Brandom 1997, 191)

It is, thus, sufficient that the interpreter knows that I am in general reliable in distinguishing Toltec from Mayan potsherds to justify my non-inferential belief.

Finally, McDowell rejects Brandom's critique that his notion of perceptual experience is the result of residual individualism. He states that "the very idea of a thinker is unintelligible except in the context of the idea of initiation into a shared language, conceived as a repository of tradition" (McDowell 1996b, $295 \mathrm{f}$ ). The notion of perceptual experience, thus, is anti-individualistic; it acknowledges that there is a social dimension of the logical space of reasons.

The root of the disagreement between Brandom and McDowell is their respective views concerning justification of perceptual judgments and the extent of the social dimension of the space of reasons. While McDowell argues that every single perceptual judgment has to be justified by a perceptual experience that stands in direct rational relations to the world, Brandom claims that I can hold perceptual judgments without being able to justify them, as long as there is somebody who interprets my judgment and is able to justify it for me. McDowell suggests that their disagreements are based on different conceptions of justification. "Brandom assumes, and, amazingly, takes me to assume, that justification that rules out falsity cannot be had for empirical claims" (McDowell, 2002, 98). While Brandom seems to suggest that we can be entitled to claims that are false, as it is the case in perceptual error, McDowell insist that "in the best case the subject can have an entitlement consisting in the fact that she sees that there is a candle in front of her" $(2002,99)$. If there is no actual candle in front of the person, but only the mirror image of a candle, she is not entitled (in McDowell's sense) to the claim that there is a candle. He admits that "some notion of entitlement might have application in ... [this] mirror case. It might be rational (doxastically blameless) for that subject . . . to claim that there is a candle in front of her" $(2002,99)$. His own strict notion of entitlement, which he claims to be closer to Sellars' intentions, is "a notion for which entitlement and truth do not come apart" $(2002,99)$.

This discussion has some interesting implications for the account of constitution that I am proposing. Like McDowell, I use the notion of prejudgmental perceptual experience and think that once constitutive commitment is established, one does not need an interpreter to justify a perceptual judgment. 
I have argued that perceptual experiences stand in direct, intentional relations to the objects that are perceived. Brandom could object that this characterization of perceptual experiences amounts to individualizing the space of reasons and, as in his critique of McDowell's position, he could argue that this individualization is a symptom of a residual individualism.

I do not think that this critique is justified. Brandom is right when he points out that the space of reasons is a shared space ${ }^{11}$; one position in that space can be occupied by several persons at the same time, as it were. Nevertheless, this social conception of the space of reasons does not imply that my perceptual judgments can be justified only through an interpreter who justifies the fact that I am meeting the reliability conditions. I think that Brandom does not put enough emphasis on the fact that in order to have observational knowledge one has to stand in direct contact with objects in one's environment. Individuals have perceptual experiences, each of them standing in direct contact with its object. The relation between experience and object is based on a particular causal chain, it is an impact from a particular object on a particular person's sense organs.

I have argued above that we can establish constitutive commitment only on a social basis. Once one has established constitutive commitment, however, one does not need an interpreter to constitute the object and the perceptual experience, which, in turn, can justify perceptual judgments. This transition is made by the person who stands in a causal relation to the object perceived. In some respects, therefore, occupying a specific position in the space of reasons is an individual achievement. The fact that one is able to occupy positions in the space of reasons, on the other hand, is possible only because one shares social practices with the group, in which one grows up, and because perceptual experiences are caused by the perceived object. ${ }^{12}$ The account that I am proposing is, thus, characterized by a strong anti-individualistic element.

Burge characterizes individualism as a position according to which "the nature and individuation of an individual's mental kinds are 'in principle' independent of the nature and individuation of all aspects of the individual's environment" (Burge 1986, 117). Individualism, then, is a position according to which the content and kind of a mental episode are independent of the individual's physical and social environment. The fact that individuals have perceptual experiences and that they can occupy this kind of position in the logical space of reasons without the help of an interpreter does not imply that my position is individualistic according to Burge's definition. Brandom might still argue that the assumption that a person can stand in direct contact with objects in her environment is the result of a different form of individualism 
that he calls 'residual individualism.' In that case, however, he has to show what exactly he means by 'residual individualism' and, most importantly, why this form of individualism is problematic.

\section{THE SOCIAL ASPECT OF THE MIND AND PHENOMENOLOGICAL ANALYSIS}

The use of Sellars' notion of the logical space of reasons might cause a tension in the account of constitution that I have outlined above; especially with the claim that we can master moves in the logical space of reasons only through social practices and that consequently one can have mental episodes only if one has grown up in a social group. According to this view, positions in the space of reasons are shared positions which can be occupied by several persons at the same time. This characterization, however, seems to undermine an aspect of mental episodes that is quite essential: mental episodes are private, in the sense that they are experienced by the person who has them. Moreover, this person has a special authority with respect to the mental episodes she experiences. This authority stems from the asymmetry between ascribing mental episodes to oneself and ascribing them to someone else. Yet, if mental episodes are shared positions in the space of reasons, it seems to be difficult, if not impossible, to explain this asymmetry.

Burge discusses in several places the connection between Descartes' view that we have direct knowledge of our own mental episodes and individualism. He points out that Descartes argues that from the fact that he has "a clear and distinct idea of himself only as a thinking and unextended thing" (Burge 1988, 650), it follows that the mind can exist independently of the body.

One can argue in analogy that, since one can 'shut off' these thoughts from all corporeal substance, they are independent for their natures from physical bodies in the environment, and presumably from other thinkers. This line of argument implies that knowledge of one's own thoughts guarantees the truth of individualism. (Burge 1988, 651)

Thus, Burge argues that individualism can be a consequence of first person authority. The problem is that Husserl's phenomenological method is also based on one's authority of one's own mental episodes. Everything that concerns the physical world, and thus the relation between perceptual experiences and perceived objects, are bracketed in the phenomenological reduction. Burge even names Husserl in a list of philosophers who hold an individualistic position. ${ }^{13}$ It seems, therefore, that there is a tension between the anti-individualistic account of constitution that $\mathrm{I}$ am proposing and Husserl's 
philosophical method, a tension that might be pressing since I have used some of Husserl's results to formulate that account.

Burge criticizes Descartes' position using an argument that was first brought up by Arnauld. ${ }^{14} \mathrm{He}$ points out that our having a clear and distinct idea about our current mental episodes does not necessarily entail individualism because it does not provide us with "sufficient clarity about the nature of mental events to justify him [i.e., Descartes] in claiming that their natures are independent of relations to physical objects" (Burge 1988, 651). This argument shows that Descartes' conclusion does not follow from his premises, but it does not explain why many philosophers found individualism appealing. Using Putnam's twinearth example ${ }^{15}$, Burge discusses why we have the strong intuition that by introspection we could not tell the difference between a mental experience about water on earth and one about twater on twin-earth. He acknowledges that these two episodes are exactly the same with respect to their "pure phenomenological feels" (Burge 1988, 653). We can individuate these episodes, however, by having them while we form second order episodes that are directed towards them:

We 'individuate' our thoughts, or discriminate them from others, by thinking those and not the others, self-ascriptively. Crudely put, our knowledge of our own thoughts is immediate, not discursive. (Burge $1988,656)$

Accordingly, I can individuate the episode about water as the episode that I have now, even though I might not be able to distinguish this episode from one about twater. Burge holds that knowledge about one's own thoughts is a second-order episode that includes a first-order episode. The cognitive content of the second-order episode "is logically locked (self-referentially) onto the first-order content which it contains and takes as its subject matter" (Burge 1988, 660).

Burge holds that even though we are infallible about having a certain mental episode, we might not know what this episode is about or how its content could be explicated:

One clearly does not have first-person authority about whether one of one's thoughts is to be explicated or individuated in such and such a way. Nor is there any apparent reason to assume that, in general, one must be able to explicate one's thoughts correctly in order to know that one is thinking them. (Burge 1988, 662)

Thus, Burge argues, like Descartes, that we can know our own mental states and that this self-knowledge is infallible. Their positions differ, however, in 
the way they characterize self-knowledge. While Burge holds that this kind of knowledge is self-referential, Descartes is "construing self-knowledge as a perfected perceptual knowledge" (Burge 1988, 660). For Descartes, episodes that lead to self-knowledge are directed towards an object, just like perceptual experiences, with the only difference that the objects that they are directed at are mental episodes rather than physical objects. The difficulty of this position is, according to Burge, that one has to explain where the infallibility of selfknowledge comes from. In addition, Burge states that this strategy is misconceived: "Justification lies not in the having of supplemental background knowledge, but in the character and function of the self-evaluating judgments" (Burge 1988, 660).

The analogy between perception and self-knowledge is the root of Descartes' individualism. Descartes argues that we have complete and infallible knowledge about our mental episodes. The problem arises when anti-individualists like Burge point out that the content of a perceptual experience depends the object that caused it. Accordingly, the experience of water and that of twater have different contents, even though we might not be able to tell the difference. This example suggests that our self-knowledge, conceived in the Cartesian way, might not be as infallible as it first seemed and that we need further justification for it. One way to react to these worries is to argue that knowing about the relation to the actual object is not relevant for selfknowledge and to deny that the content of the experience depends on the object that is perceived; in other words, to fall back on individualism.

Burge's account of self-knowledge has striking similarities with Brentano's account of inner perception. Brentano distinguishes between inner observation and inner perception. ${ }^{16}$ Inner observation is a mental episode that is directed towards another mental episode that one experiences simultaneously. Brentano holds the principle of the unity of consciousness, though, according to which we can have only one mental episode at a time. If we are directed towards more than one object in different ways, for example if we hear a melody and see a violinist at the same time, these mental episodes form a unity, they form one single mental episode. ${ }^{17}$ Consequently, we cannot have an episode of inner observation and another one that is observed at the same time. In inner observation we could, thus, only be directed towards past mental experiences. In consequence, one cannot actually observe, but only remember one's own mental episodes. Memory, however, is not infallible and can therefore not lead to infallible self-knowledge. ${ }^{18}$ Hence, Brentano would agree with Burge that the Cartesian position according to which self-knowledge is based on mental episodes that are directed towards other mental episodes cannot lead to infallible self-knowledge. 
Inner perception, on the other hand, is infallible. According to Brentano, every mental episode is directed towards an object. Besides that, however, every mental episode is incidentally also directed towards a secondary object, namely itself. Brentano explains the notion of secondary object, using the example of an auditory experience:

In the same mental phenomenon in which the sound is present to our minds we simultaneously apprehend the mental phenomenon itself. What is more, we apprehend it in accordance with its dual nature insofar as it has the sound as content within it, and insofar as it has itself as the content at the same time. We can say that the sound is the primary object of the act of hearing, and that the act of hearing itself is the secondary object. (Brentano 1995, 127)

Thus, Brentano's notion of inner perception is very similar to Burge's notion of self-referential self-knowledge, although there is one crucial difference between the two notions. While Brentano holds that every single mental episode has to be directed towards itself as a secondary object, Burge does not state that self-knowledge is part of every mental episode. Both philosophers agree in denying that infallible self-knowledge can derive from mental episodes that have other mental episodes as their objects, though.

What consequences has this discussion for the phenomenological method of describing mental episodes from a first-person point of view? The Arnauld/Burge argument shows that from first person authority and the fact that we can introspect our own mental episodes, it does not follow that our mental episodes can exist independently of our physical environment or other thinkers. This shows that phenomenology is not necessarily incompatible with anti-individualism. It might seem, however, that Burge's position allows only for a very impoverished version of phenomenology: our knowledge about our current mental episodes is infallible, but we might not even know what they are about nor be able to explicate them. Husserl's phenomenological method, on the other hand, is based on the principle that we can describe our own mental episodes with a high degree of accuracy.

I think, however, that the two positions are closer than it might seem at first. This becomes clear when we remind ourselves that the phenomenologist is interested in the structure of mental episodes, and not in the physical objects towards which we are directed in our perceptual experiences. Since self-knowledge, according to Burge, stems from second order episodes the content of which is self-referentially locked to that of the first-order content, it does not even create a difficulty that we might not be able to explicate the first-order episode. We can individuate the episode 
on the basis of the self-referential relation between the second-order and the first-order episode. We might not know whether a specific perceptual experience is about water or twater, and still have a second-order episode that is about that experience and, thus, indirectly directed towards water or twater, respectively.

In sum, the fact that phenomenological analysis is based on first-person descriptions of one's mental episodes does not imply that it is an individualistic position or that one could have mental episodes independently of their social foundation. Burge's anti-individualism, on the other hand, allows for first-person descriptions of one's own mental episodes, as the parallel between his account of self-knowledge and Brentano's account of secondary consciousness shows: Brentano's method of descriptive psychology is based on the fact that mental episodes are incidentally directed towards themselves. 


\section{Chapter Five}

\section{Constitution and Idealism}

The main problem in adopting the notion of constitution in the context of philosophy of mind is that it can have the flavor of creating or establishing reality; the expression 'to constitute objects' might suggest that the existence of objects depends on an activity of the mind; thus, it might seem that the adoption of this notion invites a form of idealism. Indeed, as I have pointed out above, there is an affinity between the notion of constitution and transcendental idealism in the work of Husserl. Kern shows that Husserl's turn towards transcendental idealism was made possible by his account of genetic constitution. ${ }^{1}$ A similar point is made by Ingarden who characterizes the fundamental thesis of transcendental idealism in the following way:

what is real is nothing but a constituted noematic unit (individual) of a special kind of sense which in its being and quality results from a set of experiences of a special kind and is quite impossible without them. (Ingarden 1975, 21)

Since the account of constitution that I have outlined above is strongly influenced by Husserl's phenomenology, I will now go on to discuss whether my account also implies a form of idealism. I will show that it neither implies nor invites idealism; rather it provides an interesting perspective on the realismidealism debate. I will try to develop this perspective by considering a lateWittgensteinian argument, according to which the position of the idealist or idealist sceptic, who has a general doubt concerning the existence of physical objects, cannot be formulated meaningfully.

\section{A LATE-WITTGENSTEINIAN ARGUMENT}

In his last book $O n$ Certainty Wittgenstein discusses problems of knowledge. He develops an argument against positions that can be characterized by their giving different answers to the general question "Do physical objects exist (in- 
dependently of the mind)?," namely metaphysical realism on the one hand and idealism or scepticism on the other. Wittgenstein's contention is that these positions cannot be formulated meaningfully. He says about the metaphysical realist's basic assumption: "And yet 'There are physical objects' is nonsense" $(O C, \$ 35)$. The same holds for the negation of this phrase that characterizes the idealist's position. In this section I will outline the line of reasoning that leads Wittgenstein to this radical conclusion. Wittgenstein presented his considerations in his characteristic style; he did not try to press them into the structure of an argument, they are more like philosophical musings. My presentation of Wittgenstein's argument in several steps is therefore a reconstruction of the argument rather than an outline that inherits its structure from the original text.

When Wittgenstein makes scepticism and idealism the main targets of his critique, he is really talking about one and the same position. If we characterize metaphysical realism by its basic assumption that physical objects exist and that their existence does not depend on the existence of the realm of the mental, then idealism can be characterized as the position that rejects this claim, thus holding that the existence of the material world depends on the existence of a mind.

It could be said of the latter's [i.e, the idealist's] position that it is sceptical with regard to his opponent's (the realist's) position, and this accords with the customary use of the term 'sceptical'. Hence, whoever denies our everyday belief in the existence of physical objects, is sceptical with regard to this one particular postulation, and Wittgenstein calls this view 'idealist scepticism'. (Haller 1988, 100) ${ }^{2}$

Hence, in the argument that I am going to reconstruct, the words 'scepticism' and 'idealism' are used interchangeably.

The first premise of Wittgenstein's argument is that the truth value of any given sentence can be determined only relative to a picture of the world, i.e., a background of further assumptions and practices. In order to determine the truth value of the sentence "I know that this is my hand," for example, one has to understand not only the meaning of the words of which the sentence is composed, one also has to know the truth-criteria of the sentence. According to Wittgenstein, the proposition is part of a language-game, which determines both the meaning of the words and the truth-criteria. The language-game is part of a background or picture of the world. Even though we can describe several aspects of that background by making some of our tacit assumptions explicit, by stating, for example, "I have two hands," "I have never been on the moon," etc., the background is not a clearly defined, ho- 
mogenous set of propositions. It is rather

an agglomeration of a huge number of sub-systems, each with a fluctuating boundary and a 'mixed' content. These subsystems are related to what Wittgenstein calls language-games. One could say that every language-game has a foundation which is a fragment of the player's VorWissen [pre-knowledge]. (von Wright 1972, 57)

Since it is the background that determines the truth value of any given proposition, we cannot meaningfully say about the background itself that it is true or false. It is rather a picture of the world that is taken to be accurate. Wittgenstein states:

But I did not get my picture of the world by satisfying myself of its correctness; nor do I have it because I am satisfied of its correctness. No: it is the inherited background against which I distinguish between true and false. (OC, \$94)

Even though we cannot attribute a truth value to the background as a whole, we can consider each of the tacit assumptions it contains in isolation. If we do so, we can attribute a truth value to them. This can eventually lead to one's refining the background or changing it altogether and adopting a different picture of the world. In order to illustrate this point, Wittgenstein discusses the proposition "The earth had existed . . . for many years before my body was born," which is one of the propositions that Moore added to the

whole long list of propositions, which may seem, at first sight, such obvious truisms as not to be worth stating: they are, in fact, a set of propositions, every one of which (in my opinion) I know, with certainty, to be true. (Moore 1959, 32)

Wittgenstein objects that the truth of this proposition is not obvious, it rather depends on the language-game which it is part of, like the truth value of any other proposition. We can imagine people or communities who have a different picture of the world, for whom the proposition is false. Wittgenstein illustrates this point with the example of a king who has been told for all of his life that the world started to exist with his birth. All his education was based on this assumption, which was compatible with, or even explained by everything he was ever taught. For him, the proposition "The earth had existed for many years before my body was born" is not at all an obvious truism, it is simply false; it contradicts everything the king has always taken for granted. Due to the differences in the background, the king and Moore play different lan- 
guage-games. In consequence, the words they utter have different meanings; different truth criteria are applied. Strictly speaking, the king and Moore seem to use the same words, but they really speak two different languages. Moore, thus, cannot list this proposition as an obvious truth without specifying the role it plays in his language-game.

What happens if Moore meets the king and tries to convince him of the truth of this proposition? The king would not accept any evidence that Moore can provide. When Moore points out that there are buildings that are more than 100 years old, for example, the king could reply that they obviously have been created together with the rest of the world when he was born, and they were designed to trick people about their actual age. The only way that Moore could convince the king of the truth of the proposition, Wittgenstein claims, is to get him to adopt a different picture of the world; the king would have to change his background, as it were. "I do not say that Moore could not convert the king to his view, but it would be a conversion of a special kind; the king would be brought to look at the world in a different way" $(O C, \$ 92)$.

Moore's strategy to show that the idealist or the sceptic are wrong consists in providing a list of sentences that are obviously true. Wittgenstein states that this strategy fails because it does not take into account what role the word 'to know' plays in our language-game. "Moore's mistake lies in this-countering the assertion that one cannot know that, by saying 'I do know it" (OC, $\$ 521)$. This move, of course, cannot be very convincing for the idealist sceptic. Moore should rather have pointed out what role the expression 'I know' plays in our language-game and in which situations one is entitled to use it. Providing a list of propositions that seem to be obvious truisms without showing that their truth depends on a background does not help, since for every one of these propositions we can imagine a background according to which they turn out to be obviously false. This shows that the propositions listed by Moore are not obvious truisms; Moore's strategy, thus, misses the point. $\mathrm{He}$ should have rather pointed out that the king, who claims that Moore does not really know (some of) the propositions listed, is obviously applying a different set of truth-criteria, and, thus, playing a different language-game. "I know' often means: I have the proper grounds for my statement. The other, if he is acquainted with the language-game, must be able to imagine how one may know something of the kind" $(O C, \$ 18)$.

Let us now turn to the question of how this background or picture of the world is acquired and what it consists of. Wittgenstein describes the acquisition of a background as part of the process of growing up and learning to play a language-game. The background is not a set of beliefs that one can learn one by one; we rather acquire a whole set of beliefs at once. "When we 
first begin to believe anything, what we believe is not a single proposition, it is a whole system of propositions. (Light dawns gradually over the whole.)" $(O C, \$ 141)$. In addition, the background does not only consist of propositions, it also involves certain forms of behavior and practices.

But is it wrong to say: 'A child that has mastered a language-game must know certain things'? If instead of that one said 'must be able to do certain things', that would be a pleonasm, yet this is just what I want to counter the first sentence with. (OC, \$534).

The basis of the child's background is not her acquisition of the knowledge that there are chairs and cups, for example, but her learning that she can sit on chairs and drink from cups, etc. She can learn to play a language-game that attributes meaning and truth-criteria to propositions like "I know that there is a chair" only on the basis of this kind of background that can be described as a practice rather than as a set of propositions. "The child, I should like to say, learns to react in such-and-such a way; and in so reacting it doesn't so far know anything. Knowing begins at a higher level” (OC, \$538). Consequently, the basis of every language-game consists in a practice rather than a set of propositions: "it is our acting, which lies at the bottom of the language-game" $(O C, \$ 204)$.

Wittgenstein, thus, allows for a hierarchy of different parts of the background, some of them being more basic than others; but, as von Wright points out, there is "no rigid order among language-games, neither logically nor from the point of view of genetic development" (von Wright, 1972, 57). In other words, we cannot have a strict and stable hierarchy that describes different levels of the background or of language-games. Even though some language-games can be acquired only on the basis of others, this does not mean that there is a logical hierarchy between them, nor that the acquisition of a specific language-game that is more basic is a necessary condition for the acquisition of a more complex one.

We have seen that according to Wittgenstein the background is not just a set of propositions, it rather reaches down to the actual world: our acting lies at the bottom of the language-game, as he puts it. At one point Wittgenstein even goes so far as to say that the background contains facts. After pointing out that it is hard to imagine that we could be wrong in our knowing that water boils and does not freeze under such and such circumstances, he states: "This fact is fused into the foundations of our language-game" $(O C, \$ 558) .{ }^{3}$ In another place, Wittgenstein states that "the possibility of a language-game is conditioned by certain facts. In that case it would seem as if the language-game must 'show' 
the facts that make it possible. (But that is not how it is.)" $(O C, \$ \$ 617 \mathrm{f})$. These passages suggest that Wittgenstein does not accept the view that there is a gap between language and reality. World and language rather form one whole, it does not make sense to draw a strict demarcation line between the two. Wittgenstein, thus, gives up the view that meaning is independent of what in fact is the case. Rather he holds that if the facts were completely different from what we thought, our language-game would change.

If we imagine the facts otherwise than as they are, certain languagegames lose some of their importance, while others become important. And in this way there is an alteration-a gradual one-in the use of the vocabulary of a language. $(O C, \$ 63)$

A few paragraphs later, Wittgenstein adds "When language-games change, then there is a change in concepts, and with the concepts the meanings of words change" (OC, \$65). Hence, according to Wittgenstein's later views, language is not merely representing facts that are on the other side of a gap. Rather facts determine what language-games we can play; they form the very basis of the latter. Hertzberg characterizes this position in the following way: "On Certainty emphasizes what we might call the 'this-worldliness' of our language: our language-games are tied to the actual world we live in" (Hertzberg 1976, 151).

So far I have shown that according to Wittgenstein we can attribute a truth value to a proposition only relative to a background or a picture of the world. It would be wrong, however, to characterize this background merely as a set of propositions; it also contains actions and facts and, thus, reaches down to the physical world. Let us now turn to the question of how this can shed light on the realism-idealism debate.

The idealist's position is characterized by a general doubt concerning the question of whether physical objects exist (independently of the mind). Wittgenstein argues that this general doubt cannot be formulated meaningfully. He claims that in order to doubt any single assumption, one has to accept a series of other ones. "If you tried to doubt everything, you would not get as far as doubting anything. The game of doubting itself presupposes certainty" $(O C, \$ 115)$. Wittgenstein illustrates this point with the example of a pupil who doubts everything the teacher tells him, the existence of physical objects, the meaning of words, etc. He would interrupt the teacher in the history class, for example, and express his doubts whether the world existed a hundred years ago. In this situation the teacher can only react by telling his sceptical pupil that in this context his doubts do not make sense. First the pupil has to learn, he has to acquire a picture of the world in order to play the 
relevant language-game. Only then he can go on to doubt some of the propositions he has been taught, one by one. "The child learns by believing the adults. Doubt comes after belief" (OC, $\$ 160)$.

Metaphysical realism, idealism, and idealist scepticism are positions that try to come up with an answer to the general question "Do physical objects exist?" This question, however, can be understood only if it is part of a language-game that determines its meaning.

The idealist's question would be something like: "What right have I not to doubt the existence of my hands?" (And to that the answer could be: I know that they exist.) But someone who asks such a question is overlooking the fact that a doubt about existence only works in a languagegame. Hence, that we should first have to ask: what would such a doubt be like?, and don't understand this straight off. (OC, \$24)

Wittgenstein's point is not that the idealist or the metaphysical realist are wrong, he rather shows that they cannot even formulate their concerns without undermining the very language-game they play, for the latter is part of a bigger background that determines meaning and truth-conditions for the statements that characterize their positions. Wittgenstein argues, as we have seen above, that this background contains facts, it reaches down to the actual world, as it were. The very fact that we are playing language-games, thus, forces us to accept the existence of (at least some) physical objects. Hence, the general question of whether physical objects exist undermines the basis of the language-game which it is part of, in other words, it undermines the background that determines its meaning. In consequence, this general question is meaningless, and so are all positions that try to answer, rather than reject it. Therefore, both idealism and metaphysical realism are positions that cannot be formulated meaningfully. ${ }^{4}$

While it makes sense to question whether a particular object exists, it is the generalization of that question that turns doubt into nonsense. I might, for example, ask whether the American continent really exists. The answer to that question will influence my behavior: if a European reader believes the story-teller in Peter Bichsel's short story America Does Not Exist, for example, she will go to the travel agency and cancel her trip to New York, etc. The idealist's and the metaphysical realist's answer to the sceptical question, on the other hand, does not influence their behavior at all.

What the realist and the idealist say, whether it be a realism or idealism of the transcendental or of the empirical type, differs in toto not only from what they do, but also from the ground on which they play out their 
language game. Accordingly, if either one tries to teach a child the use of the expression 'chair', the differences will not be differences between the facts that are taught, nor will they be differences of languages used; they will rather, as Wittgenstein says, be differences between 'battle cries'. $($ Haller 1988, 112)

In conclusion, we can reconstruct Wittgenstein's argument in the following way: The truth value of any proposition can be determined only in a language-game which rests on a background or picture of the world. The background consists not only of propositions, but also of actions and facts and thus reaches down to the actual world. In order to play a language-game, one consequently has to presuppose the existence of (at least some) objects. The general doubt concerning the existence of physical objects undermines this presupposition and thus undermines the very basis of the language-game of which it is part. Both metaphysical realism and idealism have this general doubt as a starting point, but react to it in different ways. Therefore, both positions cannot be formulated meaningfully. Thus, if Wittgenstein's argument is correct, the "problem of the existence of the external world . . . is in fact solved, before it can be raised" (von Wright 1972, 53).

\section{CONSTITUTION AND THE REALISM-IDEALISM DEBATE}

There is a parallel between Wittgenstein's late theory of meaning and the account of constitution I am proposing. While Wittgenstein argues that the meaning of words depends on their use in language-games which rest on a holistic background, I have claimed that the constitution of objects depends on a retentional background. Perceptual experiences undergo retentional modification and, eventually, become part of the retentional background. In consequence, the latter contains retentionally modified experiences that stood in direct contact to the object towards which they were directed. Thus, the retentional background reaches down to the actual world. Accordingly, there is no gap between mind and world; we can rather speak of the 'this-worldliness' of mental episodes.

The thesis that perceptual experiences stand in direct contact to physical objects has an important implication for the question of whether my account of constitution entails a form of idealism. If what $I$ have said so far is right, having mental episodes presupposes that there are (at least some) physical objects that exist independently of our having mental episodes. Thus, the account of constitution that I have outlined above is incompatible with the main thesis of idealism, according to which the existence of 
the physical objects towards which we are directed depends on the existence of mental episodes.

We can even go a step further and argue with Wittgenstein that idealism and metaphysical realism are positions that cannot be formulated meaningfully or better-to put it into the context of the account of constitution-that are unintelligible. Since the retentional background contains retentionally modified episodes, in which we were immediately directed towards actual objects, it reaches down to the actual world. Consequently, when the metaphysical realist or idealist consider the general question of whether physical objects exist, they undermine the basis of the retentional background. Thinking about the sceptic's challenge, thus, is a mental episode that questions the basis of the retentional background which is a necessary prerequisite for having mental episodes; in other words, if there were no physical objects, we could not have mental episodes and consequently could not come to wonder whether physical objects exist. Mimicking Wittgenstein's way of speaking, we can state that the question whether physical objects exist cannot be meaningfully thought. The very fact that we have mental episodes, thus, renders the realism-idealism debate unintelligible.

A short look at the history of philosophy, however, should make us suspicious about whether these few remarks can actually silence both the metaphysical realist and the idealist. In fact, we do not have to go further than considering some interpretations of Wittgenstein's argument to find out that this suspicion is justified: Wittgenstein's position, it has been argued, does not reject, but rather implies a form of idealism. Let us have a closer look at the line of reasoning that was proposed by Bernard Williams. ${ }^{6}$ In his early philosophy Wittgenstein stated that the "limits of my language mean the limits of my world" (TLP 5.6). Williams argues that there is continuity in Wittgenstein's thought with respect to this statement. He acknowledges that Wittgenstein turned away from the solipsistic aspects of the Tractatus in his later work, but still holds that the limits of our language mean the limits of our world. ${ }^{7}$ In his later philosophy Wittgenstein claims, according to Williams, that "what the world is for us is shown by the fact that we can make sense of some things and not of others" (Williams 1974, 84). And a few lines later Williams states:

Since the fact that our language is such and such, and thus that the world we live in is as it is, are, as presently construed, transcendental facts, they have no empirical explanation; anything that can be empirically explained, as that certain external features of the world are this way rather than that, or that we (as opposed to Hopi Indians, or again as opposed to cats) see things in a certain way, or deal with things in 
one way rather than another - all these fall within the world of our language, and are not the transcendental facts. (Williams 1974, 84)

Our language, according to this line of reasoning, determines how we see certain facts. People who grow up in other cultures might see the world in a completely different way. However, we cannot step outside of language, we cannot explain why the structure of our language is how it is; it might be completely different, as are the structures of languages of different cultures, like that of Hopi Indians. Even if we learn to speak the language of the Hopi Indians, our picture of the world is still determined by a language (just that it is now determined by a different language with a different structure). In other words, we can never know whether language provides an accurate picture of the world because we cannot compare the world as we refer to it in our language-games to the world as it is independently of language; we can see the world only through the lenses of a language, so to speak. By learning another language we could learn to see the world through different lenses, as it were, but, according to this picture, we can never see the world directly; we must always wear some sort of lenses when looking at it. On the basis of these observations, Williams draws the conclusion that Wittgenstein held a form of idealism not only in the Tractatus, but also in his later work:

The fact that in this way everything can be expressed only via human interests and concerns, things which are expressions of mind, and which themselves cannot ultimately be explained in any further terms: that provides grounds, I suggest, for calling such a view a kind of idealism. (Williams 1974, 85)

Williams' argument, if successful, equally applies to the account of constitution that I am proposing. The constitution of objects depends on the retentional background that one has established, i.e., it depends on one's constitutive commitment. One could, thus, say with Williams that we can know objects only as they are constituted in our mental episodes; we see the world only through the lenses of constitution, as it were. If somebody has a retentional background that is sufficiently different from ours because, for example, she grew up in a different culture, this person would constitute objects in a different way. However, we cannot step outside of constitutive commitment to compare the object as it is in itself with the constituted object. Even if we try to have an empirical or scientific understanding of why we constitute objects in the way we do, every explanation we could come up with would lie within the limits of our constitutive 
commitment ${ }^{8}$, it could be argued. To use Davidson's metaphor, "we can't get outside of our skins to find out what is causing the internal happenings of which we are aware" (Davidson 1986, 312). Moreover, we seem to be trapped in this position for, as I have argued above, we are not even free to give up constitutive commitment, but are rather forced to carry on. Once we have put on some sort of lenses, we cannot take them off any more; we could only improve or change them, but we are no longer in a position to get rid of them altogether.

Williams' argument is based on what I will call the "transcendental assumption" that we can distinguish between the (raw, unstructured) world, the world as it is in itself, on the one hand, and the world as it figures in our language-games or in our mental episodes, on the other. Williams does not provide any textual evidence, however, that Wittgenstein shared this transcendental assumption. In addition, this assumption is based on the premise that "there are physical objects independently of how we refer to them in our language-games" which, for Wittgenstein, is a proposition that cannot be formulated meaningfully. Rather than arguing for or against transcendental idealism, Wittgenstein would rather point out that this problem is a nonsensical one. Williams, thus, cannot prove that Wittgenstein held a form of idealism.

These considerations only show, however, that Wittgenstein did not draw the conclusion that his position implies a form of idealism. Williams could still argue that he should have drawn this conclusion, and that his later philosophy in fact does imply transcendental idealism. On similar lines it might also be argued that the account of constitution that I am proposing implies this kind of idealism. Whether the idealistic interpretation of Wittgenstein and of the account of constitution that $I$ have outlined is convincing depends on whether the transcendental assumption is correct or not. In other words, it depends on whether we can meaningfully distinguish between the constituted object (or, in Wittgenstein's case, the object as it is given in the language-game) on the one hand, and the object as it is in itself, on the other. Once one has accepted this distinction, it can be argued that the structure of empirical reality, i.e., the reality we experience, is a product of subjectivity, and that the raw, unstructured world is not accessible to us. McDowell, who calls that perspective the sideways-on picture ${ }^{9}$, describes its basic assumption in the following way:

We are asked to suppose that the fundamental structure of the empirical world is somehow a product of subjectivity, in interaction with supersensible reality, which, as soon as it is in the picture, strikes us as the seat of true objectivity. (McDowell 1996a, 42) 
The transcendental assumption has been subject of extensive discussions in the history of philosophy; hence this is not the place to show that a position with that historical dimension is wrong. However, since Wittgenstein's later philosophy, as well as the account of constitution that I have outlined above, only imply transcendental idealism if one accepts the transcendental assumption, I will draw attention to an alternative that can do without that assumption. I will not argue for or elaborate on this position. The mere fact that there is an interesting alternative to both idealism and metaphysical realism-one that even has affinities to some of the major assumptions of the account of constitution sketched-shows that the account of constitution that I have sketched can not only avoid idealism and metaphysical realism, but can also be combined with positive claims concerning these questions.

According to this position the structure of the empirical world is not a product of subjectivity that is imposed on a supersensible reality, but rather a feature of the world that exists independently of human beings. The basic idea, thus, is to reject the distinction between constituted object and the object as it is in itself. A position that holds this view has been proposed recently by Hilary Putnam under the title 'natural realism' and by John McDowell, who calls his position 'naturalized platonism.' We find expressions of a position along these lines also in Wittgenstein's later philosophy, e.g. in Philosophical Investigations, where he says: "When we say, and mean, that such-and-such is the case, we-and our meaning-do not stop anywhere short of the fact; but we mean: this is so" (PI, \$95).

The main assumption of this modest form of realism is that there is no raw, unstructured reality; the world rather consists of objects and facts towards which we are directed immediately in our mental episodes. Perceptual experiences, thus, do not impose a structure on the world as it is in itself, but rather provide 'glimpses of reality,' as McDowell puts it. Putnam characterizes natural realism in the following way:

A natural realist, in my sense, does hold that the objects of normal, 'veridical' perception, are usually 'external' things. ... The natural realist ... holds that successful perception is just a seeing, or hearing, or feeling, etc., of things 'out there,' and not a mere affection of a person's subjectivity by those things. (Putnam 1994, 454)

Accordingly, we can stand in direct cognitive contact to the actual objects of our perceptual experiences. This position rejects, of course, the old empiricist picture according to which we perceive, or better: our perception is mediated by sense data, impressions, or other representations of the objects, but not the objects themselves. When Putnam states that we perceive 'things out there' he 
rejects the claim that "perception involves an interface between the mind and the 'external' things we perceive" (Putnam 1994, 488) and that our perception has to be mediated by a causal relation between the object and the perceptual experience. Putnam argues that the fact that we can describe the world differently in various language-games does not mean that objects are different from how they are described in these language-games. Different descriptions of one and the same object or event can be true, given that their meaning and truth criteria are determined by different backgrounds.

Earlier in this chapter I argued that idealism and metaphysical realism are unintelligible positions. Now I am using natural realism to show that constitution does not necessarily imply transcendental idealism. This might create the impression that I am accepting an unintelligible position to avoid another one. Hence, it is important to point out that there is a crucial difference between natural and metaphysical realism. The former is the attempt to acknowledge the fact that in some of our mental episodes we are immediately directed towards physical objects, it is, in other words, "insisting that 'external' things, cabbages and kings, can be experienced" (Putnam 1994, 464). Unlike metaphysical realism, it is not a reaction to the general doubt whether physical objects exist. Rather than theorizing about the ontological dependence between mental episodes and physical objects, it contents itself with showing the role physical objects play in the process of constitution. Hence, the

natural realist account urged on us by Austin and Wittgenstein, is, in the end, not an 'alternative metaphysical account,' ... Winning through to natural realism is seeing the needlessness and the unintelligibility of a picture that imposes an interface between ourselves and the world.

(Putnam, 1994, 487)

This short discussion shows, as I hope, that natural realism provides an interesting alternative to those ontological positions that presuppose the transcendental assumption. Even though I could not provide a knock-down argument to the effect that the transcendental assumption is false or untenable, the very fact that we do have a convincing alternative allows us to dismiss positions that rest on this problematic assumption. 



\section{Conclusion}

In the preceding pages I sketched a theory of constitution that takes up elements of Husserlian phenomenology to address problems that are discussed in analytic philosophy of mind. I started out by showing that the great influence of Descartes' ontological distinction between res extensa and res cogitans has created a gap between the realm of the mental and the realm of the physical that has become unbridgeable. Two dominant strategies in philosophy of mind in the twentieth century, reductionism and eliminativism, are only reactions to, rather than rejections of, Descartes' distinction. In consequence, they cannot explain the relation between mind and world other than by denying that there is a fundamental difference between the mental and the physical. I suggested that by adopting the notion of constitution we can develop a perspective that acknowledges the difference between the realm of the mental and the realm of the physical without creating an unbridgeable gap between them.

In order to introduce the notion of constitution I showed how it was used by philosophers in the past. I concentrated on the accounts of Husserl and Haugeland, two philosophers from very different backgrounds who developed a notion of constitution to explain the relation between mind and world. Both Husserl and Haugeland agree that constituting an object does not mean creating it, nor does it mean interpreting an object as something else. While Husserl explains the process of constitution by analyzing the partial intentions of our mental phenomena, Haugeland's account is closely related to the notion of rule following. Husserl, who used constitution as a basic notion in his philosophical system, argued that we constitute both the objects towards which we are directed and the mental episodes in which we are directed towards them. Haugeland, on the other hand, analyzed different aspects a theory of constitution has to account for by distinguishing rules that describe the constitutive process and abilities one has to master in order to constitute objects; he distinguishes constitutive regulations, constitutive standards, constitutive skills, and constitutive commitment. 
After contrasting these two positions I outlined an account of constitution that adopts relevant aspects of Husserl's and Haugeland's theories and puts them into the Sellarsian/McDowellian framework based on the distinction between the logical space of reasons and the logical space of nature. This account, which is motivated by the insight that causal theories cannot suffice to explain the content of our perceptual experiences, shows how a holistic background can achieve this task. In order to describe the relation between holistic background and an occurrent mental episode I adopted the Husserlian notion of a holistic retentional background. Husserl argued that mental episodes do not disappear from consciousness once they are over. Rather they undergo retentional modification, which makes them "sink down into the past," gradually losing clarity and liveliness, until they become part of the retentional background.

The actual process of constitution takes several steps. At the lowest level, we have partial intentions which are intentional (in a pre-objective sense) and undergo temporal modification. Due to passive association, which is based on the regularities of similarity, continuity, and contrast, these partial intentions form affective unities. In order to constitute objects, we have to establish a connection between the occurrent affective unity and the retentional background, which functions like a reservoir of objects from which we draw in the process of constitution; this feature can be described on the basis of association. The constitution of the object establishes the intentional relation of the mental episode to the actual object. In the case of perceptual experiences, it establishes a direct, intentional relation between the episode and the physical object (in a broad sense).

According to this account, every mental episode requires a retentional background of past mental episodes. In order to have one's first episodes, one has thus to develop a first, minimal background, which is based on three elements: primal impressions and the laws of association; our biological makeup and physical environment; and the social group in which we are acculturated. Moreover, when growing up, we learn to constitute not only objects, but also the mental episodes in which we are directed towards these objects. I showed that due to the laws of association we constitute sensory fields, which eventually allow us to constitute objects in different ways as seen objects, heard objects, etc., in our perceptual experiences. By our being initiated to the social practices of the group in which we grow up, especially by acquiring language, the most complex and subtle of our social practices, we learn to constitute a large variety of mental episodes.

In the remainder of the book I discussed some of the consequences of this account of constitution. First I turned to its social aspect. Since we learn 
to constitute various kinds of mental episode through social practices, we have to conclude first that different cultures might have (some) different kinds of mental episode; and second that there cannot be ineffable mental episodeswe can always express them in language or some other social practice, in virtue of their rational relations to other mental episodes. If we characterize mental episodes through their rational relations to other episodes, however, we have to have a broad understanding of "rational relation." Moreover, the social aspect of the account of constitution presented entails an anti-individualistic position. A comparison of the views of Burge and Brentano has shown, however, that this does not create a tension for the account offered, for phenomenology is compatible with anti-individualism.

Since the charge of idealism was brought up against two philosophers who have adopted the notion of constitution, most importantly against Kant and Husserl, I have argued that constitution does not entail a form of idealism. I used a late-Wittgensteinian argument to show that metaphysical realism and idealism are unintelligible positions. My account of constitution might still be charged with implying transcendental idealism - as it happened also in the case of Wittgenstein's later philosophy-but I showed that an argument along these lines rests on the problematic assumption that we can meaningfully distinguish between the object as it is in itself and the constituted object.

With the account of constitution sketched I tried to pursue two goals: first, I tried to systematically approach a central question in the philosophy of mind by developing a perspective that acknowledges, but does not overemphasize the differences between the realm of the mental and the realm of the physical; and second, by combining the work of philosophers who come from very different backgrounds, most importantly of Husserl, Haugeland, Sellars, McDowell, and Wittgenstein, I aimed to demonstrate that Husserlian phenomenology and analytic philosophy of mind are not two incompatible and mutually repellent traditions, but can rather be combined in an approach that we might call "analytic phenomenology." And while there might be other ways to bring the two traditions closer together, e.g. by focusing on the work of other phenomenologists and analytic philosophers-some of which may prove equally fruitful-I hope to have achieved at least the modest goal to demonstrate that the results of Husserlian phenomenology can warrant new perspectives and interesting insights on some of the central problems of analytic philosophy of mind, which shows that it is not only an interesting chapter in the history of philosophy; it can also become a most valuable ally when systematically addressing problems of contemporary analytic philosophy of mind. 



\section{Notes}

\section{NOTES TO INTRODUCTION}

1 Dummett, for example, points out that in 1903 Frege and Husserl would have appeared to any German student of philosophy who knew their work "not, certainly, as two deeply opposed thinkers: rather as remarkably close in orientation, despite some divergence of interests" (Dummett 1993, 26). Mohanty explores the relation between the Frege and Husserl in his (1982), and Føllesdal's groundbreaking comparison of Frege's philosophy and Husserl's position at the times of Ideas (1913) in his article "Husserl's Notion of Noema" (1969) has started an extensive debate on the parallels in the work of the two.

2 For the relation of Anglo-Saxon analytic philosophers to phenomenology cf., for example, Simons (1992), Thomasson (2002), and Brandl (2002); for the relation between the Vienna Circle and the phenomenological movement, cf., for example, Mayer (1991), Schmit (2000), Piazza (2002) and (2004), and Huemer (2002).

3 There are several, often ignored, points which a historical comparison would have to take into account. It is quite interesting, for example, that Sellars, who hardly refers to Husserl in his philosophical texts, mentions in his intellectual autobiography that Husserl had a strong influence on his work. He writes that in his years in Buffalo he was influenced by Marvin Farber "whose utter respect for the structure of Husserl's thought with the equally firm conviction that this structure could be given a naturalistic interpretation was undoubtedly a key influence on my own subsequent philosophical strategy" (Sellars 1975, 283). In addition, Sellars gave a paper at a symposium of the Society for Phenomenology and Existential Philosophy, where he explicitly stated that "for longer than I care to remember I have conceived of philosophical analysis (and synthesis) as akin to phenomenology" (Sellars 1978, 170). In this paper Sellars takes the phenomenological reduction as his starting point, without, however, referring to Edmund Husserl. Sellars' paper is replied by Mohanty (1978) and Sukale (1978). The 
relations between Sellars and Husserl are (to my knowledge) not often studied in the secondary literature. There are, however, exceptions: cf., for example, Soffer (2003) and Thomasson (forthcoming), for recent contributions both of which give a clearer perspective on the parallels, but also on the differences between the positions of Husserl and Sellars.

4 A similar project has been pursued with a collection of articles compiled by Hubert Dreyfus and Harrison Hall, which demonstrate the relevance of Husserl's thought for cognitive science, and by Eduard Marbach, who has made an impressive case for the significance of Husserl's work in philosophy of mind in his Mental Representation and Consciousness (1993). There are also examples of philosophers who have relied on nonHusserlian phenomenology to address problems in the philosophy of mind, most recent examples are-apart from John Haugeland (cf. especially his collection Having Thought)—Sean Kelly (2001) and Gregory McCulloch (2003). My goal is to situate results of Husserlian phenomenology in a discussion that has its roots in the work of Wilfrid Sellars and John McDowell.

\section{NOTES TO CHAPTER ONE}

1 The other criteria are: psychological phenomena-and only those-are presentations or phenomena based upon presentation; seem to have no spatial extension; are objects of inner perception; have not only intentional, but also actual existence; and always appear as a unity (cf. Brentano 1995, 77100). Brentano actually never used the term "intentionality," but rather speaks of "intentional inexistence." The prefix "in" does not stand for negation; it rather means existing in something.

2 When I quote Husserl, I will add the reference to the original German text. Whenever possible, I will quote from the Husserliana edition, henceforth $H u a$, followed by volume and page number.

3 For a discussion of Brentano's later account of intentionality cf., e.g., Kraus (1924/95) or Føllesdal (1978). For an overview of his early accounts of intentionality, cf. Chrudzimski (2001).

4 This standard interpretation of Descartes' position is not without difficulties. For a critique cf. Baker and Morris (1996) who conclude that Descartes actually held a form of occasionalism. Even they acknowledge, however, that Descartes typically uses causal idioms to describe the relation between mind and body.

5 Cf. McDowell 1996a, xiv: ". . to coin a phrase that is Sellarsian at least in spirit".

6 For a discussion of this point cf. Sedivy (2004), who provides an interesting comparison of Sellars' adverbial theory of sense-data with Wittgenstein's analysis.

7 I will say more about Sellars' distinctions and discuss the question whether it does have any ontological implications below. 
8 In the introduction that was added to the second edition McDowell writes that the point could as well be made against Sellars: "For these purposes, Sellars and Davidson are interchangeable" (McDowell 1996a, xvi).

9 Cf. Brandom (1996, 245).

$10 \mathrm{McDowell}$ is, of course, aware of these parallels. Pointing out the similarities between his position and Hegel's absolute idealism he contends that with his apparatus he is able "to domesticate the rhetoric of that philosophy [i.e., absolute idealism]" (McDowell 1996a, 44). He also explicitly states that he does not want to be called a Pittsburgh Neo-Hegelian, a label occasionally used by Robert Brandom to refer to McDowell and himself: "I am resisting being cast as the hind legs of a pantomime horse called 'Pittsburgh neoHegelianism"' (McDowell 2002, 98).

11 Frege develops his critique of psychologism in The Foundations of Arithmetic, Husserl in his Logical Investigations, vol. 1.

12 I am not thinking of social structures that we find in some species of animals other than humans, e.g., in ant colonies. From all we know these animals do not have the tools to reflect or reorganize the social structure they live in. And while this might not be necessary for forming a social structure, it certainly is for forming a social structure of a certain complexity or even a culture.

\section{NOTES TO CHAPTER TWO}

1 For a concise overview of the use of the notion of constitution in the history of philosophy cf. Hogrebe (1976).

2 Cf. Hogrebe (1976, 993f).

3 Differentiae constitutivae. In medieval philosophy, this expression is replaced by the term 'differentia specifica.'

4 "Der eigentliche Durchbruch von Wort und Problem erfolgte aber zweifellos erst bei E. Husserl" (Hogrebe 1976, 1002).

5 The way Husserl developed his notion of constitution over the years, however, was influenced by his reading of Kant. For a detailed discussion of. Kern (1964, 246-75).

6 "... ein spezifisch Husserlscher Begriff, den Husserl, in dem von ihm verwendeten Sinn, nicht der philosophischen Tradition verdankt."

7 Mayer points out that there are significant parallels between Husserl's and Carnap's notion of constitution (cf. Mayer (1991) and (1992)). Mayer, however, discusses mainly Husserl's Ideas (vols. 1 and 2). She does not point out that for Husserl there are no basic objects that form the basis of the system but she rather states that the basis of constitution is (for both philosophers) the stream of consciousness. Husserl explicitly argues, however, that the stream of consciousness is constituted (cf. Husserl 1991, 77 [Hua X, 378]). Cf. also Küng who points out that "it seems, in principle, impossible, that the train of definitions of some constructional system [like Carnap's] could be an adequate 
representation of the progression of transcendental constitution" (Küng 1975, 73). Küng goes on to argue that the comparison between Carnap and Husserl can be helpful for an understanding of the higher levels of constitution, i.e., the ones that Mayer is focusing on.

8 I have slightly changed the translation. The translator of the English edition translates "Konstitutionssystem" as "constructional system" and "konstitutieren" as "construct." For my point it is important, however, that in the original German version Carnap actually uses the words "Konstitution" and "konstituieren."

9 Cf., for example, Simons (1987).

10 Cf. Fink (1976, 203).

11 For a detailed historical study on Husserl's notion of constitution of. Sokolowski (1964) and Ströker (1993).

12 Cf. Husserl (1969, 87 [Hua XVII, 90f]).

13 A similar position is also held by Biemel $(1959,195)$ and Sokolowski $(1964$, 35).

14 I am not suggesting that Husserl actually did subscribe to psychologism (at least not to the problematic form of psychologism he criticized in Logical Investigations) in his early work. This widespread view has recently been challenged by a number of scholars; for a discussion of. Mohanty (1982, 18-42) and (1997). I do not want to settle this question here. I do want to point out, however, that Husserl definitely did change his views on logic between Philosophy of Arithmetic and Logical Investigations. In the foreword of the latter, the first part of which appeared in 1900, Husserl mentions that the part that deals with psychologism goes back to a series of lectures given at Halle in 1896, i.e., two years after Frege's review. Alluding to his alleged psychologism in Philosophy of Arithmetic he remarks, quoting Goethe: "There is nothing with which one is more severe than the errors that one has just abandoned" (Husserl 1970, 43 [Hua XVIII, 7]). Apart from Frege, also Bolzano and Lotze had a strong influence on the development of Husserl's views on logic between 1891 and 1900; cf. Beyer (1996), Føllesdal (1982a) and (1982b); for the significance of Husserl's move for his relation to Franz Brentano and his school, of. Huemer (2004).

15 Cf. Sokolowski $(1964,54 \mathrm{ff})$.

16 "Diese kategoriale Formung oder Erzeugung der Sachverhaltsform bedeutet also, daß der Sachverhalt seine Form, seine gegliederte Struktur nicht unabhängig vom prädikativen Akt hat, sondern sie erst durch diesen konstruiert oder konstitutiert wird."

17 The last part of Husserl's course Hauptstücke aus der Phänomenologie und Theorie der Erkenntnis from 1904/05 was On the Phenomenology of Time. It was published, with some changes and additions in 1928. Even though Edith Stein did most of the editorial work, the text was published under the 
name of Martin Heidegger who only proofread the text (cf. Boehm 1966, XXIV). It is reprinted together with other texts on the same topic in Hua X. The English translation was published in 1991.

18 The later part of Husserl's course Hauptstücke aus der Phänomenologie und Kritik der Vernunft from 1907 which is often referred to as Dingvorlesung [thing-lecture] is published in Hua XVI. The English translation was published in 1997.

19 In his course on time consciousness in 1905 Husserl distinguishes objective time, "the time of nature in the sense of natural science" (Husserl 1991, 5 [Hua X, 4]) and immanent time, time as it is experienced. For methodological reasons, Husserl suspends all questions concerning objective time, which is why he speaks of pre-empirical time in the following quotation. Sokolowski points out that the strategy of suspending objective time "foreshadow $[s]$ the phenomenological reduction of his later philosophy" (Sokolowski 1964, 74).

20 Cf. Mohanty $(1995,57 \mathrm{ff})$.

21 Husserl continued to refine and revise his phenomenological reduction throughout his lifetime. Iso Kern distinguishes three major ways how Husserl introduces the phenomenological reduction: the way via intentional psychology, the way via ontology, and the Cartesian way, cf. Kern (1977). In his later work, especially in Crisis, Husserl criticizes the Cartesian way because it is characterized by its loss of the external world. I discuss Husserl's phenomenological reduction in more detail in my (2003).

22 In the more recent translation (1982) this passage is translated quite differently and, as I think, wrongly. An even clearer statement of this idea can be found in Formal and Transcendental Logic, where Husserl says in retrospect that he did not discuss the topics of time consciousness in Ideas I for pedagogical reasons, cf. Husserl (1969, 286 [Hua XVII, 292]).

23 For a more detailed discussion of the retentional background cf. below, chapter 3.

24 "Bewußtsein besteht durch und durch aus Bewußtsein, und schon Empfindungen so wie Phantasma ist 'Bewußtsein"'.

25 Cf. Holenstein (1972, $110 \mathrm{ff})$.

26 Cf. Holenstein $(1972,27)$.

27 At a later stage Husserl mentions that the difference between active and passive is only a gradual one and that no strict borderline can be drawn. This is because he holds at this time that there are no processes where the ego is not involved; it is, however, involved to a greater or lesser degree.

28 In what follows I am referring to Dretske (1981, 153-68).

29 I profited from a discussion with John Haugeland in my formulation of this point.

30 Haugeland argues that being committed to constitutive standards does not even require language capacities, but it does require the having of concepts. 
This argument is based on the assumption that having concepts does not require language (cf. 1998a, 255ff). Haugeland tries to support this assumption with a rather adventurous thought experiment about super-monkeys that do not master a language but play chess and thus apply concepts. He does not, however, explain what exactly concepts are. Since this argument is not central for the present point, I will not discuss it in more detail.

31 Cf. Haugeland (1998b, 348).

32 Haugeland distinguishes between two notions of 'possible': 'possible' in the narrow or strict sense "includes only that which would accord with the constitutive standards, were it to occur" (Haugeland 1998b, 332). 'Possible' in the wider sense, or 'conceivable,' "comprises everything that the players, qua players, would have the resources to recognize or otherwise cope with, were it to occur" (Haugeland 1998b, 332). The excluded zone is "that zone of the conceivable that lies 'out of bounds' for some domain-that which, though conceivable, is impossible in the strict sense" (Haugeland 1998b, 333).

33 We have seen above that in Logical Investigations Husserl allows for exceptions from this principle: he argues that categorical objects come to exist in the process of constitution. These objects, however, are based on other objects that have to exist independently of the process of constitution. The categorical object or state of affairs that the book lies on the table, for example, depends on a book and a table the existence of which does not depend on the constitution of the categorical object.

34 "Kein gewöhnlicher 'Realist' ist je so realistisch und so concret gewesen als ich, der phänomenologische 'Idealist' (ein Wort, das ich übrigens nicht mehr gebrauche)". It seems quite important that Husserl made this remark in 1934 and thus in the last period of his work for sometimes it is argued that Husserl's early philosophy tends to be realistic, while after the publication of the Ideas I in 1913 (or after the transcendental turn in 1905/06) it tends towards idealism. Cf., for example, Ingarden (1998a, 183).

35 Cf., e.g., Ingarden (1975), or Philipse (1995). Ingarden states explicitly that there is a connection between the development of Husserl's notion of constitution and that of his transcendental idealism, cf. $(1975,21 \mathrm{ff})$.

36 Cf. Ameriks (1977).

37 Cf. Holmes (1975).

38 Cf. Hall (1982).

39 I am referring here to changes that do not need intellectual skills in order to be effected, even when the people who effect those changes are able to perform those skills. Since, for Haugeland, having constitutive standards requires the having of concepts, there needs to be a minimum degree of complexity to one's mental life in order to be able to effect changes in one's constitutive standards. Consequently, this argument is not about newlyborn babies or animals. 


\section{NOTES TO CHAPTER THREE}

1 For a discussion of this point cf., for example, Chisholm/Sellars (1958).

2 It is not exaggerated to state that Sellars' philosophy has shaped a good part of the discussion in the philosophy of mind of the second half of the twentieth century. This fact is worth mentioning, for Sellars' name is hardly mentioned by authors who advocate a Sellarsian position. Daniel Dennett notes this regrettable omission in his paper "Mid-term Examination: Compare and Contrast," where he states: "Sellars's influence has been ubiquitous but almost subliminal (if one judges by the paucity of quotations among functionalists). It is clear that Putnam, Harman, and Lycan. . have been quite directly influenced by Sellars, but Dennett, Fodor, Block, and Lewis show the Sellars influence largely at second hand, and mainly via Putnam's very influential series of papers reprinted in [Mind, Language, and Reality]" (Dennett, 1987, 341). In his introduction to the new edition of Empiricism and the Philosophy of Mind Richard Rorty explains Sellars' invisibility with the fact that his interest in the history of philosophy was the main obstacle for a wider reception of his work. "Sellars believed that 'philosophy without the history of philosophy is, if not blind, at least dumb,' but this view seemed merely perverse to much of his audience" (Rorty, 1997, 3).

3 Cf. McCulloch (2003, 2ff).

4 Cf. Davidson (1980).

5 Davidson's theory even allows for the extravagance that every event can be described as a physical or a mental event. Due to his monism, he has to accept that any event that can be described as a mental event can also be described as a physical event. In "Mental Events" he states that his criterion for mental events allows us to conclude that every event that can be described as a physical event can also be described as a mental one. He explains this consequence with the example of a collision of two stars in distant space that can be described with the purely physical predicate ' $P x$,' which is true only at the time when the collision occurs. "This particular time, though, may be pinpointed as the same time that Jones notices that a pencil starts to roll across his desk. The distant stellar collision is thus the event such that $P x$ and $x$ is simultaneous with Jones' noticing that a pencil starts to roll across his desk. The collision has now been picked out by a mental description and must be counted a mental event. This strategy will probably work to show every event to be mental" (Davidson 1980, 211f). Davidson shows, however, that this consequence is not harmful for his distinction between mental and physical events.

6 Davidson changes his position regarding the ontological status of the events. In "Mental Events" he seems to suggest that events are bare, i.e., they are neither physical nor mental, but open to be described in both waysand once they are described, they count as mental or as physical events, tespectively. This view, however, embraces a dualism of scheme and content, 
"of organizing system and something waiting to be organized" (Davidson 1984, 189), a view which Davidson harshly criticizes in his later philosophy. As a consequence, he replaces his early notion of events in later texts with one according to which events are individuated by their spatio-temporal locations, cf. $(1985,175)$. According to this notion, however, all events are primarily physical events. It could thus be argued that with this move Davidson silently changes position, trading monism for materialism.

$7 \mathrm{McDowell}$, for example, suggests dropping the principle that he calls the "fourth dogma of empiricism" (McDowell 1985, 398).

8 Cf. Dretske (1981, 153-68). I have discussed this argument in chapter 2.

9 I should mention that Husserl does not use this example to present a critique of causal theories. On the basis of his methodological principle, the phenomenological reduction, he brackets the realm of the physical altogether.

10 Cf. Haugeland (1998a, 242-6). I discuss Haugeland's argument in chapter 2.

11 Searle first developed the background hypothesis in the context of philosophy of language, cf. Searle (1978). For his discussion of the background of intentional experiences cf. (1983, esp. 141-59) where he distinguishes between a background of non-intentional capacities and a holistic network of other intentional states. In The Rediscovery of the Mind (1992, esp. 175-96) he modifies his background-hypothesis, arguing that the network is part of the background of non-intentional capacities. For my point, these details of Searle's account are not relevant.

12 Cf. Searle (1983, 144-53).

13 Cf. Sellars (1997, 39f, \$16).

14 Most of the texts that I am consulting are from the early 1920s. My interpretation of Husserl is based on his rejection of the matter-form schema that he developed from 1907 on.

15 Cf. chapter 2 . For a more detailed discussion cf. Holenstein (1972, 86-117) and Sokolowski (1964).

16 Holenstein develops a similar distinction between two meanings of 'passive' in $(1972,193 \mathrm{f})$.

17 This point was not at all obvious at the time. Husserl contradicts his teacher Brentano, for example, whose theory of time-consciousness had a great influence on the development of Husserl's position.

18 Cf. esp. Hua X and Hua XI.

19 Brentano develops the notion of original association in the early $1870 \mathrm{~s}$. From 1890 on he calls these phenomena "proteraestheses." For an overview of the development of Brentano's theory of time-consciousness, cf. Huemer (forthcoming).

20 I have taken these diagrams from Husserl (1991, 376 [Hua X, 365]).

21 Cf. Husserl (1991, 28, 32, and 372 [Hua X, 26, 31, and 362]). 
22 Translation slightly altered. "Jedes konkrete Datum der lebendigen Gegenwartssphäre versinkt, wie wir wissen, in die phänomenale Vergangenheit, unterliegt der retentionalen Wandlung und führt dabei notwendig in das affektive Nullgebiet, dem es sich einverleibt und in dem es nicht nichts ist."

23 Husserl stresses that no part of the background can be understood in isolation, but only in its being intertwined with the rest of the background, cf. (Hua XI, 101).

24 Cf. (Hua XI, 128): "Aber was dem jeweiligen Gegenstand inhaltliche Einheit gibt, was Unterschiede des einen und anderen inhaltich ausmacht, und zwar für das Bewußtsein und aus seiner eigenen konstitutiven Leistung, was Teilung und Teilverhältnis bewußtseinsmäßig möglich macht u. dgl. das sagt uns die Zeitanalyse nicht, da sie ja eben von dem Inhaltlichen abstrahiert."

25 "Die primitivsten Gegebenheiten des Bewusstseins konstituieren sich als assoziative Verschmelzungen, die dank ihres Kontrasts gegenüber einem andersartigen Hintergrund das Ich zu affizieren vermögen."

26 "eine Funktion der drei Assoziationsgesetze der Ähnlichkeit, des Kontrasts und der Kontiguität".

27 Cf. Holenstein $(1972,88 f)$.

28 This critique is not immediately reflected in his writing, however. In Ideas I, published in 1913, he still holds up the distinction between matter and form. I say more about the development of Husserl's critique of his early matter form schema above, cf. chapter 2 .

29 Cf. Holenstein $(1972,107)$ : "An keiner Stelle . . . sagt er sich entschieden von der Annahme von Empfindungsdaten los."

30 Cf. Holenstein $(1972,110 \mathrm{ff}$ ).

31 Cf. Holenstein $(1972,107 \mathrm{ff}$.). In his analyses of time consciousness, Husserl presents other arguments against the matter-form schema that center around the temporal structure of mental episodes. As I have pointed out earlier in this section, Husserl does not make the move to apply these arguments to the constitution of objects.

32 "It is due to the three constitutive laws of similarity, contrast, and continuity that every affection has gestalt-structure" (Holenstein 1972, 50 [my translation: "An diesen drei konstitutiven Gesetzen der Ähnlichkeit, des Kontrastes und der Kontinuität liegt es, dass jede Affektion eine Gestaltstruktur aufweist."]

33 "Gleichsam unter der Hand löst Husserl damit in seiner Phänomenologie der Assoziation den Empfindungsbegriff durch gestaltpsychologische Termini ab".

34 Husserl, manuscript C 16 IV, p. 23 (March 1932), quoted in Holenstein $(1972,112)$ [my translation: "die Uraffektion von Nicht-Objekten, von intentionalen Einheiten (vor-objektiven) und die spätere Affektion von apperzipierten und schließlich von Objekteinheiten." 
35 I have slightly altered the translation. In this place Steinbock's (generally very good) translation does not render perfectly the meaning of the German text. Steinbock has "Affective unities are constituted," which does not express the idea that they constitute themselves. The German original is: "Affektive Einheiten müssen sich konstituieren, damit sich in der Subjektivität überhaupt eine Gegenstandswelt konstituieren kann" (my italics).

36 Cf. Husserl 2001, 227 [Hua XI, 177]: "It is the constant reservoir of objects that have achieved living institution in the process of the living present."

37 This point was made by Goodman in his article "Seven Strictures on Similarity." Goodman argues that "similarity, ever ready to solve philosophical problems and overcome obstacles, is a pretender, an impostor, a quack. It has, indeed, its place and its uses, but is more often found where it does not belong, professing powers it does not possess" (Goodman 1972, 437).

38 Even though this modification undermines the main principle of phenomenology, there are some places where Husserl makes a similar move, as Holenstein points out. He refers to a quotation of Ideas II where Husserl writes "Sense data can occur only if there are sense organs, nervous systems, etc. in objective reality" (Hua IV, 289 [my translation: "Empfindungsdaten können nur auftreten, wenn in objektiver Wirklichkeit Sinnesorgane sind, nervöse Systeme usw. "]). Holenstein points out, however, that already a few years later, in Formal and Transcendental Logic, Husserl calls these considerations a "perfect countersense" [perfekter Widersinn] (Husserl 1969, 230 [Hua XVII, 238]) because it requires us to combine results that can be achieved only in the phenomenological attitude, with others that one can have only in the natural attitude, cf. Holenstein $(1972,99)$.

39 Moreover, he concentrates on two aspects of this book only. He refers to Husserl in his discussion of the mathematization of nature and quotes his "important idea that the 'primary qualities' of physics are not a set of 'properties' that we have discovered things to have, but a set of idealized abstractions" (Putnam 1994, 469).

40 I have outlined Dretske's problem concerning causal theories of perception above, chapter 2 .

41 James develops this example in a letter to Dickinson S. Miller, dated August 5,1907 , printed in James $(1920,295 f)$.

42 In this passage, Sellars does not talk about acquiring a background, but of a battery of concepts that we need in order to have observational knowledge.

43 There might be some cases of severe brain damage that do not allow one to carry on with one's constitutive commitment. One cannot, however, decide to look around and not constitute objects for a couple of days or so.

44 "Ausbreitung und Zusammenschluss zu Feldgestalten [werden von Husserl] als eine besondere Art intentionaler Konstitution analysiert, als passive Assoziation. Die 'Sinnesdaten' breiten sich aus und verschmelzen zu 
Einheiten, weil es offensichtlich zu ihrem Wesen als Affektion gehört, intentional über sich hinauszuweisen."

45 In this context, Holenstein points out that Husserl's contention that affective unities constitute sensory fields-a process that requires that affective unities are intentional-was one of the reasons that made Husserl give up the notion of raw sense data; cf. Holenstein (1972, 101ff.).

46 Learning to move in the space of reasons goes, as Haugeland has pointed out, hand in hand with acquiring constitutive skills, i.e., the ability to distinguish correct from incorrect moves and to point out errors, e.g. criticize false beliefs, when committed by others.

47 Cf. Sellars $(1997,78, \$ 38)$.

\section{NOTES TO CHAPTER FOUR}

1 I am assuming here that their language can be translated into ours. For a discussion on that topic and a rejection of the distinction between conceptual scheme and empirical content, which he calls the third dogma of empiricism, cf. Davidson (1984).

2 For a similar distinction between feelings and mental episodes $\mathrm{cf}$. McDowell $(1989,288)$.

3 Sellars distinguishes between intralinguistic moves, language entry transitions and language exit transitions in (1963).

4 Cf. Sellars $(1997,73 \mathrm{ff}, \$ 35)$.

5 Sellars develops his notion of material inference in his (1953).

6 A similar point is made by Brandom, cf. $(1997,192 \mathrm{f}, \mathrm{fn} .3)$.

7 Cf. Searle (1983, 7ff).

8 This example was made famous by Wittgenstein, cf. (PI 194, xi) who gives reference to Jastrow's Fact and Fable in Psychology.

9 This debate followed the publication of their books, Mind and World and Making it Explicit, respectively, in 1994. It started out with a Symposium in Philosophy and Phenomenological Research (McDowell (1995) and Brandom (1995)), continued with several Book Symposia on their books that contain a review article and the author's reply (McDowell (1996b), (1997), (1998b) and Brandom (1996), (1997), (1998)), and was closed (for the moment, at least) with an article by John McDowell (2002), in which he replies Brandom's critiques.

10 Brandom uses the expression "Pittsburgh Neo-Hegelians" to refer to both McDowell and himself. McDowell, as I have mentioned above, explicitly rejects this label as a description of his own position (cf. 2002, 98). Nonetheless, both Brandom and McDowell do hold a conceptualist position.

11 Cf. Brandom (1995, 904).

12 In the (so far) last article of his exchange with Brandom, McDowell responds to the charge of individualism in a similar way. "A rational animal could not have 
acquired the conceptual capacities in whose possession its rationality consists except by being initiated into a social practice. But as I see things, the capacities transform their possessors into an individual who can achieve standings in the space of entitlement by her own efforts" (McDowell, 2002, 105).

13 Cf. Burge $(1986,117)$.

14 Cf. Burge $(1988,651)$, for Arnauld's argument cf. (1641/1984, 141ff.)

15 Cf. Putnam $(1975,223 \mathrm{ff}$.).

16 Cf. Brentano (1995, 29ff.) and (1995, 127ff.).

17 Cf. Brentano $(1995,94 f f$.$) .$

18 Cf. Brentano (1995, 34ff.).

\section{NOTES TO CHAPTER FIVE}

1 Cf. Kern (1964, 276ff.). He points out, however, that the account of genetic constitution was not the only aspect of Husserl's thought that lead to his transcendental idealism.

2 Wittgenstein uses the expression 'idealist scepticism” in (OC, \$37).

3 It seems that the full impact of this passage is not always appreciated among Wittgenstein scholars. Even Georg Henrik von Wright, co-editor of Wittgenstein's posthumously published On Certainty, distorts this sentence when he quotes it in his article on On Certainty. Von Wright quotes this sentence in the following way: "Their truth 'is fused into the foundations of our language game' (\$558) . . ." (von Wright 1972, 167). Wittgenstein, however, is not writing about the truth-value of some description of a fact, but the very fact itself being fused into the foundations of our language game.

4 I should mention at this point that Wittgenstein's argument does not show that all forms of idealism and realism are nonsensical. I will show in the next section that his position allows for natural realism.

5 Haller refers to Wittgenstein $(Z, \$ 414)$.

6 Cf. Williams (1974).

7 Cf. Williams (1974, 82).

8 I am paraphrasing Williams: "such an explanation would, once more, have to lie within the limits of our language" (Williams 1974, 93).

9 Cf. McDowell (1996a, 34f). 


\section{Bibliography}

Alighieri, Dante. 1982. The Divine Comedy. Vol. 3: Paradiso. Trans. by Allen Mandelbaum. Berkeley: University of California Press.

Ameriks, Karl. 1977. "Husserl's Realism," in: Philosophical Review LXXXVI, 498-519.

Arnauld, Antoine. 1641/1984. "Fourth Set of Objections," in: The Philosophical Writings of Descartes, vol. 2. Trans. by John Cottingham, Robert Stoothoff, and Dugald Murdoch. Cambridge: Cambridge University Press, 138-53.

Baker, Gordon and Katherine Morris. 1996. Descartes' Dualism. London: Routledge. Bernet, Rudolf, Iso Kern, and Eduard Marbach. 1993. An Introduction to Husserlian Phenomenology. Evanston: Northwestern University Press.

Beyer, Christian. 1996. Von Bolzano zu Husserl. Eine Untersuchung über den Ursprung der phänomenologischen Bedeutungslebre. Dordrecht: Kluwer.

Bichsel, Peter. 1971. Stories for children. Trans. by Michael Hamburger. London: Calder \& Boyars.

Biemel, Walter. 1959. "Die entscheidenden Phasen der Entfaltung von Husserls Philosophie," in: Zeitschrift für Philosophische Forschung XIII, 187-213.

Boehm, Rudolf. 1966. "Einleitung," in: Hua X, xi-lxvii.

Brandl, Johannes. 2002. "Gilbert Ryle: A Mediator between Analytic Philosophy and Phenomenology," in: Southern Journal of Philosophy XL (suppl.), 143-51.

Brandom, Robert. 1995. "Knowledge and the Social Articulation of the Space of Reasons," in: Philosophy and Phenomenological Research LV, 895-908.

Brandom, Robert. 1996. "Perception and Rational Constraint: McDowell's Mind and World," in: Enrique Villanueva (ed.), Philosophical Issues 7: Perception. Atascadero, California: Ridgeview, 241-59.

Brandom, Robert. 1997. "Replies," in: Philosophy and Phenomenological Research LVII, 189-204.

Brandom, Robert. 1998. "Perception and Rational Constraint," in: Philosophy and Phenomenological Research LVIII, 369-74.

Brentano, Franz. 1995. Psychology from an Empirical Standpoint. Linda McAlister. Trans. by A.C.Rancurello, D.B.Terrell, and L.McAlister (eds), 2nd ed., intr. by Peter Simons. London: Routledge. 
Burge, Tylor. 1986. "Cartesian Error and the Objectivity of Perception," in: Philipp Petit and John McDowell (eds), Subject, Thought and Context. Oxford: Clarendon Press, 117-36.

Burge, Tylor. 1988. "Individualism and Self-Knowledge," in: Journal of Philosophy LXXXV, 649-63.

Carnap, Rudolf. 1967. The Logical Structure of the World. Trans. by Rolf George. Berkeley: University of California Press.

Chisholm, Roderick and Wilfrid Sellars. 1958. "Chisholm-Sellars Correspondence on Intentionality," in: Minnesota Studies in the Philosophy of Science 2, 521-39.

Chrudzimski, Arkadiusz. 2001. Intentionalitätstheorie beim frühen Brentano. Dordrecht: Kluwer.

Churchland, Paul M. 1981. "Eliminative Materialism and the Propositional Attitudes," in: Journal of Philosophy 78, 69-90.

Claesges, Ulrich. 1997. "Editor's Introduction," in: Husserl, Edmund: Thing and Space. Lectures of 1907. Trans. by Richard Rojcewicz. Dordrecht: Kluwer, xvii-xxix.

Davidson, Donald. 1980. "Mental Events," in: Essays on Actions and Events. Oxford: Clarendon Press, 207-25.

Davidson, Donald. 1984. "On the very Idea of a Conceptual Scheme," in: Inquiries into Truth and Interpretation. Oxford: Clarendon Press, 183-99.

Davidson, Donald. 1985. "Reply to Quine on Events," in: Ernest LePore and Brian McLaughlin (eds), Actions and Events. Perspectives on the Philosophy of Donald Davidson. Oxford: Blackwell, 172-6.

Davidson, Donald. 1986. "A Coherence Theory of Truth and Knowledge," in: Ernest Lepore (ed.), Truth and Interpretation: Perspectives on the Philosophy of Donald Davidson. Oxford: Basil Blackwell, 307-19.

Davidson, Donald. 1987. "Knowing One's Own Mind," in: Proceedings and Addresses of the American Philosophical Association LX, 441-58.

Davidson, Donald. 1991. "Epistemology Externalized," in: Dialectica 45, 191-202.

De Boer, Theodore. 1978. The Development of Husserl's Thought. Trans. by Theodore Plantinga. The Hague: Nijhoff.

Dennett, Daniel. 1987. "Mid-Term Examination: Compare and Contrast," in: The Intentional Stance. Cambridge: MIT Press, 339-50.

Descartes, René. 1991. The Philosophical Writings of Descartes. Vol. 3. J. Cottingham, R. Stoothoff, D. Murdoch and A. Kenny (eds), Cambridge: Cambridge University Press.

Dretske, Fred. 1981. Knowledge and the Flow of Information. Oxford: Blackwell.

Dreyfus, Hubert and Harrison Hall (eds). 1982. Husserl, Intentionality, and Cognitive Science. Cambridge: M.I.T. Press.

Dummett, Michael. 1993. Origins of Analytical Philosophy. Cambridge: Harvard University Press.

Fink, Eugen. 1976. "Operative Begriffe in Husserls Phänomenologie," in: FranzAnton Schwarz (ed.), Näbe und Distanz. Freiburg: Alber, 180-204. 
Fodor, Jerry. 1995. "Encounters with Trees," in: London Review of Books, 20 April $1995,10-1$.

Føllesdal, Dagfinn. 1969. "Husserl's Notion of Noema," in: Journal of Philosophy 66, 681-7.

Føllesdal, Dagfinn. 1978. "Brentano and Husserl on Intentional Objects and Perception," in: Roderick M. Chisholm and Rudolf Haller (eds), Die Philosophie Franz Brentanos: Beiträge zur Brentano-Konferenz. (Appeared also as Grazer philosophische Studien 5). Amsterdam: Rodopi, 1978, 83-94.

Føllesdal, Dagfinn. 1982a. "Brentano and Husserl," in: Hubert Dreyfus and Harrison Hall (eds), Husserl, Intentionality, and Cognitive Science. Cambridge: M.I.T. Press, 31-41.

Føllesdal, Dagfinn. 1982b. "Response by Dagfinn Føllesdal," in: Hubert Dreyfus and Harrison Hall (eds), Husserl, Intentionality, and Cognitive Science. Cambridge: M.I.T. Press, 52-6.

Frege, Gottlob. 1950. The Foundations of Arithmetics: $A$ logico-mathematical enquiry into the concept of number. Trans. by J. L. Austin. New York: Philosophical Library.

Frege, Gottlob. 1972. "Review of Dr. E.Husserl's Philosophy of Arithmetic," in: Mind 81, 321-37. [The review was first published in 1894: "Dr. E.G. Husserl: Philosophie der Arithmetik. Psychologische Untersuchungen. Erster Band. Leipzig, 1891. C.E. Pfeffer," in: Zeitschrift für Philosophie und philosophische Kritik, N.F., 103, 313-32.]

Goodman, Nelson. 1972. "Seven Strictures on Similarity," in: Problems and Projects. Indianapolis: Bobbs-Merrill, 437-47.

Hall, Harrison. 1982. "Was Husserl a Realist or an Idealist?" in: Hubert Dreyfus and Harrison Hall (eds), Husserl, Intentionality, and Cognitive Science. Cambridge: M.I.T. Press, 169-90.

Haller, Rudolf. 1988. "Was Wittgenstein a Sceptic? or On the Differences Between Two 'Battle Cries'," in: Questions on Wittgenstein. Trans. by Jane Braaten. London: Routledge, 100-13.

Haugeland, John. 1998a. "Objective Perception," in: Having Thought. Cambridge: Harvard University Press, 241-65.

Haugeland, John. 1998b. "Truth and Rule-Following," in: Having Thought. Cambridge: Harvard University Press, 305-61.

Hertzberg, Lars. 1976. "On the Factual Dependence of the Language-Games," in: Acta Philosophica Fennica XXVIII, 126-53.

Hogrebe, Wolfram. 1976. "Konstitution," in: Joachim Ritter and Karlfried Gründer (eds), Historisches Wörterbuch der Philosophie 4. Basel: Schwabe, 992-94 and 997-1004.

Holenstein, Elmar. 1972. Phänomenologie der Assoziation: Zur Struktur und Funktion eines Grundprinzips der passiven Genesis bei Husserl. The Hague: Nijhoff.

Holmes, Richard H. 1975. "Is Transcendental Phenomenology Committed to Idealism?" in: The Monist 59, 98-114. 
Huemer, Wolfgang. "Die Entwicklung von Brentanos Theorie des Zeitbewusstseins," to appear in: Brentano Studien (forthcoming).

Huemer, Wolfgang. 2002. "Logical Empiricism and Phenomenology: Felix Kaufmann," in: Friedrich Stadler (ed.), The Vienna Circle and Logical Empiricism. Re-evaluation and Future Perspectives (Vienna Circle Institute Yearbook X). Dordrecht: Kluwer, 151-62.

Huemer, Wolfgang. 2003. "Phenomenological Reduction and Aesthetic Experience: Husserl Meets Hofmannsthal," in: Wolfgang Huemer and Marc-Oliver Schuster (eds), Writing the Austrian Traditions. Relations between Philosophy and Literature. Edmonton: Wirth-Institute for Austrian and Central European Studies (University of Alberta), 121-30.

Huemer, Wolfgang. 2004. "The Case against Psychologism: Husserl's Relation to the School of Franz Brentano," in: Arkadiusz Chrudzimski and Wolfgang Huemer (eds), Phenomenology and Analysis. Essays on Central European Philosophy. Frankfurt: ontos, 199-214.

Husserl, Edmund. 1931. Ideas: General Introduction to Pure Phenomenology. Trans. by W. R. Boyce Gibson. London: George Allen \& Unwin Ltd.

Husserl, Edmund. 1960. Cartesian Meditations: An Introduction to Phenomenology. Trans. by Dorion Cairns. The Hague: Nijhoff.

Husserl, Edmund. 1969. Formal and Transcendental Logic. Trans. by D.Cairns. The Hague: Nijhoff.

Husserl, Edmund. 1970. Logical Investigations. Trans. by J. N. Findlay. London: Routledge.

Husserl, Edmund. 1982. Ideas Pertaining to a Pure Phenomenology and to a Phenomenological Philosophy: First Book. Trans. by F. Kersten. The Hague: Nijhoff.

Husserl, Edmund. 1991. On the Phenomenology of the Consciousness of Internal Time (1893-1914). Trans. by J. B. Brough. Dordrecht: Kluwer.

Husserl, Edmund. 1994. Briefwechsel. Bd. VII: Wissenschaftlerkorrespondenz. Karl Schuhmann (ed.), Dordrecht: Kluwer.

Husserl, Edmund. 1997. Thing and Space: Lectures of 1907. Trans. by Richard Rojcewicz. Dordrecht: Kluwer.

Husserl, Edmund. 2001. Analysis Concerning Passive and Active Synthesis. Lectures on Transcendental Logic. Trans. by Anthony J. Steinbock. Dordrecht: Kluwer.

Husserl, Edmund. Hua IV. Ideen zu einer reinen Phänomenologie und phänomenologischen Philosophie. Zweites Buch: Philosophische Untersuchungen zur Konstitution. Husserliana IV. Marly Biemel (ed.), The Hague: Nijhoff, 1952.

Husserl, Edmund. Hua X. Zur Phänomenologie des inneren Zeitbewußtseins (1893-1917). Husserliana X. Rudolf Boehm (ed.), The Hague: Nijhoff, 1969.

Husserl, Edmund. Hua XI. Analysen zur passiven Synthesis: Aus Vorlesungs- und Forschungsmanuskripten 1918-1926. Husserliana XI. Margot Fleischer (ed.), The Hague: Nijhoff, 1966.

Husserl, Edmund. Hua XXIII. Phantasie, Bildbewußtsein, Erinnerung: Zur Phänomenologie der anschaulichen Vergegenwärtigungen. Texte aus dem Nachlaß 
(1898-1925). Husserliana XXIII. Eduard Marbach (ed.), The Hague: Nijhoff, 1980.

Ingarden, Roman. 1975. On the Motives which led Husserl to Transcendental Idealism. Trans. by Arnór Hannibalsson. The Hague: Nijhoff.

Ingarden, Roman. 1998a. "Die Hauptphasen der Entwicklung der Philosophie Edmund Husserls," in: Gesammelte Werke, Bd. 5: Schriften zur Phänomenologie Edmund Husserls. W. Galewicz (ed.), Tübingen: Niemeyer, 134-208.

Ingarden, Roman. 1998b. "Das Konstitutionsproblem und der Sinn der konstitutiven Betrachtung bei Edmund Husserl," in: Gesammelte Werke, Bd. 5: Schriften zur Phänomenologie Edmund Husserls. W. Galewicz (ed.), Tübingen: Niemeyer, 237-67.

James, William. 1920. The Letters of William James Vol. II. Henry James (ed.), Boston: The Atlantic Monthly Press.

Kelly, Sean. 2001. Relevance of Phenomenology to the Philosophy of Language and Mind. New York: Garland.

Kern, Iso. 1964. Husserl und Kant: Eine Untersuchung über Husserls Verhältnis zu Kant und zum Neukantianismus. Den Haag: Nijhoff.

Kern, Iso. 1977. "The Three Ways to the Transcendental Phenomenological Reduction in the Philosophy of Edmund Husserl," in: Husserl: Expositions and Appraisals. Frederick Elliston and Peter McCormick (eds), Notre Dame: University of Notre Dame Press, 126-49.

Kortooms, Toine. 2002. Phenomenology of Time. Edmund Husserl's Analysis of TimeConsciousness. Dordrecht: Kluwer.

Kraus, Oskar. 1924/1995. "Introduction of the Editor," in: Brentano (1995), $369-408$.

Küng, Guido. 1975. "The Phenomenological Reduction as Epoche and as Explication," in: The Monist 52, 63-80.

Marbach, Eduard. 1993. Mental Representation and Consciousness. Towards a Phenomenological Theory of Representation and Reference. Dordrecht: Kluwer.

Mayer, Verena. 1991. "Die Konstruktion der Erfahrungswelt: Carnap und Husserl," in: Erkenntnis 35, 287-303.

Mayer, Verena. 1992. "Carnap und Husserl," in: Wissenschaft und Subjektivität: Der Wiener Kreis und die Philosophie des 20. Jahrbunderts. Berlin: Akademie Verlag, 185-201.

McCulloch, Gregory. 2003. The Life of the Mind. An Essay on Phenomenological Externalism. London: Routledge.

McDowell, John. 1985. "Functionalism and Anomalous Monism," in: Ernest LePore and Brian McLaughlin (eds), Actions and Events: Perspectives on the Philosophy of Donald Davidson. Oxford: Basil Blackwell, 387-98.

McDowell, John. 1989. "One Strand in the Private Language Argument," in: Grazer Philosophische Studien 33/34, 285-303.

McDowell, John. 1994. "The Content of Perceptual Experience," in: The Philosophical Quarterly 44, 190-205. 
McDowell, John. 1995. "Knowledge and the Internal," in: Philosophy and Phenomenological Research LV, 877-93.

McDowell, John. 1996a. Mind and World. 2nd edition. Cambridge: Harvard University Press.

McDowell, John. 1996b. "Reply to Gibson, Byrne, and Brandom," in: Enrique Villanueva (ed.), Philosophical Issues 7: Perception. Atascadero: Ridgeview, 283-300.

McDowell, John. 1997. "Brandom on Representation and Inference," in: Philosophy and Phenomenological Research LVII, 157-62.

McDowell, John. 1998a. "The Woodbridge Lectures 1997: Having the World in View: Sellars, Kant, and Intentionality," in: Journal of Philosophy XCV, 431-91.

McDowell, John. 1998b. "Reply to Commentators," in: Philosophy and Phenomenological Research LVIII, 403-31.

McDowell, John. 2002. "Knowledge and the Internal Revisited," in: Philosophy and Phenomenological Research LXIV, 97-105.

Mohanty, Jitendra Nath. 1978. "Remarks on Sellars' Paper on Perceptual Consciousness," in: Ronald Bruzina and Bruce Wilshire (eds), Crasscurrents in Phenomenology. The Hague: Nijhoff, 168-98.

Mohanty, Jitendra Nath. 1982. Husserl and Frege. Bloomington: Indiana University Press.

Mohanty, Jitendra Nath. 1995. "The Development of Husserl's Thought," in: Barry Smith and David Woodruff Smith (eds), The Cambridge Companion to Husserl. Cambridge: Cambridge University Press, 45-77.

Mohanty, Jitendra Nath. 1997. "The Concept of Psychologism in Frege and Husserl," in: Philosophy and Rhetoric 30, 271-90.

Moore, George Edward. 1959. "A Defence of Common Sense," in: Philosophical Papers. London: Allen and Unwin, 32-59.

Philipse, Herman. 1995. "Transcendental Idealism," in: Barry Smith and David Woodruff Smith (eds), The Cambridge Companion to Husserl. Cambridge: Cambridge University Press, 239-323.

Piazza, Tommaso. 2002. "Fenomenologia nell'Aufbau? Carnap, Husserl e la costituzione del mondo", in: Roberta Lanfredini (ed.) Forma e contenuto. Milano: LED, 85-112.

Piazza, Tommaso. 2004. "The Quest for the Synthetic A Priori: Husserl and Schlick's Debate Revisited," in: Arkadiusz Chrudzimski and Wolfgang Huemer (eds), Phenomenology and Analysis: Essays on Central European Philosophy. Frankfurt: ontos, 2004, 233-56.

Putnam, Hilary. 1975. "The Meaning of 'Meaning'," in: Mind, Language, and Reality: Philosophical Papers, Vol. 2. Cambridge: Cambridge University Press, 215-71.

Putnam, Hilary. 1981. Reason, Truth, and History. Cambridge, Cambridge University Press. 
Putnam, Hilary. 1994. "The Dewey Lectures 1994: Sense, Nonsense, and the Senses: An Inquiry into the Powers of the Human Mind," in: Journal of Philosophy XCI, 445-517.

Rinhofner-Kreidl, Sonja. 2000. Edmund Husserl. Zeitlichkeit und Intentionalität. Freiburg/München: Alber.

Rorty, Richard. 1997. "Introduction," in: Wilfrid Sellars, Empiricism and the Philosophy of Mind. Cambridge: Harvard University Press, 1-12.

Schmit, Roger. 2000. "Moritz Schlick und Edmund Husserl. Zur Phänomenologiekritik in der frühen Philosophie Schlicks", in: Grazer Philosophische Studien 58/59, 223-44.

Seager, William. 1999. Theories of Consciousness. An Introduction and Assessment. London: Routledge.

Searle, John. 1978. "Literal Meaning," in: Erkenntnis 13, 207-24

Searle, John. 1983. Intentionality: An Essay in Philosophy of Mind. Cambridge: Cambridge University Press.

Searle, John. 1992. The Rediscovery of the Mind. Cambridge: M.I.T. Press.

Sedivy, Sonia. 2004. "Wittgenstein's Diagnosis of Empiricism's Third Dogma: Why Perception is not an Amalgam of Sensation and Conceptualization," in: Philosophical Investigations 27, 1-33.

Sellars, Wilfrid. 1953. "Inference and Meaning," in: Mind 62, 313-38.

Sellars, Wilfrid. 1963. "Some Reflections on Language Games," in: Science, Perception and Reality. London: Routledge, 321-58.

Sellars, Wilfrid. 1975. "Autobiographical Reflections," in: Hector-Neri Castañeda (ed.), Action, Knowledge and Reality: Critical Studies in Honor of Wilfrid Sellars. Indianapolis: Bobbs-Merrill, 277-93.

Sellars, Wilfrid. 1978. "Some Reflections on Perceptual Consciousness," in: Ronald Bruzina and Bruce Wilshire (eds), Crosscurrents in Phenomenology. The Hague: Nijhoff, 169-85.

Sellars, Wilfrid. 1997. Empiricism and the Philosophy of Mind. Cambridge: Harvard University Press.

Simons, Peter. 1987. Parts: A Study in Ontology. Oxford: Clarendon Press.

Simons, Peter. 1992. Philosophy and Logic in Central Europe from Bolzano to Tarski. Dordrecht: Kluwer.

Smith, Barry. 1995. "Common Sense," in: Barry Smith and David Woodruff Smith (eds), The Cambridge Companion to Husserl. Cambridge: Cambridge University Press, 394-437.

Smith, David Woodruff and Ronald McIntyre. 1982. Husserl and Intentionality. A Study of Mind, Meaning, and Language. Dordrecht: Reidel.

Soffer, Gail. 2003. "Revisiting the Myth: Husserl and Sellars on the Given," in: Review of Metaphyics LVII, 301-338.

Sokolowski, Robert. 1964. The Formation of Husserl's Notion of Constitution. The Hague: Nijhoff. 
Ströker, Elisabeth. 1993. Husserl's transcendental phenomenology. Trans. by: Lee Hardy. Stanford: Stanford University Press.

Sukale, Michael. 1978. "Perception, Knowledge, and Contemplation," in: Ronald Bruzina and Bruce Wilshire (eds), Crosscurrents in Phenomenology. The Hague: Nijhoff, 199-208.

Süßbauer, Alfons. 1995. Intentionalität, Sachverhalt, Noema: Eine Studie zu Edmund Husserl. München: Alber.

Thomasson, Amie. 2002. "Phenomenology and the Development of Analytic Philosophy," in: Southern Journal of Philosophy XL (suppl.), 115-42.

Thomasson, Amie. "First Person Knowledge in Phenomenology" in: David W. Smith and Amie Thomasson (eds), Phenomenology and Philosophy of Mind. Oxford University Press, forthcoming.

Williams, Bernard. 1974. "Wittgenstein and Idealism," in: Understanding Wittgenstein. Royal Institute of Philosophy Lectures, Vol. 7. London: Macmillan, 76-95.

Wittgenstein, Ludwig. PI. Philosophical Investigations. Trans. by: G.E.M. Anscombe, 2nd edition, Oxford: Blackwell, 1958.

Wittgenstein, Ludwig. TLP. Tractatus Logico Philosophicus. Trans. by: D.F. Pears and B.F. McGuinness. London: Routledge, 1961.

Wittgenstein, Ludwig. Z. Zettel. G.E.M. Anscombe and G.H. von Wright (eds). Trans. by G.E.M. Anscombe, Oxford: Blackwell, 1967.

Wittgenstein, Ludwig. OC. On Certainty. G.E.M. Anscombe and G.H. von Wright (eds). Trans. by Denis Paul and G.E.M. Anscombe, New York: Harper Torchbooks, 1969.

Wright, Georg Henrik von. 1972. "Wittgenstein on Certainty," in: Problems in the Theory of Knowledge. Georg Henrik von Wright (ed.), The Hague: Nijhoff, 47-60.

Zweig, Stefan. 1944. The Royal Game. Trans. by B.W. Huebsch. New York: Viking Press. 


\section{Index}

\section{A}

Affective unity, see Unity, affective Alighieri, Dante, 72-73

Ameriks, Karl, 110n. 36

Aristotle, 10, 17

Arnauld, Antoine, 83, 85

Association, 26, 54-57, 62-63, 65, 75, 102

Association, original, see Proteraesthesis

Austin, John, 58

\section{B}

Background, 4, 25, 27, 38, 44-54, 56-57, 59-60, $61-64,65-67,76,88-94,95-96$, 99102

Baker, Gordon, 106n. 4

Bernet, Rudolf, 20, 24, 26

Beyer, Christian, 108n. 14

Bichsel, Peter, 93

Biemel, Walter, 108n. 13

Block, Ned, $11 \ln .2$

Boethius, 17

Bolzano, Bernard, 108n. 14

Brandl, Johannes, 105n. 2

Brandom, Robert, 8, 76-81, 107n. 10, 115nn. 9, 10,12

Brentano, Franz, 5-6, 40, 44, 51, 84-6, 103, 106n. 1, 3, 108n. 14, 112n. 17, 19

Burge, Tylor, 81-86, 103

C

Carnap, Rudolf, 18, 36, 107n. 7, 108n. 8

Causal theories, see perception, causal theories of Chisholm, Roderick, 111 n. 1

Chomsky, Noam, 18

Chrudzimski, Arkadiusz, 106n. 3

Churchland, Paul, 41-43

Commitment, constitutive, 4, 31-32, 34, 57,

$61-66,72,80-81,96-97,101$
Creation of objects vs. constitution of objects, 2 , $20,21-22,27,33,35-36,48-49$, $57,87,101$

D

Davidson, Donald, 8-9, 43-44, 77, 97, 107n. 8, 111 n. $5,6,115$ n. 1

De Boer, Theodore, 19-20

Dennett, Daniel, 11 In. 2

Descartes, René, 1, 3, 6-8, 10, 12, 14-15, 44, $82-84,101,106$ n. 4

Dretske, Fred, 27-29, 31, 45-46, 59, 109n. 28, 114n. 40

Dreyfus, Hubert, 106n. 4

Dummett, Michael, 105n. 1

\section{E}

Eliminativism, 2, 3, 10-12, 41-43, 101

Experience, 2, 7-9, 13-14, 18, 22-26, 27-30, 38, $44-48,48-53,56,57-61,63-64$, $65-67,70-76,76-81,82-86,94$, $97-99,102$

Farber, Marvin, 105n. 3

Fink, Eugen, 19

Fodor, Jerry, 43, $111 \mathrm{n} .2$

Folk psychology, 37, 42-43

Føllesdal, Dagfinn, 105n. 1, 106n. 3, 108n. 14

Frege, Gottlob, 2, 10, 20, 105n. 1, 107n. 11, 108 n. 14

\section{G}

Genetic phenomenology, 24-26

Goethe, Johann Wolfgang von, 108n. 14

Goodman, Nelson, 114n. 37 
H

Habermas, Jürgen, 18

Habit, see trace

Hall, Harrison, 106n4, 110n. 38

Harman, Gilbert, 111n. 2

Haugeland, John, 3, 17-19, 27-38, 46, 49, 57, 61, 64, 101-103, 106n. 4, 109n. 29-110n. 32, 110n. 39, 115n. 46

Hegel, Georg Wilhelm Friedrich, 9, 107n. 10

Heidegger, Martin, 34, 109n. 17

Hertzberg, Lars, 92

Hogrebe, Wolfram, 17f, 107n. 1

Holenstein, Elmar, 25-26, 54-56, 65, 112nn. 15, $16,114 \mathrm{n} .38,115 \mathrm{n} .45$

Holmes, Richard, 110n. 37

Husserl, Emund, 1-6, 10, 12f, 17-27, 31, 34-39, $45-46,48-65,69,75,82-83,85$, 87, 101-3, 105nn. 1, 3, 106n. 4, 106n. 2, 107nn. 11, 5, 7, 108nn. $11,14,17,109$ nn. 18f, 21f, 27 , 110n. 33-5, 112nn. 9, 14, 17, $113 \mathrm{nn} .23,28,31,114 \mathrm{nn} .38,39$, 115n. 45, 116n. 1

I

Idealism, 4, 6, 7, 10, 12, 25-26, 35, 38, 58, $87-99,103$

Individualism, 15, 76-82, 82-86, 103

Ingarden, Roman, 18, 87, 110nn. 34, 35

Inference, $40-41,47-48,73-75$

Informational relations, 27-29, 46-46, 59

Inner perception vs. inner observation, 84-85

Intentionality, 5-6, 19, 20, 39, 40, 44, 48, 55-58, $62,65,72,81,102$

Interpretation, Constitution as, 2, 33, 35, 48-49, 67,101

J

James, William, 58-60

$\mathbf{K}$

Kant, Immanuel, 17-18, 35, 38, 103, 107n. 5 Kelly, Sean 106n. 4

Kern, Iso, 20, 24, 26, 87, 107n. 5, 109n. 21, 116n. 1 Kraus, Oskar, 106n. 3

Küng, Guido, 107n. 7

L

Language, $15,38,62-63,66,69-73,90,92$, 95-96, 102-103
Language-game, 66, 88-94, 96-97, 99

Lewis, David, 111n. 2

Lotze, Rudolf Hermann, 108n. 14

Lycan, William, 111n. 2

$\mathbf{M}$

Marbach, Eduard, 20, 24, 26, 106n. 4

Materialism, 7, 10-12

Matter-form schema, 20, 23, 24, 25, 49, 55

Mayer, Verena, 105n. 2, 107n. 7

McCulloch, Gregory, 43, 106n. 4

McDowell, John, 2, 7-10, 57-58, 60, 72, 76-81, $97-98,102-103,106 \mathrm{n} .4,107 \mathrm{nn}$. $8,10,112$ n. 7,115 n. 2,115 nn. 9 , 10,12

Misperception, 14, 31, 59-60

Mohanty, Jitendra Nath, 105n. 1, 3, 108n. 14

Monism, 12, 43-44

Moore, George Edward, 89-90

Morris, Katherine, 106n. 4

Myth of the Given, 8-9, 48, 54-56, 58, 60

\section{$\mathbf{N}$}

Nature, logical space of, $2,3,7,10-12,40-44$, $45,55,57-58,72,102$

O

Occasionalism, 7

Ockham, William of, 14

P

Partial intentions, 22, 24-25, 37, 46, 50-51, $53-55,58,62,101-102$

Passivity, 4, 26, 49-50, 54, 62-63, 75-76, 102

Perception, causal theories of, 27, 29, 44-46,59, 102

Philipse, Herman, 110n. 35

Piazza, Tommaso, 105n. 2

Platonism, 13-14, 98

Porphyry, 17

Primal impression, 22, 24-25, 37, 50-51, 53-54, 62,102

Protention, 22, 24, 37, 50-51, 53

Proteraethesis, 51

Psychologism, 10, 20

Putnam, Hilary, 39, 58-60, 83, 98-99, 111n. 2, 114 n. 39

Q

Quine, Willard Van Orman, 56 


\section{$\mathbf{R}$}

Realism, 4, 58-59, 87-88, 92-95, 98-99, 103

Reasons, logical space of, 2, 3, 7-8, 10-12, $40-44,45,47,54,54-58,60,63$, $65-67,69-70,72-75,76-82,102$

Reduction, phenomenological, $6,23,34,36$, $57-58,82$

Reductionism, 3, 10-12, 41, 101

Regulation, constitutive, 31-32

Relation, informational, see Informational relation

Relation, rational, 7-8, 10-12, 40, 42-43, 45, $47-48,54,60,66,69-70,72-76$, $77,79-80,103$

Retention, 22, 24-25, 27, 37, 50-54, 56-57, $59-60,61-64,65-66,76,94-96$, 102

Rorty, Richard, 11 ln. 2

Ryle, Gilbert, 2

Russell, Bertrand, 2

\section{$S$}

Searle, John, 18, 46-47, 75, 112n. 11

Scheme, conceptual, 44, 71, 111 n. 6

Schmit, Roger, 105n. 2

Sedivy, Sonia, 106n. 6

Sellars, Wilfrid, $2-3,7-8,10,39-47,54,57,61$, $64,67,73-74,77,80,82,102-103$, 105n. 3, 106nn. 4, 6, 7, 107n. 8,

Seneca, 17

$111 \mathrm{nn} .1,2,114 \mathrm{n} .42,115 \mathrm{n} .3,5$

Sense-data, 8, 20, 25, 48, 54-56, 65, 98

Sensations, 8-9, 72-73

Similarity, 54, 56-57, 63, 65, 102

Simons, Peter, 105n. 2, 108n. 9
Skills, constitutive, 31-34

Smith, Barry, 26

Social praxis, 4, 38, 62, 69-71, 73, 81, 82, 91 , 102-103

Soffer, Gail, 106n. 3

Sokolowski, Robert, 20, 108nn. 11, 13, 109n. 19, 112 n. 15

Standards, constitutive, 29-34, 36-38

Static phenomenology, 24

Stein, Edith, 108n. 17

Steinbock, Anthony, 114n. 35

Ströker, Elisabeth, 23, 108n. 11

Sukale, Michael, 105n. 3

Süßbauer, Alfons, 21

\section{$\mathbf{T}$}

Thomasson, Amie, 105n. 2, 106n. 3

Time consciousness, phenomenology of, 3-4, $22-25,36,48,50-53$

Transcendental assumption, 97-99

Trace, constitution leaving a, 24-27, 37-38

$\mathrm{U}$

Unity, affective, 54-57, 62-63, 65-66, 76, 102

\section{W}

Williams, Bernard, 95-7

Wright, Georg Henrik von, 89, 91, 94, 116n. 3

Wittgenstein, Ludwig, 4, 15, 58, 87-99, 103, 106n. 6, 115n. 8, 116nn. 2-4

Z

Zweig, Stefan, 30 




